\title{
Prospects for Improvement in Geothermal Well Technology and Their Expected Benefits
}

June 1978

Prepared By

The Mitre Corporation

For U.S. Department of Energy Assistant Secretary for Energy Technology Division of Geothermal Energy Washington, DC 20545

Under Contract No. EG-77-C-01-4014

This report was prepared as an account of work sponsored by the United States Government. Neither the United States nor the United States Department of Energy, nor any of their employees, nor any of their contractors, subcontractors, or their employees, makes any warranty, express or implied, or assumes any legal liability or responsibilty for the accuracy, completeness or usefulness of any information, apparatus, product process disclosed, or represents that its use would no infringe privately owned rights.

NOTE: This publication was prepared for the Energy Research and Development Administration (ERDA) prior to the establishment of the Department of Energy. Therefore; wherever ERDA is mentioned, its functions have been transferred to DOE. 


\section{DISCLAIMER}

This report was prepared as an account of work sponsored by an agency of the United States Government. Neither the United States Government nor any agency Thereof, nor any of their employees, makes any warranty, express or implied, or assumes any legal liability or responsibility for the accuracy, completeness, or usefulness of any information, apparatus, product, or process disclosed, or represents that its use would not infringe privately owned rights. Reference herein to any specific commercial product, process, or service by trade name, trademark, manufacturer, or otherwise does not necessarily constitute or imply its endorsement, recommendation, or favoring by the United States Government or any agency thereof. The views and opinions of authors expressed herein do not necessarily state or reflect those of the United States Government or any agency thereof. 


\section{DISCLAIMER}

Portions of this document may be illegible in electronic image products. Images are produced from the best available original document. 


\section{NOTICE}

This report was prepared as an account of work sponsored by the United States Government. Neither the United States nor the United States Department of Energy, nor any of their employees, makes any warranty, express or implied, or assumes any legal liability or responsibility for the accuracy, completeness, or usefulness of any information, apparatus, product, or process disclosed, or represents that its use would not infringe privately owned rights. Reference herein to eny specific commercial product, process, or service by trade name, mark, manufacturer, or otherwise, does not necessarily constitu te or imply its endorsement, recommendation, or fevoring by the United States Government or any agency thereof. The views and opinions of authors expressed herein do not necessarily state or reflect those of the United States Government or any agency thereof. 
This study reviews performance restrictions on current geothermal drilling technology and their impact on drilling costs, with the consequent impact on electric power costs. Sensitivities of drilling costs to changes in drilling performance are analyzed. A programmatic goal for improving drilling performance is offered. The likely cost savings to the nation if the goal is attained are estimated through the use of a geothermal well drilling scenario for the 1978-1990 period, which was derived from DOE's geothermal power on-line scenario. The present worth of the expected savings stream (benefit) is offered as a point of departure for justifying programmatic costs for improving drilling technology. 

LIST OF ILLUSTRATIONS vii

LIST OF TABLES ix

1.0 INTRODUCTION AND CONCLUSIONS 1

1.1 Goal of the Study 1

1.2 Estimate of Benefits to be Derived from a

1.3 Major Results 4

$\begin{array}{ll}1.4 & \text { Limitations of This Study } \\ & 15\end{array}$

$\begin{array}{ll}2.0 & \text { COST AND SENSITIVITY ANALYSIS: THE ECONOMICS OF } \\ \text { DRILLING TECHNOLOGY } & 21\end{array}$

2.1 Sensitivity Analysis of Costs Parameters 21

2.2 Trade-off Analysis for Rotating Costs 28

2.3 Significance of Rotating Costs to Well Costs 36

3.0 ESTIMATING THE BENEFITS OF IMPROVED GEOTHERMAL WELI.

3.1 Wel1 Drilling Requirements and Schedules 39

3.1.1 Exploration Wells 41

3.1.2 Production and Reinjection Wells 43

3.1.3 Replacement Wells 46

3.1 .4 Total Wells 46

3.2 Well Costs by Prospects 49

3.3 Cost Reduction Profile 54

3.3.1 Gross Savings From Expected Technology
Improvements

3.3.2 Adjusting For the Expected Extra Costs
of the New Technology

3.4 Potential Savings from Improved Technology 60

3.5 Targeting a Federal Research Program Through
Benefit/Cost Analysis

4.0 CURRENT PROBLEMS IN GEOTHERMAL DRILLING AND THEIR
COST IMPACT

4.1 The Drilling Environment 70

4.2 The Components of Conventional Drilling Technology 75

4.3 Drilling Fluids 82 
TABLE OF CONTENTS, Concluded

Page

4.4 Limits of Other Materials and Equipment $\quad 85$

4.5 Logging

4.6 Drill Bits

86

4.7 Down-hole Motors

4.8 Influence of Technology Limits on Drilling Costs

89

5.0 RESEARCH AND DEVELOPMENT REQUIREMENTS 93

5.1 Research Needs for Equipment 95

5.1 .1 Drill Bits

95

5.1.2 Packers

96

5.1.3 Down-hole Motors 97

5.1.4 Tubular Goods 98

5.2 Methods 98

5.2.1 Keeping Hole Straight 98

5.2.2 Directional Drilling 99

5.2.3 Lost'Circulation Control 100

5.2.4 Slim Hole Drilling 100

5.2.5 Well Control 101

5.2.6 Control of $\mathrm{H}_{2} \mathrm{~S}$ Effects 102

5.3 Materials 102

5.3.1 Cement 102

5.3 .2 Stee1 103

5.3.3 Elastomers 103

5.3.4 Lubricants 104

$\begin{array}{ll}\text { REFERENCES } & 105\end{array}$

APPENDIX A - COST ANALYSIS CURVES 109

APPENDIX B - ENVIRONMENTAL IMPACT OF NEW TECHNOLOGY 123

$\begin{aligned} \text { APPENDIX C - TRAVEL CONTACTS MADE DURING COURSE OF } & 127 \\ \text { THE STUDY } & \end{aligned}$

$\begin{array}{ll}\text { BIBLIOGRAPHY } & 129\end{array}$ 


\section{LIST OF ILLUSTRATIONS}

FIGURE NUMBER

Page

2-1 Change in Cost Sensitivity Coefficient with

Change in Bit-Life

2-2 A Typical Iso-Cost (Indifference) Curve

2-3 Normalized Indifference Rotating Cost Saving Curves for $Z=10,000$ Feet, $C=400 \$ /$ Hour, $B=$ $\$ 2,000, v=0.0011$ Hour $/$ Foot and $D=0.0$ Feet

2-4 Normalized Indifference Rotating Cost Saving Curves for $\mathrm{Z}=10,000, \mathrm{~B}-\$ 2,000$ and $\mathrm{L}=12$ Hours

3-1 Assumed Rotating Cost Savings by Year

3-2 Gross and Net Savings by Year

4-1 Rotary Rig Fluid Circulation and Mud Treating System

A-1 Normalized Indifference Curves for $\mathrm{Z}=2,000$ Feet, $C=400 \$ /$ Hour, $B=\$ 2,000$ and $v=0.0011$ Hour/Foot

A-2 Normalized Indifference Curves for $Z=6,000$ Feet, $C=400 \$ /$ Hour, $B-\$ 2,000$ and $v=0.0011$ Hour/Foot

A-3 Normalized Indifference Curves for $Z=10,000$ Feet, $C=400 \$ /$ Hour, $B=\$ 2,000$ and $v=0.0011$ Hour/Foot

A-4 Normalized Indifference Curves for $Z=14,000$ Feet, $C=400 \$ /$ Hour, $B=\$ 2,000$ and $v=0.0011$ Hour/Foot

A-5 Normalized Indifference Curves For $\mathrm{Z}=2,000$ Feet, $C=400 \$ /$ Hour, $B=\$ 10,000$ and $v=0.0011$ Hour/Foot

A-6 Normalized Indifference Curves for $Z=6,000$ Feet, $C=400 \$ /$ Hour, $B=\$ 10,000$ and $\nu=0.0011$ Hour/Foot 
A-7 Normalized Indifference Curves For $Z=10,000$ Feet, $C=400 \$ /$ Hour, $B=\$ 10,000$ and $v=0.0011$ Hour / Foot

A-8 Normalized Indifference Curves for $Z=14,000$ Feet, $C=400 \$ /$ Hour, $B=\$ 10,000$ and $v=0.0011$ Hour/Foot

A-9 Normalized Indifference Curves for $Z=18,000$ Feet, $C=400 \$ /$ Hour, $B=\$ 2,000$ and $v=0.0011$ Hour/Foot 
1-I Sensitivity of Electric Cost to Drilling Cost for the First Electric Production Plants of $50 \mathrm{MW}_{\mathrm{e}}$

1-II Postulated Power on-Line 5

1-III Estimated Total Number of We1ls Required to

Support Power on-Line Scenario

1-IV Characteristics of the Prospects 9

1-V Maximum Expected Cost Savings by Year and Prospect

1-VI Conversion of Expected Savings Stream to Present Value

2-I Definition of Sensitivity Coefficients 24

2-II Changes in Rotating Cost Sensitivity Coefficients as a Result of Changes in some Drilling Parameters 27

2-III Drilling and Completion Costs at the Geysers 37

3-I Power on-Line Schedule 40

3-II Requirement for Exploration Wells 42

3-III Requirement for Production Wells 44

3-IV Requirement for Re-Injection Wells 45

3-V Requirement for Replacement of Production We11s 47

3-VI Estimated Total Number of Wells Required to
Support Power on Line Scenario

3-VII Footage Costs for Geothermal Drilling as a
Function of Rock Type and Well Depth

3-VIII Characteristics of the Prospects 53 


$$
\text { LIST OF TARLES, Concluded }
$$

\section{TABLE NUMBER}

3-IX Maximum Expected Cost Savings by Year and Prospect

3-X Conversion of Expected Savings Stream to Present Value

4-I Geology of Selected Geothermal Sites

4-II Geothermal Drilling Characteristics of Selected International Sịtes

4-III Expected Sequence of Commercial Maturity of the Five Types of Geothermal Resources and Their Geological Characteristics

4-IV Geological Classification of Reservoirs

4-V Factors Which Determine Penetration Rate 


\subsection{INTRODUCTION AND CONCLUSIONS}

The need for rapid development of all domestic energy sources into economic producers is evident. The capacity of geothermal resources to contribute to this need is, to a great extent, defined by the economics with which the resource can be tapped and this, in turn, defines the requirement for effective well drilling and completion procedures. Geothermal resources can be extracted by making use of oil and gas drilling technology but the excessive costs associated with conventional drilling technology may inhibit the evolution of the geothermal industry. Therefore, new, cheaper, or more effective methods of drilling and completion need to be developed to reduce the cost of electric power generated from geothermal energy.

\subsection{Goal of the Study}

The purposes of this report are: to establish the need for advances in drilling technology with explicit reference to prospective sites of geothermal development, and also to address the expected benefit of such advances in comparison with research and development costs.

The study has covered the following points:

1) the impact of drilling cost on electric power costs

2) appropriate benefit-cost arguments to be used in targeting the size of a research program and the rate of expenditure of the funds

3) identification of the required number of wells and a drilling schedule

4) drilling technology areas and their relative influence on the cost to drill and complete geothermal wells 
5) research areas which offer potential savings in the cost to drill.

The study is limited to a review of steam, geopressured and liquid-dominated hydrothermal resources for electrical power production.

\subsection{Estimate of Benefits to be Derived from a Research Program}

The cost of resource extraction influences the consumer price of the product, in this case electric power. It is important to define in a quantitative way the relationship between electric costs and well. costs. This has been done by investigation of results of a MITRE/ METREK mode1 of electric costs for a number of prospective geothermal development sites (prospects). [1]

The data appear in Table 1-I. They indicate that at most prospects, a considerable savings could be obtained by investing in a research program which promises to reduce costs for drilling and completion. Furthermore, it is shown in Section 3 that the potential total savings in drilling for near-term resources are quite considerable. A most important consideration when dealing with the financial benefits of new technology is the extent to which it allows electric production that is competitive in rates with electricity generated by other means. When geothermal energy is rendered economically competitive, the government investment in research can be expected to be rewarded by rapid commercialization of the already identified prospects, as well as active exploration for new prospects. The reduction of drilling costs alone will 
TABLE $1-I$

SENSITIVITY OF ELECTRIC COST TO DRILLING COST FOR THE FIRST ELECTRIC PRODUCTION PLANTS OF $50 \mathrm{MWe}[1]$

\section{PROSPECTIVE GEOTHERMAL} DEVELOPMENT SITE

Brawley*, CA

Brawley, CA

Coso Hot Spring, CA

East Mesa*, CA

Heber*, CA

Mono-Long Valley, CA

Salton Sea*, CA

Salton Sea, CA

Beowawe, $\mathrm{N}$

Brady Hot Spring, NV

Cove Fort/Sulphurdale*, UT

Roosevelt Hot Springs, UT

Steamboat Springs, NV

Valles Caldera, NM

Lassen, CA :

Surprise Valley*, CA

Alvord*, OR

Bruneau-Grandview*, ID

Raft River*, ID

Vale Hot Springs*, on

Weiser/Crane Creek*, ID

Ch andler*, AZ

Leach*, NV

The rmo*, UT

Saf ford*, AZ

Glass Mountain, CA

Puna, HI

Baker Hot Springs*, WA
POSTULATED YEAR

ON LINE

(First 50 MWe Plant)

1983
1983
1985
1985
1985
1985
1983
1983
1983
1983
1985
1983
1985
1983
1987
1986
1987
1987
1988
1988
1988
1986
1987
1988
1987
1990
1990
1990

WELL COSTS ASSUMED

(In Thousands of Dollars)

Production

Re-Injection

400
400
615
600
600
615
400
400
984
656
1523
533
328
984
615
923
2437
2138
607
591
923
1711
2138
1219
2138
1426
2281
2138

400
400
615
600
600
615
400
400
984
656
1015
533
328
984
615
615
1625
1426
607
394
615
1140
1426
812
1426
1426
2281
1426

\% CHANGE IN EXPECTED ELECTRIC RATE PER \% CHANGE IN DRILLING COST

* A binary cycle plant is assumed. All other prospects are assumed to use the flashed. steam system of energy conversion. 
rarely be sufficient to make geothermal plants competitive. Other cost-reducing technological and policy measures (e.g., tax incentives) will be influential in establishing competitiveness through a reduction in the cost of power.

\subsection{Major Results}

It is the assumption in the remainder of this report that technology advances in drilling and other areas will occur in such a way that a power on-line schedule will be achieved as is defined in Table 1-II (derived from ERDA [3]) and that a drilling cost reduction schedule, as defined in section 3 of this report, will be attained. The power on-line schedule covers 37 current prospects which have been postulated to produce power by suitable conversion of steam, liquiddominated hydrothermal or geopressured resources. As shown in the table, for the next five years, only The Geysers field is expected to produce electric power. Under these assumptions, production from liquid-dominated hydrothermal areas would begin in 1983. By 1986, geopressured resources are expected to contribute. The end result is that yearly additions of power should grow slowly from 1978 through 1989 and will reach a plateau for the period 1990-95. Hot dry rock resources may be significant contributors to power on line by the turn of the century and beyond. They were not included in the reference scenario, and they have not been addressed in this report.

The analysis of Section 2 provides a mechanism for computing the schedule of wells required to support the power on-line scenario. These data appear in Table 1-III and include, by prospect and year, 
TABLE 1-II

POSTULATED POWER ON-LINE (MWe):3]

\begin{tabular}{|c|c|c|c|c|c|c|c|c|c|c|c|c|c|c|c|c|}
\hline 1578 & 1975 & 1980 & 1481 & 1982 & 1983 & 1584 & 1985 & 1986 & 1907 & 1968 & 1989 & 1940 & 1991 & 1992 & 1993 & 1994 \\
\hline$=7 i$ & 190 & 275 & 165 & 275 & 100 & 220 & 110 & u & 0 & 0 & 0 & 0 & 0 & 0 & j & 0 \\
\hline & ن & 0 & 0 & 0 & $c$ & J & 0 & 25 & 0 & 100 & 100 & 200 & 200 & 200 & 200 & 200 \\
\hline 0 & c & 0 & 0 & J & $=3$ & J & IJ) & 15 & 75 & (נ) & (1): & 103 & $10 \mathrm{~J}$ & (10) & (1) & נJ \\
\hline 0 & i & 0 & 0 & 0 & 50 & 0 & u & 100 & J & 100 & 0 & 100 & 100 & 100 & 160 & 100 \\
\hline 0 & 0 & i & $c$ & 0 & 50 & 0 & 0 & 30 & 0 & 100 & 0 & 100 & 100 & 100 & 100 & 100 \\
\hline 0 & 0 & 0 & 0 & 3 & 53 & J & 5) & J & 130 & (J) & נינ 1 & נJ & 120 & 10J & 1) & 13) \\
\hline u & $\dot{v}$ & u & $w$ & 0 & 50 & is & 0 & 56 & 0 & 30 & 0 & 100 & 100 & 100 & 100 & 100 \\
\hline$i$ & 0 & 0 & $i$ & 0 & SC & 0 & 0 & 30 & 0 & 50 & 0 & 100 & 100 & 100 & 100 & 100 \\
\hline 0 & 0 & 0 & J & J & $\mathrm{J}$ & $\mathrm{J}$ & 53 & $3 J$ & 30 & 153 & 150 & $15 \mathrm{~J}$ & 0 & J & J & J \\
\hline$i$ & 0 & 0 & 0 & J & c & 0 & 50 & 0 & 100 & 0 & 0 & 100 & $j$ & u & 0 & 0 \\
\hline$J$ & 0 & c & c & 0 & c & 0 & 50 & 0 & 50 & 0 & 50 & 50 & 100 & 100 & 100 & 100 \\
\hline c & 0 & 0 & j & j & J & J & 5. & J & J & J & 130 & 103 & 130 & 100 & 1) & נכנ \\
\hline 0 & 0 & 0 & 0 & 0 & 0 & 0 & 100 & 100 & 100 & 10u & 100 & 100 & 100 & 100 & 100 & 100 \\
\hline 0 & 0 & - 0 & 0 & 0 & c & 0 & so & 0 & 0 & 30 & 0 & 0 & 0 & 0 & 0 & 0 \\
\hline 0 & c & J & J & J & J & 0 & 5.3 & J & J & $5)$ & J & נJ 10 & J & J & J & j \\
\hline$v$ & 0 & 0 & 0 & 0 & 0 & $\dot{u}$ & 0 & so & 0 & 50 & 100 & 100 & 100 & 100 & 100 & 100 \\
\hline 0 & 0 & 0 & $c$ & 0 & C & 0 & 0 & 50 & 0 & 0 & 0 & 100 & 50 & 0 & 0 & 0 \\
\hline 0 & 2 & J & J & J & 1] & J & J & ) & 5. & J & $\mathrm{J}$ & 3 & 120 & ננग & ננग & 100 \\
\hline i & 0 & 0 & 0 & 0 & 0 & 0 & u & 0 & 50 & 0 & 0 & 50 & 50 & 100 & 100 & 0 \\
\hline$\ddot{ت}$ & 0 & u & $c$ & c & C & 0 & 0 & 0 & $=0$ & 0 & 0 & 100 & 100 & 100 & 100 & 100 \\
\hline 0 & J & J & J & 3 & $i$ & J & J & J & J J & , & J & $5 \mathrm{~J}$ & J & J & 0 & 0 \\
\hline$c$ & 0 & 0 & C & 0 & 0 & 0 & $v$ & 0 & $5 C$ & 0 & 0 & 50 & 50 & 50 & 50 & 50 \\
\hline 0 & i & 0 & $c$ & 0 & C & 0 & 0 & 0 & 50 & 0 & 0 & 50 & 50 & ou & 50 & 50 \\
\hline 0 & c & 0 & 0 & 0 & $i$ & 0 & 0 & j & 50 & j & $u$ & 30 & su & 50 & 50 & 50 \\
\hline 0 & 0 & 0 & C & u & C & 0 & 0 & u & >0 & 0 & 0 & 50 & 50 & 5) & 5) & 5J \\
\hline J & J & J & J & J & 0 & נ & D) & J & 50 & 0 & j & 30 & 50 & so & 50 & 100 \\
\hline 0 & 0 & 0 & 0 & $j$ & $c$ & 0 & 0 & 0 & 50 & j & 0 & so & 50 & 50 & 50 & 100 \\
\hline 0 & u & 0 & 0 & 0 & $c$ & 0 & 0 & 0 & 50 & 0 & 0 & 0 & J & J & J & J \\
\hline J & J & $J$ & $\mathrm{~J}$ & J & J & J & j & 0 & 0 & bo & 0 & 100 & 100 & 100 & 100 & 100 \\
\hline c & 0 & u & $i$ & 0 & $c$ & $\ddot{0}$ & 0 & j & 0 & 50 & 0 & 50 & 50 & 50 & 50 & 50 \\
\hline u & $u$ & 0 & 0 & 0 & C & 0 & 0 & 0 & 0 & 50 & 0 & 3 & J & נग & (J) & ננ \\
\hline 3 & J & .) & J & 3 & 0 & J & 0 & $u$ & 0 & 50 & 0 & 50 & 0 & 0 & 0 & 0 \\
\hline 0 & 0 & 0 & c & 0 & i & 0 & 0 & $J$ & 0 & j & 0 & so & j & 0 & 0 & 0 \\
\hline 0 & 0 & 0 & 0 & 0 & c & C & 0 & 0 & 0 & 0 & 0 & 1) & 231 & 230 & ננ 2 & (2) \\
\hline J & J & J & J & $J$ & 0 & , & 0 & 0 & 0 & 0 & 0 & so & 0 & 0 & 0 & 0 \\
\hline C & 0 & 0 & $c$ & 0 & C & 0 & 0 & J & 0 & j & u & 50 & 0 & 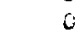 & 0 & 0 \\
\hline 0 & u & $c$ & $i$ & $u$ & o & 0 & 0 & 0 & 0 & 0 & J & b) & j & J & J & J \\
\hline$\therefore 71$ & $i \oplus 0$ & 273 & 105 & 275 & 460 & $2<0$ & 000 & ouj & 1675 & 1200 & ن نن8 & 2050 & 2150 & 2250 & 2250 & 2250 \\
\hline
\end{tabular}


TABLE 1-III

ESTIMATED TOTAL NUMBER OF WELLS REQUIRED TO SUPPORT POWER ON-LINE SCENARIO

GeYstristsitaMi, CA BFAZLRIIA, TX

SALILA SLA, CA
VALLES CAI ULhA, MM ORAUYY, NV

KUESEVELT, UT

SE ÖnA wi NV

CESLANi,

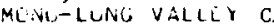
COVE FORT/SULPHURDALE, UT

HËLP, CA

GEYSERS IHYULEI, CA

EASI MESA, CA

SUKPF ISE VALLLY, CA

CHANULEK, AZ

a

CALCASIEU PATKISH, LA

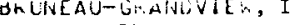

LASSEN, CA

KENEUY CWINTY, TX

ALVunL, OR

Malaglikba, TX

CAMLIUN,

CCRPUS CHA L TI,

SAFHLAD, AZ

intISEKARAT.E CFELIK, ID

VALE, OR

THEKML, UT

KATI KIVEK, ID
GLAS, MLUVIAIN, CA

BAKER HOT SPRINGS, WA

\begin{tabular}{|c|c|c|c|c|c|c|c|c|c|c|c|c|c|}
\hline 1970 & 1914 & 1940 & A أن & $1 \times 0<$ & lsos: & $1^{4}+x^{2}+4$ & $1 \%(3)$ & isda & 1987 & 1980 & 1400 & 1940 & 1.TAL \\
\hline 74 & 51 & 79 & 5 & te & 44 & $\ll$ & is & $2 j$ & $<3$ & 23 & 23 & 23 & 329 \\
\hline $\mathrm{c}$ & 0 & 0 & 10 & 0 & 0 & 3.) & 5 & $12 c$ & 126 & 250 & 254 & 202 & 1008 \\
\hline 0 & $u$ & 0 & 12 & 5 & 19 & 10 & 11 & 21 & 22 & 23 & 24 & 25 & 184 \\
\hline c & $u$ & $u$ & 16 & ' & 1 & 30 & 1 & 40 & 8 & 42 & 42 & 44 & 237 \\
\hline 5 & 0 & 0 & 22 & 3 & 2 & 24 & 2 & 53 & 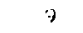 & 50 & 50 & 54 & 290 \\
\hline c & $\checkmark$ & 0 & 12 & 0 & 16 & 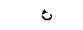 & 21 & 27 & 20 & 24 & 30 & 31 & 209 \\
\hline U & 0 & 0 & 13 & 5 & 1 & 19 & 1 & 20 & 7 & 34 & 24 & 35 & 164 \\
\hline 5 & 0 & 0 & 10 & 2 & 1 & 24 & 1 & $\angle 3$ & 7 & 40 & 10 & 42 & 202 \\
\hline 0 & ن & 10 & 0 & 5 & 25 & $<5$ & $\therefore c$ & 01 & 63 & c 7 & 11 & 13 & 314 \\
\hline 0 & 0 & 10 & 0 & 0 & 25 & 0 & 41 & 0 & 4 & 44 & 4 & 7 & 141 \\
\hline 0 & 0 & 10 & 0 & ن & 24 & 0 & 25 & $t$ & 26 & $<0$ & 46 & 41 & 210 \\
\hline 0 & 0 & c & u & $a$ & 28 & u & 90 & 7 & 55 & 55 & 50 & 01 & 294 \\
\hline 0 & 0 & 5 & 0 & ", & 45 & 4' & 40 & 31 & 34 & 57 & to & 03 & 433 \\
\hline 0 & 0 & 0 & $u$ & $u$ & 27 & 5 & 2 & $\angle 9$ & 2 & 4 & 4 & 4 & 77 \\
\hline 0 & $u$ & 10 & 0 & v & $\angle 3$ & $=$ & $<$ & 20 & 2 & 50 & 4 & 7 & 133 \\
\hline 0 & 0 & 0 & is & 0 & 0 & $\therefore b$ & b & 37 & 0.7 & 1,9 & 73 & 77 & 573 \\
\hline 0 & 0 & 6 & 10 & $i$ & 0 & 20 & 0 & 1 & 7 & 38 & 30 & 0 & 146 \\
\hline 0 & 0 & ¿ & 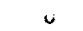 & 10 & $i$ & 0 & 34 & 5 & 7 & 41 & 75 & 17 & $\angle 49$ \\
\hline 0 & 0 & 0 & 0 & 10 & 0 & 0 & 60 & 5 & 7 & 67 & 67 & 124 & 340 \\
\hline 0 & 0 & 0 & $v$ & lu & $u$ & $\overline{0}$ & 19 & 5 & 0 & 44 & 44 & +7 & 175 \\
\hline c & u & 0 & 0 & 10 & 0 & $u$ & 16 & 5 & l & 17 & 1 & 2 & 52 \\
\hline c & 0 & 0 & 0 & 10 & 0 & 0 & 60 & 5 & 7 & 67 & 6.7 & 69 & 285 \\
\hline 0 & 0 & u & 0 & 10 & 0 & 0 & 19 & 5 & 6 & 25 & $2 b$ & 20 & 110 \\
\hline u & 0 & 0 & $v$ & 10 & $\bar{u}$ & 0 & ou & 5 & 7 & 67 & 67 & $6 y$ & 235 \\
\hline 0 & 0 & 0 & 0 & iv & 0 & 0 & 60 & 5 & 7 & 0.7 & $4 l$ & 69 & 285 \\
\hline$u$ & 0 & 0 & u & 10 & $u$ & 0 & 00 & 5 & $t$ & .7 & 6.7 & 69 & 285 \\
\hline C & $u$ & 0 & 0 & 10 & 0 & " & bu & 5 & $t$ & $c 7$ & 67 & 09 & 285 \\
\hline 0 & 0 & $u$ & $u$ & 10 & 0 & i) & $1 \%$ & 0 & l & 1 & 1 & 1 & 33 \\
\hline c & 0 & $c$ & $u$ & $i$ & 10 & $v$ & $u$ & 47 & b & 12 & $c_{i 2}$ & प8 & 344 \\
\hline$i$ & 0 & 0 & ju & 0 & 10 & j & c & 47 & 5 & 50 & bo & 53 & 215 \\
\hline 0 & 0 & 0 & 0 & 0 & 10 & 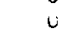 & 0 & 19 & 0 & 0 & 0 & 44 & 85 \\
\hline 0 & $u$ & u & 0 & 0 & 5 & 6 & 0 & ol 1 & 0 & 82 & 0 & 16 & 186 \\
\hline 0 & 0 & c & 0 & c & 0 & 0 & 10 & 0 & 0 & 24 & 0 & 2 & 36 \\
\hline 0 & $u$ & 0 & $v$ & $i$ & 0 & 0 & (i) & 0 & 5 & 29 & 53 & 55 & 152 \\
\hline 0 & 4 & c & $\nu$ & 0 & 0 & U & iv & $\mathrm{c}$ & 0 & 12 & 0 & 5 & 87 \\
\hline 0 & 0 & 0 & 0 & $v$ & 0 & 0 & 10 & 0 & 0 & 30 & 0 & i & 51 \\
\hline 0 & u & 0 & $u$ & 0 & $v$ & 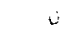 & 10 & $v$ & 0 & 72 & $j$ & 5 & 87 \\
\hline 34 & 51 & ich & $i 1 / 4$ & 211 & sl & siv & 771 & 1.17 & 588 & ty $2<<$ & 1540 & 1107 & 0650 \\
\hline
\end{tabular}


the requirements for exploration, production, reinjection and replacement wells.

As described in Section 3, a number of factors were used in development of the well requirements. They include:

- current knowledge of each prospective development site,

- probable electric production that can be achieved from a production we11,

- probable reinjection well requirements,

- probable lifetime of production wells and,

- the expected lead time requirements for drilling

exploration, production and injection wells as well

as replacement well schedules.

In order to compute cost savings which might result from improved technology, the well requirements were used in conjunction with a calculation of the probable cost of the various well types by prospect and year. The well costs are derived from an empirical model which utilized as input:

- plant type (flash or binary),

- well-bore size,

- difficulty in drilling the overburden rock,

- temperature of the reservoir fluid at the surface,

- nominal footage costs experienced at various depths in various formations,

- depth of the reservoir and,

- the type of well (exploration, production, reinjection or replacement). 
The input to and results from the well cost model appear in Table 1-IV.

The potential cost savings in a particular year were developed from a consideration of the costs associated with drilling and completion of a well. Basically, there are four types of costs involved:

1) costs while drilling (so-called rotating costs)

2) costs during periods of work when no drilling occurs (repairs, logging, etc.)

3) costs of completion

4) other costs (construction of roads, transportation costs, etc.).

of these costs, only the first and third were assumed to be potential areas for cost reduction. In order to account for the probably increased cost of the new technology, a reduced savings schedule was computed.

The considerations of the discussion above were then used with the well requirements and well costs to estimate the savings which might be achieved. In the calculation of the savings, it was assumed that the savings could be applied to all capital costs of the well. Therefore, some consideration must be given in using the data to the fraction of the well capital cost that can be affected by research and development (i.e., categories 1 and 3, above). Analysis of a drilling budget indicated that perhaps two-thirds of the total capital costs might be subject to reduction as a result of an $R \& D$ program. Because the fraction cited is only an example, the savings 
TABLE 1-IV

CHARACTERISTICS OF THE PROSPECTS

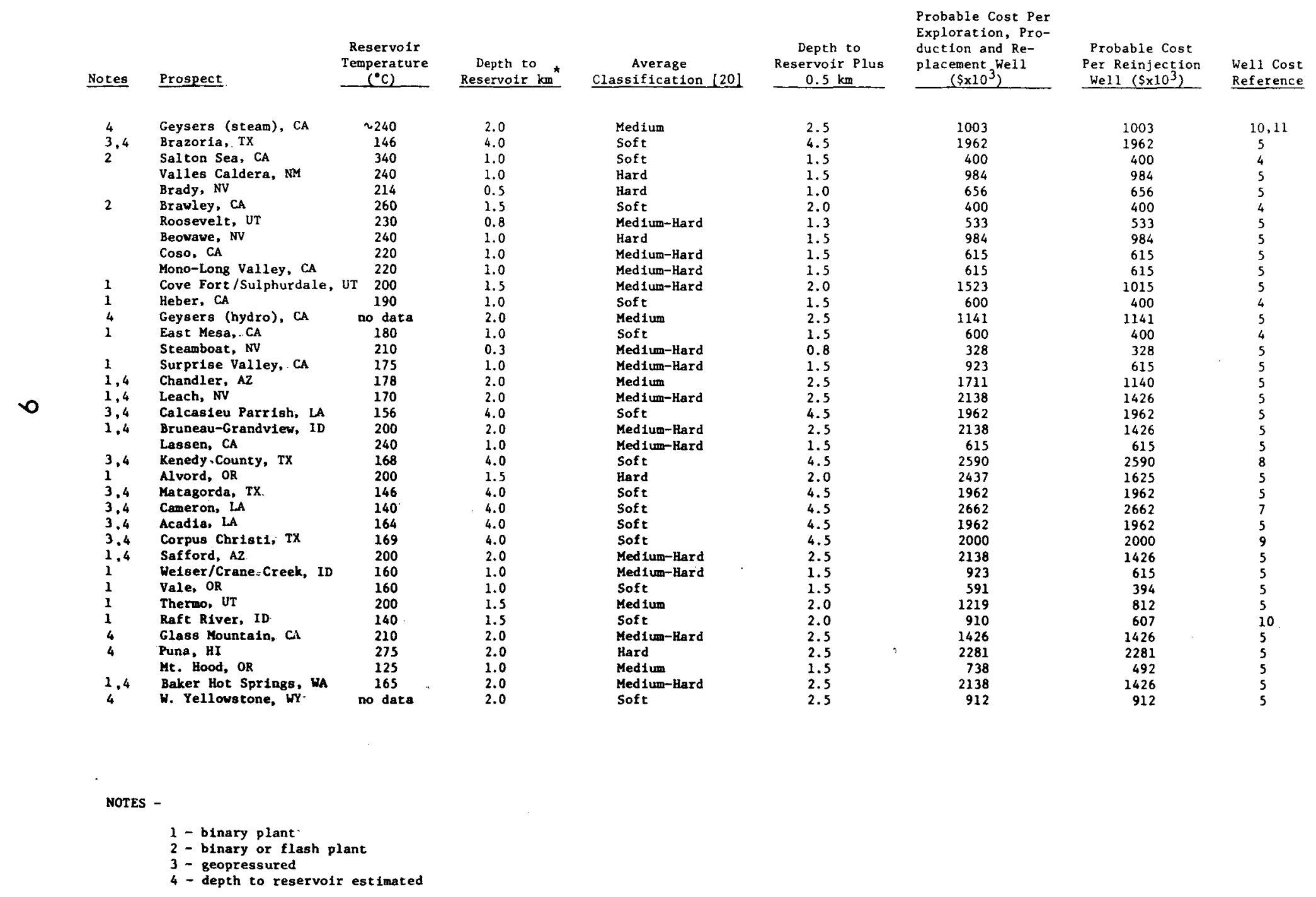


displayed are those derived assuming that all capital costs can be reduced. A simple multiplication of the total estimated savings by the fraction of reducible well costs would produce the correspondingly reduced savings. The estimate of total savings appears in Table $1-\mathrm{V}$. The results in Table $1-\mathrm{V}$ as well as all economic analyses in this report are expressed in 1977 dollars. Thereby, the effects of inf tion are removed from consideration.

The total maximum (undiscounted) savings which might be achieved can be seen to be considerable (in excess of $\$ 3$ billion). It can be seen further that under the schedules used, the rewards from research investments will be felt most heavily in the years of major drilling activity. On the basis of an assumption that two-thirds of the well capital costs are reducible, the maximum resulting savings would be about $\$ 2$ billion.

The estimated cost savings represent only one step in the analysis required to arrive at a target research budget. Table 1-VI summarizes the expected savings and their timing (as derived from the postulated power on-line scenario) and also illustrates the benefit base to be used in the budget analysis. In making the calculations, special consideration is given to the years 1988, 1989, and 1990 . The maximum savings for those years depended on the successful use of novel drilling methods. These savings were used in the computation of Table I-V. However, inasmuch as the probability of success of novel methods may be low (somewhere between 1 in 3 and 1 in 
TABLE $1-\mathrm{V}$

MAXIMUM EXPECTED COST SAVINGS BY YEAR AND PROSPECT ${ }^{*}$ (million of dollars)

(1) Savarios (a) GNALCEIA, TX

SALILN SLR, CA
VALLES CALISEA, NM

BhAUY, N

ERAWLEY, CA

-.LL. St VELI, UT

GLinAmi,

ACTUV-LCLY Y YALLEY, CA COVE FORT/SULPHURDALE, UT

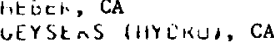

CASI MESA, CA

SUHAPISE VALLLY, CA

CHANLLLLK, AZ

CALCASIES PATHISH, LA

brusit Al,-GMAidutich, ID

LASSEId, CA

AL VOKK.1), OR

MA I ACLIIUA, TX

LAMEKLLN, LA

ACAULA, LA

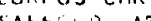

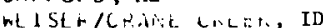

VALE, OR

IHEKM, UT

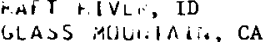

PUNA, HI

MI. IIITIS, OR

BAKER HOT SPRINGS, WA

Berelliositive, MT werotislsita11, Ca

a

\begin{abstract}
isos
\end{abstract}

$$
1334
$$

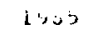

lio

1yol

1 บัก

1485

1sso

IGTAL

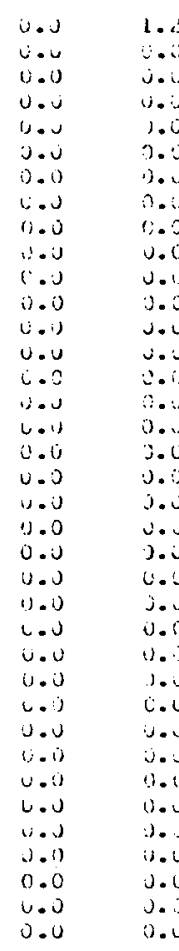

$\begin{array}{ll}3.3 & 4.1 \\ 1) .0 & 1.5\end{array}$$$
\text { i.j }
$$

u.j

0.0
0.0$$
\text { jo.s }
$$

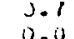$$
0.3
$$

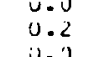

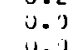

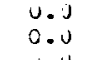

u.u$$
0.0
$$

0.0
0.0
0.0

\begin{tabular}{|c|c|}
\hline ; & \\
\hline 1.1 & 41.3 \\
\hline 1.1 & 100 \\
\hline i. 2 & 1.0 \\
\hline 10.2 & 0.7 \\
\hline 1.0 & \\
\hline 0.1 & 2.0 \\
\hline U. 2 &.+ \\
\hline$\therefore ?$ & 7. \\
\hline 403 & $\therefore . t$ \\
\hline 3.4 & 1.0 \\
\hline 3.0 & $\because 0$ \\
\hline 1.3 & 11.2 \\
\hline U. & $\not 3$ \\
\hline 0.1 & 1.9 \\
\hline 0.6 & $\therefore . v$ \\
\hline 19.0 & $\ldots 1$ \\
\hline 11.2 & 2.1 \\
\hline 14.4 & 1..; \\
\hline 6.2 & $\therefore 1$ \\
\hline 1.7 & vio \\
\hline ac.s & C.S \\
\hline 7.6 & $\ldots 3$ \\
\hline 19.8 & 1.4 \\
\hline 27.6 & 2.0 \\
\hline 1 14.' & 1.4 \\
\hline <u, s & 1.9 \\
\hline C. 1 & נ. U. \\
\hline$\therefore 0$ & 1.0 \\
\hline .0 & 4.9 \\
\hline 0.0 & +.0 \\
\hline U.c & 7.4 \\
\hline 2.7 & j. \\
\hline 3.4 & $u \cdot u$ \\
\hline $1 . c^{2}$ & 0.0 \\
\hline נ.. & 0.0 \\
\hline 1.2 & 11.0 \\
\hline
\end{tabular}

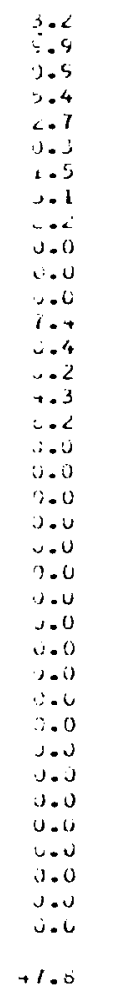

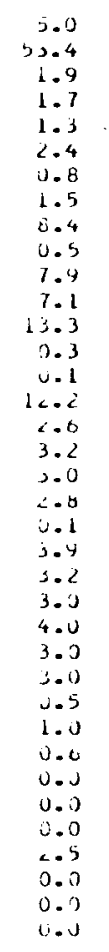

$\begin{array}{rrrr}6.1 & 7.4 & 0.8 & 59.1 \\ 150.6 & 159 & 190.4 & 549.7\end{array}$

$\begin{array}{rrrrr}5.4 & 130.6 & 153.5 & 190.4 & 549.7\end{array}$

$1.7 \quad 11.0 \quad 13.2 \quad 10.5 \quad 57.3$

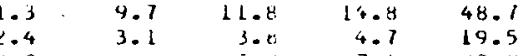

$\begin{array}{lllll}1.5 & 10.4 & 12.8 & 7.1 & 23.0\end{array}$

$\begin{array}{rrrrr}0.4 & 10.4 & 2.2 & .5 & 40.3 \\ 0.5 & 7.2 & 0.6 & 1.0 & 17.3\end{array}$

$7.9 \quad 9.1 \quad 20.5 \quad 25.0 \quad 75.5$

$\begin{array}{rrrrr}7.1 & 1.7 & 11.1 & 14.0 & 46.8 \\ 3.3 & 17.2 & 21.4 & 27.3 & 114.0\end{array}$

$i=1$
$i=2$

4.3

0.0

19.0

15.0

$3.6 \quad 3.5$

<3.J 84.1

, $7.5 \quad 144.0$

$\begin{array}{ll}3.03 & 144.5 \\ 7.29 & 196.5\end{array}$

33.198 .2

1..5 20.5

La.s 70.0

01.1 135.3

32.7158.

$\begin{array}{rl}0.0 & 10.7 \\ 1.1 & 80.8\end{array}$

$11.1 \quad 33.2$

$10.0 \quad 28.3$

$\begin{array}{ll}2.8 & 26.9 \\ 1.1 & 12.6\end{array}$

$41.4 \quad 110.4$

$\begin{array}{ll}1.4 & 10.1 \\ 2.5 & 25.5\end{array}$

* Computed by applying net savings percentage to total well costs. To the extent that only a fraction of the well cost can be impacted by new technology,

the expected savings will be correspondingly smaller. 
TABLE 1-VI

CONVERSION OF EXPECTED SAVINGS STREAM TO PRESENT VALUE

(in million of 1977 dollars)

\begin{tabular}{|c|c|c|c|c|c|c|c|c|c|c|c|c|c|c|}
\hline & Total & 1978 & 19.79 & 1980 & 1981 & 1982 & 1983 & 1984 & 1985 & 1986 & 1987 & 1988 & 1989 & 1990 \\
\hline $\begin{array}{l}\text { Profected } \\
\text { Saving }\end{array}$ & 3097.1 & 0.0 & 1.2 & 5.7 & 12.2 & 30.9 & 30.1 & 47.8 & 213.4 & 157.7 & 154.1 & $563.6 *$ & $512.9 *$ & $561.4 \star$ \\
\hline Benefit Base & & & & & & & & & & & & & & \\
\hline $\begin{array}{l}\text { ( } 10: 1 \text { benefit } \\
\text { to cost ratio } \\
\text { applied to pro- } \\
\text { jected savings) }\end{array}$ & & 0.0 & 0.1 & 0.6 & 1.2 & 3.1 & 3.0 & 4.8 & 21.3 & 15.8 & 15.4 & 56.4 & 51.3 & 56.1 \\
\hline $\begin{array}{l}\text { Present Value } \\
\text { (d) Discount Rate } \\
0 \%\end{array}$ & 229.1 & 0.0 & 0.1 & 0.6 & 1.2 & 3.1 & 3.0 & 4.8 & 21.3 & 15.8 & 15.4 & 56.4 & 51.3 & 56.1 \\
\hline $2 \%$ & 188.3 & 0.0 & 0.1 & 0.6 & 1.1 & 2.9 & 2.7 & 4.3 & 18.5 & 13.5 & 12.9 & 46.3 & 41.3 & 44.2 \\
\hline $4 \%$ & 155.7 & 0.0 & 0.1 & 0.6 & 1.1 & 2.6 & 2.5 & 3.8 & 16.2 & 11.5 & 10.8 & 38.1 & 33.3 & 35.0 \\
\hline $6 \%$ & 129.3 & 0.0 & 0.1 & 0.5 & 1.0 & 2.5 & 2.2 & 3.4 & 14.2 & 9.9 & 9.1 & 31.5 & 27.0 & 27.9 \\
\hline $8 \%$ & 108.0 & 0.0 & 0.1 & 0.5 & 1.0 & 2.3 & 2.0 & 3.0 & 12.4 & 8.5 & 7.7 & 26.1 & 22.0 & 22.3 \\
\hline $10 \%$ & 90.6 & 0.0 & 0.1 & 0.5 & 0.9 & 2.1 & 1.9 & 2.7 & 10.9 & 7.4 & 6.5 & 21.7 & 18.0 & 17.9 \\
\hline $15 \%$ & 59.8 & 0.0 & 0.1 & 0.5 & 0.8 & 1.8 & 1.5 & 2.1 & 8.0 & 5.2 & 4.4 & 13.9 & 11.0 & 10.5 \\
\hline
\end{tabular}

*Note that in 1988,1989 and 1990 , the projected saving is based un the projected net savings rate of 1987 (21.6\%) to account for the uncertainty in the savings which might result from novel technology. 
10), the expected value of the savings from novel technology is less than the expected value of the savings from conventional technology as it would be improved through 1987. Therefore, the benefit base for 1988 through 1990 was derived from savings computed at the rate postulated for $1987(21.6 \%)$. In that way, the benefits are associated with the state of the art in conventional technology and do not depend on the development of highly advanced drilling methods.

One implication of the relatively lower expected benefit of novel methods for the type of drilling envisioned by the hydrothermal and geopressured scenario through 1990 is that the justification for pursuing the development of the novel methods is more likely to rest on the needs of even more difficult drilling environments such as hot dry rock and normal gradient, neither of which were included in this analysis. Another possible implication is that we may have placed unrealistically high expectations on the success of improved conventional technology in comparison with novel methods. This latter possibility should, perhaps, be reinvestigated in the future as more site-specific and technology-specific information becomes available.

It is customary to require that the anticipated savings from federally sponsored research and development activities exceed the costs of those activities. Accordingly, we have postulated a benefit-to-cost ratio of $10: 1$ as a reasonable requirement for the design of the geothermal well technology research and development 
program. The expected benefits, as described above, were thus divided by 10 to establish a program cost target.' Since the research costs and the expected savings obtained occur in different years, the resource stream which represents one-tenth of expected savings was converted to present value at discounted rates ranging from 0 to 15 percent.

The present value ranges from $\$ 60$ million (15 percent discounting) to $\$ 230$ million (no discounting).* Under these assumptions, federal expenditures for a research and development program designed to yield the expected savings would have a cost profile with a total present value of $\$ 60$ to $\$ 230 \mathrm{million}$. Again, these results assume that the projected cost savings can be applied to all aspects of the capital cost of the well. In the more likely event that only twothirds of the costs can be impacted by $R \& D$, the program would range from $\$ 40$ to 150 million.

In addition to the determination of a well schedule, cost reduction schedule, savings and target research and development expenditures, the study also reviewed briefly the current state of the drilling art and its limitations for geothermal applications. Major findings are noted below:

(1) Limitations in the technology used in geothermal drilling are multi-regional in nature, that is, they apply to many prospective drilling sites. Only in about 20 percent of the occurrences of drilling problems can the trouble be

*This is less than $1 / 10$ of the maximum total savings of $\$ 3$ billion cited above, because possible savings in the late 1980 s resulting from novel technology were reduced by the especially low probability of success of the novel technology. 
related to a specific characteristic of a particular prospect. These might include terrain, salinity of the reservoir fluid, high temperature or rock hardness. The remaining drilling problems are common to all prospects.

(2) The fundamental limitations in equipment performance are in the area of materials. The availability of materials able to work in the geothermal drilling environment could greatly increase productivity even without major redesign of important components, such as drill bits.

(3) Research needs are dominated by the requirement for new metal and elastomer materials with better high temperature performance. New muds and cements need also be developed for geothermal applications. Logging instrumentation is another area whose improvement will be required to support the anticipated increase of geothermal drilling.

(4) Government-sponsored initiatives in the following areas could greatly enhance information transfer and commercialization of either improved conventional equipment or nove 1 technology: (1) the development of testing equipment, procedures and facilities appropriate to the geothermal environment, and (2) the encouraging of mechanisms for field testing new technology with minimal risk to commercial drillers.

(5) The justification for government participation in the research program can be linked to the relatively small market for products to support geothermal drilling. The number of geothermal wells needed to support the (electric) power online scenario ( $T a b l e s$ l-II and 1-III, respectively) does not exceed 2000 in any year prior to 1990 , and it does not exceed 500 before 1985. Compared to the 40,000-plus oil and gas wells now drilled annually in the U.S., the perceived market is likely to be too small to motivate industry to undertake major research, development and demonstration on its own in the near term. Government participation to accelerate the pace of geothermal-specific well technology therefore appears justified.

\subsection{Major Assumptions of This Study and Their Impacts}

The study results hinge on a chain of assumptions which are reasonable, but which cannot be guaranteed to prevail. The major as sumptions are: 
(1) The materialization of the benefit stream depends heavily on the realization of the postulated power-online scenarios.

(2) The approach of this study has been to postulate the performance and to evaluate its present worth assuming success. Also,

(a) increased capabilities will cost more and will therefore reduce the net savings, and

(b) no benefits from novel technology were allowed to fall below those expected from advances in conventional technology by 1987 .

(3) It is valid to apply the same postulated average performance to a variety of sites, each with different characteristics and programs.

(4) A range of discount rates from zero to 15 percent has been applied in estimating the present worth of benefits. Their validity and their impact on the results are reviewed below.

First, the realization of a postulated power on-line scenario

is assumed. The magnitude and timing of all estimated expenditures and savings are tied directly to the achievement of this scenario. If only half of the postulated scenario is realized, then roughly half (depending on which sites are brought on line) of the estimated number of wells will be drilled and completed, and half of the estimated expenditures and/or savings on wells will be realized. Further, if the timing is stretched out, then the anticipated savings will. come later. If they come sufficiently later to benefit from more technology improvements, more money may be saved, but to the extent that future savings are discounted, the present value of the delayed savings would be less. The scenario has been postulated for 
program planning purposes by the Division of Geothermal Energy, and it represents a target against which all proposed program activities can be consistently referenced and inter-compared. Thus, while the materialization of the benefit stream depends heavily on the realization of the postulated scenario, the same holds true for any other program initiative which may be competing for limited federal funds. The second major assumption is about the nature and size of the savings that could be expected from improved geothermal well technology (Figure 3-2). In particular, the approach of this study has been to postulate the performance and to evaluate its present worth assuming success. Reduced performance will yield lesser savings. METREK has not performed, nor are we aware that anyone else has performed, a systematic program design and evaluation that promises to deliver these results. At this juncture, they must be treated more as program goals than expected results. Nevertheless METREK believes that the postulated technology performance is reasonable, as employed. Research and development now underway and nearing completion promises to extend drill bit lifetime in geothermal applications by more than a factor of three mainly by materials substitution in conventionally designed bits. This, coupled with a modest increase in instantaneous penetration rate (which might be realized by adding more weight on a strengthened bit) would yield a rotating cost saving of 20 to 75 percent. Assuming that savings of these magnitudes could be expected for completion as well, the postulated 
35 percent gross savings (15 percent, net of the expected increased cost of new technological improvements), does not appear unreasonable. In reality, perhaps only about two-thirds of the costs may be so impacted, and the expected savings would be reduced accordingly. Until the program that can deliver this performance is designed and approved, the performance is but an assumption, however.

Two corollary assumptions go along with the postulated improvements in technology performance. The first has already been alluded to: the increased capabilities will cost more and will therefore reduce the net savings; METREK assumed that costs would rise proportionally to the sixth-tenths power of the postulated performance improvement (effectively, this results in a net cost reduction which is about half the gross cost reduction). There is precedent in the literature for applying the sixth-tenths power for cost scaling. Second, the gross cost reduction from novel technology that is assumed to apply from about 1988 on reached 70 percent by 1990 (about 38 percent, net of extra costs of improved technology). While technologies such as high pressure erosion drilling may yield such savings, METREK tempered such expectations by reducing their benefits so that in no case were benefits from novel technology allowed to fall below those expected from advances in conventional technology by 1987 .

The third major assumption was inherent in applying the postulated performance curve uniformly to all prospective development sites-- 
namely, that it is valid to apply the same postulated average performance to a variety of sites each with different lithology, fluid characteristics, formation temperatures and pressures, and with a variety of expected well designs and drilling and completion programs. Clearly, this is an oversimplification that should be corrected by a more detailed and site-specific analysis. Such analysis must await both a better knowledge of reservoir-specific conditions and a detailed program design that includes enough specificity of performance to permit site-specific savings estimates. The solution can be approached iteratively. This study has produced reasonable performance and RD\&D program cost targets against which a more detailed program design and more specific berefits estimates can be made. This should, in turn, be reviewed and refined periodically. This has been a first step; the next ones are likely to be more difficult.

Fourth, the familiar uncertainty arises about the proper discount rate to apply in estimating the present worth of future benefits. A variety of arguments in favor of one or another discount rate are presented in the report. METREK has not in this instance presumed to select any one rate; instead, a range of discount rates (zero to 15 percent) has been applied in estimating present worth of benefit. The results: if the postulated performance savings and the postulated scenario all materialize, and if a $10: 1$ benefit-to-cost 
performance is required and applied to the expected savings, then $\$ 60$ million ( 15 percent discounting of future benefit) to $\$ 230$ million (undiscounted) could be spent over the next 8 to 10 years on a federal RD\&D program that would promise to yield the postulated improvements. 


\subsection{COST AND SENSITIVITY ANALYSIS: THE ECONOMICS OF DRILLING TECHNOLOGY}

This section presents a brief analysis of the sensitivity of geothermal drilling costs to selected system performance parameters. The purpose is twofold: to establish reasonable ranges and limits for expectations about performance improvements, and to provide quantitative guidance for the design of a program to improve drilling performance. Trade-off analysis, incorporating indifference models, is used to:

- identify the key parameters whose improvement will achieve a significant reduction in the cost of drilling, and

- evaluate the effectiveness and limitations of possible drilling cost improvement strategies.

The results of this analytical effort will be used in Section 3 to estimate the maximum savings in drilling costs that could be achieved with maximum feasible improvement in current conventional drilling technology. The results also will be used to establish targets for setting near-term research and development goals for conventional drilling improvements.

\subsection{Sensitivity Analys is of Costs Parameters}

Sensitivity analysis is used to quantify the relative contributions of the various elements of drilling costs. In conventional (i.e., rotary) drilling, the total drilling cost is made up of those costs incurred while (a) drilling into the formation ("making hole"), (b) "tripping" or moving the drill bit or other tools out of 
the hole for replacement, (c) carrying out tasks in the hole which prevent drilling during that period (logging, etc.), (d) setting up and breaking down the rig, and (e) completing the well.

It is the purpose of this section to estimate the sensitivity of rotating cost to a number of elements. This analysis includes one aspect of non-rotating costs (tripping) but omits the costs of completion, other non-rotating costs and costs not directly associated with the well (road building, regulatory costs, etc.). It is clear that rotating costs make up only one part of the average footage cost of the well (total cost divided by depth of the we11).

In the analysis which follows, drilling, tripping and drill bit characteristics which affect them, namely instantaneous penetration rate and lifetime, will be treated explicitly. Using this formulation, the impact of bit performance and trip time on drilling cost will be determined by sensitivity analysis.

The rotating cost (F) is given by [12]:

$$
F=\frac{C\left[L+v\left(D+\frac{Z}{2}\right)\right]+B}{R L}
$$

where

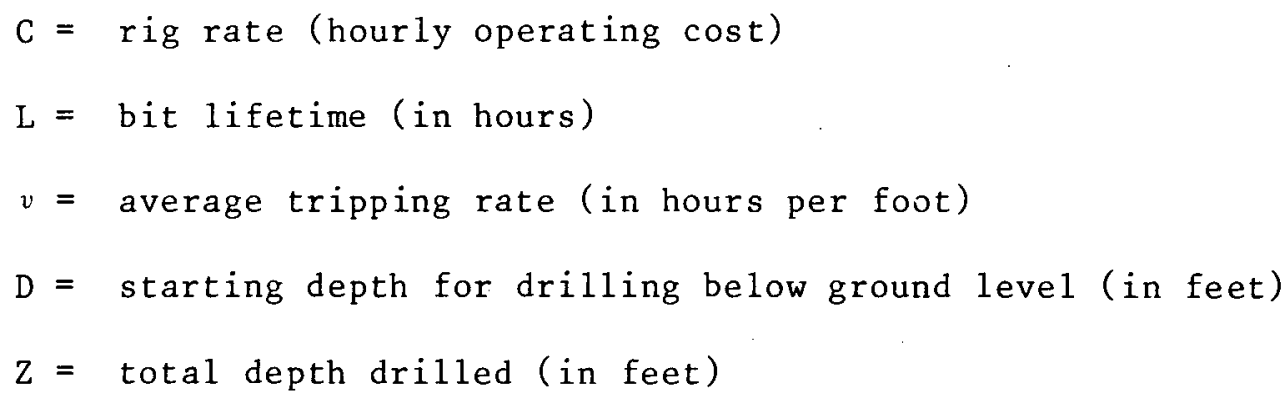




$$
\begin{aligned}
& B=\text { bit cost (in dollars) } \\
& R=\text { average instantaneous penetration rate (in feet per hour) }
\end{aligned}
$$$$
\text { The rotating cost is therefore a function of the hourly cost of }
$$
the rig, the cost of bits, bit performance and tripping rate. The average tripping rate $\nu$ is controlled by manual efforts in bit hoisting and drill pipe assembling and threading where very little improvement can be expected. Thus, the average tripping rate $v$ was assumed to remain constant (about 1.1 hours per 1000 feet of depth). The incremental change in rotating cost (dF) due to small changes in the other six parameters is [13]:

$\frac{d F}{F}=K_{R}\left(\frac{d R}{R}\right)+K_{L}\left(\frac{d L}{L}\right)+K_{C}\left(\frac{d C}{C}\right)+K_{D}\left(\frac{d D}{D}\right)+K_{Z}\left(\frac{d Z}{Z}\right)+K_{B}\left(\frac{d B}{B}\right)$

where $K_{R}, K_{L}, K_{C}, K_{D}, K_{Z}$, and $K_{B}$ are the cost sensitivity coefficients and are defined in Table 2-I.

In general, the coefficients, $K$, are found by assuming that

$$
d F=\left(\frac{\partial F}{\partial R}\right) d R+\left(\frac{\partial F}{\partial L}\right) d L+\ldots .
$$

and that

$$
\frac{d F}{F}=\frac{\partial F}{\partial R}\left(\frac{d R}{F}\right)+\frac{\partial F}{\partial L}\left(\frac{d L}{F}\right)+\ldots
$$

Rearranging,

$$
\frac{\mathrm{d} F}{\mathrm{~F}}=\frac{\partial \mathrm{F}}{\partial \mathrm{R}}\left(\frac{\mathrm{R}}{\mathrm{F}}\right) \frac{\mathrm{dR}}{\mathrm{R}}+\frac{\partial \mathrm{F}}{\partial \mathrm{L}}\left(\frac{\mathrm{L}}{\mathrm{F}}\right) \frac{\mathrm{dL}}{\mathrm{L}} \cdots \cdot
$$


TABLE 2-I

DEFINITION OF SENSITIVITY COEFFICIENTS [13]

$$
\mathrm{K}_{\mathrm{R}}=-1
$$$$
\mathrm{K}_{\mathrm{L}}=-\frac{1}{1+\frac{\mathrm{L}}{[(\nu(D+Z / 2)]+B / C}}
$$

$$
\mathrm{K}_{\mathrm{C}}=\frac{1}{1+\frac{B}{\mathrm{C}[\mathrm{L}+\nu(\mathrm{D}+\mathrm{Z} / 2)]}}
$$

$$
K_{D}=\frac{1}{1+\frac{2 C L+C V Z+2 B}{2 C \nu D}}
$$

$$
K_{Z}=\frac{1}{1+\frac{2 C(L+\nu D)+2 B}{C \nu Z}}
$$

$$
K_{B}=\frac{1}{1+\frac{C[L+v(D+Z) / 2)]}{B}}
$$


Therefore

$$
\begin{aligned}
& K_{R}=\frac{\partial F}{\partial R}\left(\frac{R}{F}\right) \\
& K_{L}=\frac{\partial F}{\partial L}\left(\frac{L}{F}\right) \quad \text { etc. }
\end{aligned}
$$

Each coefficient represents the effect on the incremental change in rotating cost when one of the parameters is slightly increased. The sensitivity coefficient, $K_{R}$, for example, can be used to determine the incremental change in rotating cost $K_{R} \cdot \frac{d R}{R}$ as a result of a change in average instantaneous drilling rate equal to $\frac{d R}{R}$. An increase to 10 percent in the instantaneous drilling rate would cause a similar percentage decrease in rotating cost, since $K_{R}$ is equal to -1 (see Table 2-I)

The starting drilling depth, D, and the total thickness drilled, $Z$, in a particular layer of the formation are fixed by the nature of the geology. Consequently, only four parameters can be changed to achieve an incremental change in rotating cost for each layer defined by $\mathrm{D}$ and $\mathrm{Z}$. These four parameters are:

- the instantaneous drilling (i.e., penetration) rate, $R$

- the bit life, L

- hourly rig rate, C

- bit cost, B.

As shown in Table 2-I, the drilling rate sensitivity coefficient $K_{R}$ is always constant and has an absolute value of 1 . As such $K_{R}$ 
is the largest coefficient in absolute value since all other $K^{\prime}$ s are fractions of the form $\frac{1}{1+X}$ with an absolute value less than 1 . Thus, an improvement in the average instantaneous drilling rate would be most effective in reducing the rotating cost. Unlike $K_{R}$, the values of $\mathrm{K}_{\mathrm{L}}, \mathrm{K}_{\mathrm{C}}$, and $\mathrm{K}_{\mathrm{B}}$ are not constants and are shown, in Table 2-I, to be dependent on the values of the other parameters--D, Z, B, C, and $L$. Table 2-II summarizes a computerized evaluation of the effect of changes in $\mathrm{Z}, \mathrm{B}, \mathrm{C}$ and $\mathrm{L}$ on $\mathrm{K}_{\mathrm{L}}$, and $\mathrm{K}_{\mathrm{B}}$, and $\mathrm{K}_{C}$, respectively. In all of these evaluations, the starting drilling depth is the ground level, so that $D$ has a value of zero. The table is used by selecting, in turn, the values for $B, C$ and $L$. The column below the value of $\mathrm{L}$ then shows the sensitivity coefficients which result from the analysis. According to Table 2-II, the sensitivity coefficient for rig costs, $K_{C}$, has the highest extreme values--ranging from .62 to .99 according to the values of $\mathrm{Z}, \mathrm{B}, \mathrm{C}$, and $\mathrm{L}$. After the average instantaneous penetrating rate, rig rate is the next most effective coefficient for controlling incremental changes in rotating costs. The sensitivity coefficients for bit 1 ife, $K_{L}$, and bit cost, $K_{B}$, range from -.03 to -.55 and from .006 to .37 , respectively. The coefficient, $\mathrm{K}_{\mathrm{C}}$, is also the least susceptible to change as the values of $Z, B, C$, and $L$ change within the limits described above. The percentage change in $\mathrm{K}_{\mathrm{C}}$ is only 37 percent as compared to 94 and 98 percent for $K_{L}$ and $K_{B}$, respectively. Further, reduced rig rate also impacts other time-consuming operations (such as logging) not included in this analysis. 
भi: $31.1: 23$

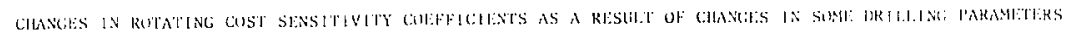

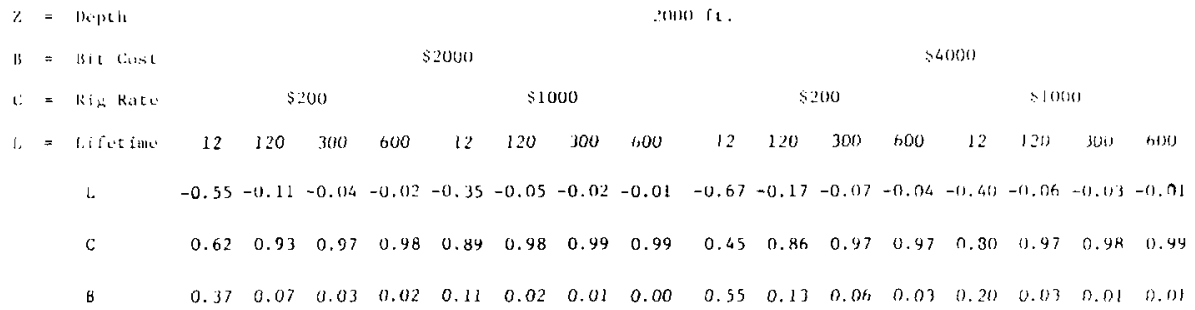


This type of parametric sensitivity analysis can also be used to establish strategies for advancing the state of the drilling art. For example, the sensitivity coefficients $K_{L}, K_{C}$, and $K_{B}$ change very little when the bit 1 ife is increased beyond 120 hours for a given set of values of $\mathrm{Z}, \mathrm{B}$, or $\mathrm{C}$. This behavior is illustrated in Figure 2-1 for the extreme values of:

- $\mathrm{Z}=18,000$ feet,

- $B=\$ 4,000$, and

- $C=\$ 1,000$ per hour.

\subsection{Trade-off Analysis for Rotating Costs}

often, the parameters in the rotating cost equation are interdependent. For example, bit lifetime, L, may be lengthened by using less weight on the bit, but this could lower the average instantaneous penetration rate, $R$. Another example applies in the case of the drilling of shallow wells (possibly for nonelectric applications). In that case, a smaller cheaper rig (with lower C) which has a lower than normal penetration rate might prove to be economical. Determination of these trade-offs requires the use of the drilling cost equation:

$$
F=\frac{C\left[L+\nu\left(D+\frac{Z}{2}\right)\right]+B}{R L}
$$




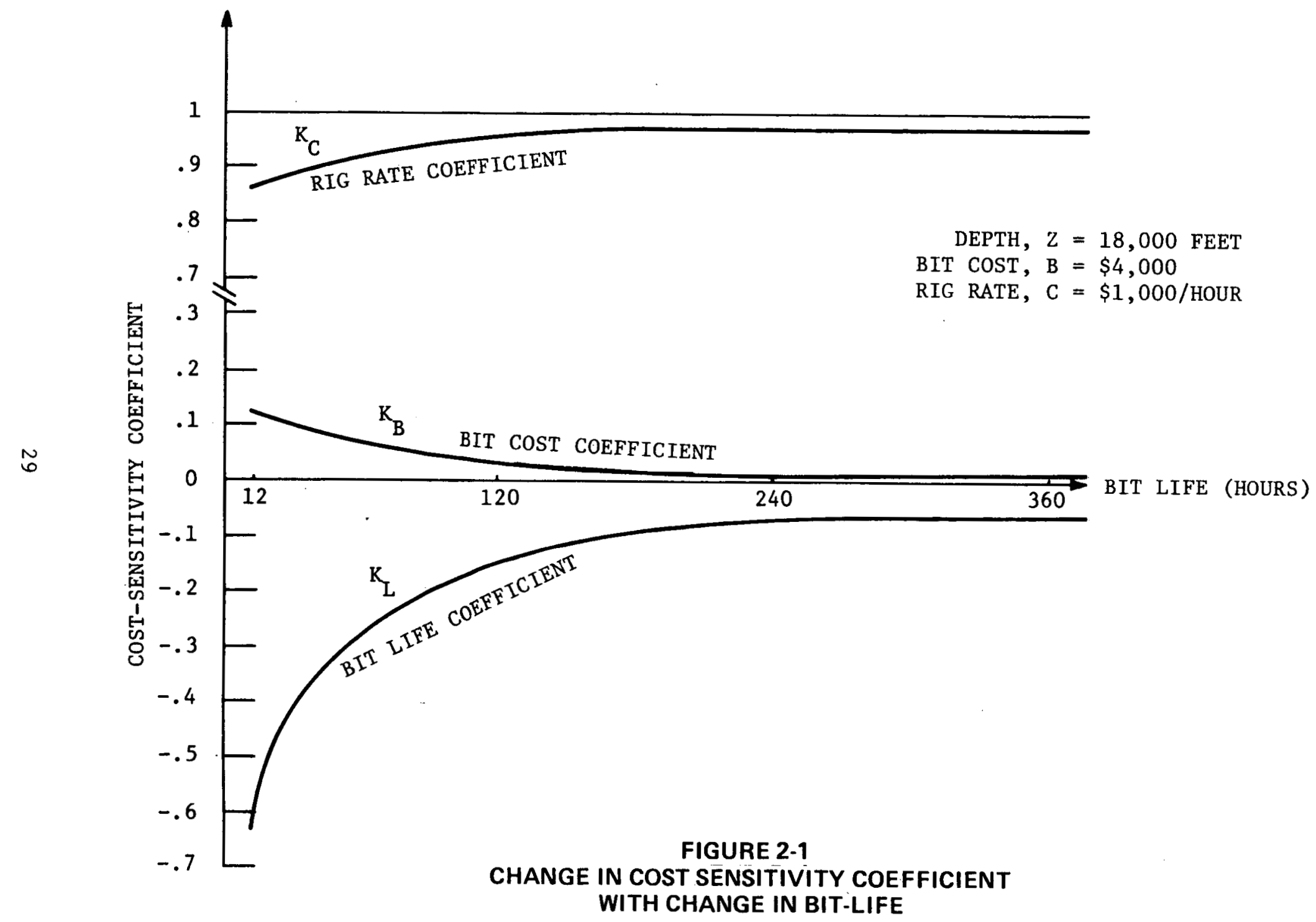


Equation (8) can be rearranged, for example, to represent the relation between $R$ and $L$ for a given $F$ as follows:

$$
R=\frac{C\left[L+v\left(D+\frac{Z}{2}\right)\right]+B}{F L}
$$

Given the values for $C, v, D, Z$, and $B$, Equation (9) can be used to determine the pairs of values of $R$ and $L$ for a fixed $F$. If plotted, these pairs of $R$ and $L$ will result in an indifference footage cost curve as shown in Figure 2-2. Any point on that curve represents the trade-off values of $R$ and $L$ for a given rotating cost. The $R$ and $L$ scale of the normalized indifference curves in Figure 2-3 is divided in multiple units of the average nominal values for current technology ( $R=10$ feet per hour and $L=12$ hours $)$. Furthermore, each indifference curve in Figure 2-3 represents a level of percentage savings. The zero percent indifference curve represents the current rotating costs given the assumed parameters included in the figure. Other curves in Figure 2-3 represent progressively higher percentage savings in rotating cost from 10 to 85 percent.

The following conclusions are drawn from Figure 2-3:

- With no increase in the current bit life (i.e., L = 12 hours), the rotating cost cannot be reduced below approximately 60 percent of its present value, even with a three-fold increase in the penetration rate.

- A three-fold increase in the bit life can reduce the rotating cost by up to 20 percent with the current penetration rate of 10 feet per hour. 


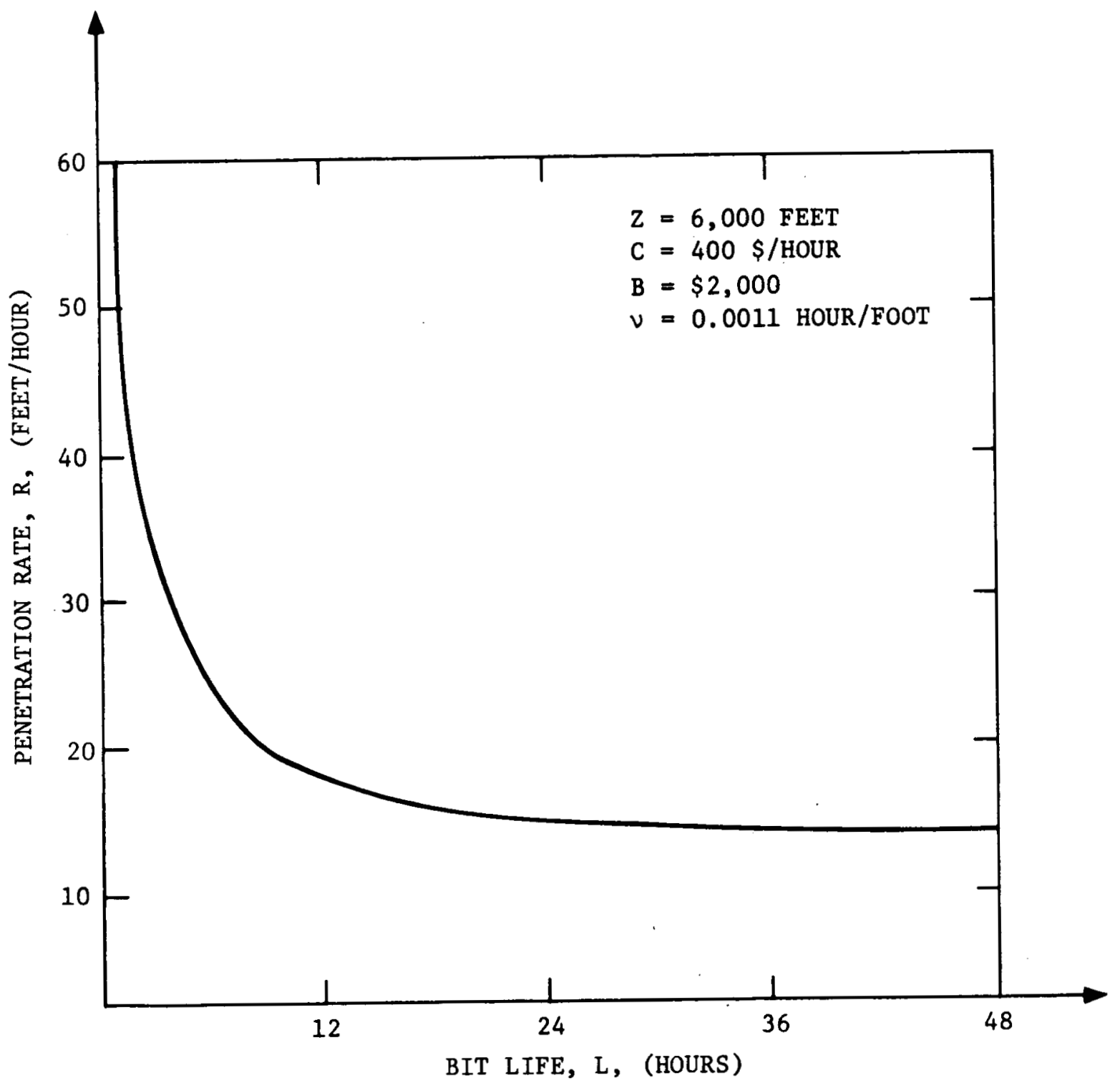

FIGURE $2-2$

A TYPICAL ISO-COST (INDIFFERENCE) CURVE 


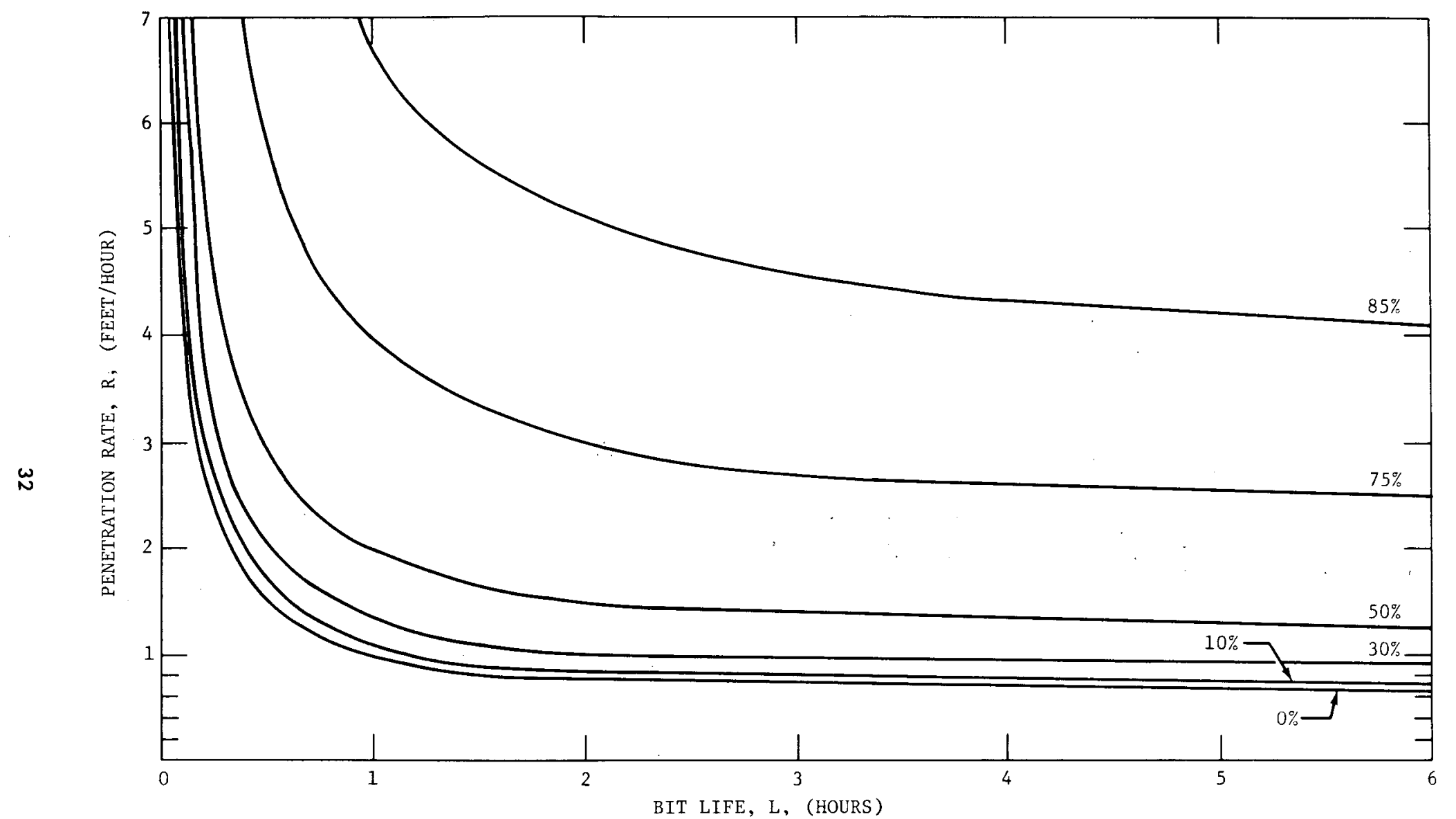

FIGURE 2-3

NORMALIZED INDIFFERENCE ROTATING COST SAVING CURVES FOR $\mathrm{Z}=10,000 \mathrm{FEET}, \mathrm{C}=400 \$ / \mathrm{HOUR}, \mathrm{B}=\$ 2,000, v=0.0011 \mathrm{HOUR} / \mathrm{FOOT}$ AND $D=0.0 \mathrm{FEET}$ 
- With a three-fold increase in both bit life and penetration rate over their current values, the present rotating cost can be reduced by up to approximately 75 percent of its present value. This increase will require significantly improved and, hence, more expensive drill bits. The higher cost of drill bits will partially offset the savings achieved by increasing the penetration rate and bit 1 ife. However, even a three-fold increase in the drill bit cost will not increase the rotating cost by more than a few percent. *

- At the current penetration rate, a 2.5 fold increase in bit life is needed to achieve a 30 percent saving in rotating cost.

The above conclusions are valid only for the specific value of total depth drilled ( $\mathrm{Z}$ ), bit cost (B), and rig rate (C). For other values of $Z, B$, and $C$, the set of normalized indifference curves in Appendix A should be consulted. In addition, the influence of reduced rotating costs on overall well cost must be addressed. This is discussed in Section 2.3.

The set of indifference curves in Figure 2-3 can also be used to determine incremental savings in drilling from one depth to another, for example from a depth of approximately 6,000 feet to 10,000 feet. To this end, the appropriate contour representing the given drilling rate and bit life for $Z=6,000$ feet is used to determine the saving in rotating cost from zero to 6,000 feet. The $Z=10,000$ feet contour is similarly used to determine the savings in

* This is consistent with the strong emphasis on bit performance and the relative indifference to bit costs expressed by people visited on the MITRE/METREK field trip. 
rotating from zero to 10,000 feet. The difference between the savings from zero to 6,000 feet and from zero to 10,000 feet represent the incremental saving in rotating cost from 6,000 to 10,000 feet.

The nominal values of $R$ and $L$ used herein are those typically quoted for medium-hard rocks. These nominal values would be much lower for hard rocks and would result in a downward shift in curves in Figure 2-3.

of the various combinations illustrated in Table 2-II, another appears worthy of note: an increased penetration rate and a reduced rig rate. The normalized indifference curves for the $\mathrm{R}-\mathrm{C}$ combination are shown in Figure 2-4.

With the $\mathrm{R}-\mathrm{C}$ combination, if the nominal rig rate is $\$ 400$ per hour, a 1.4-fold increase in the nominal penetration rate of $10 \mathrm{feet}$ per hour will result in 30 percent reduction in rotating cost. If the nominal rig rate is increased to $\$ 500$ per hour, however, a 1.71 -fold increase in the penetration rate is needed to result in an overall savings of 30 percent. At the current penetration rate of 10 feet per hour, the rotating cost can be reduced up to 40 percent if the rig rate is reduced from $\$ 400$ per hour to $\$ 200$ per hour. At a reduced rig rate of $\$ 200$ per hour, only a 20 percent increase in the current penetration rate (i.e., 12 feet per hour) is required to achieve a 50 percent saving in rotating cost. 


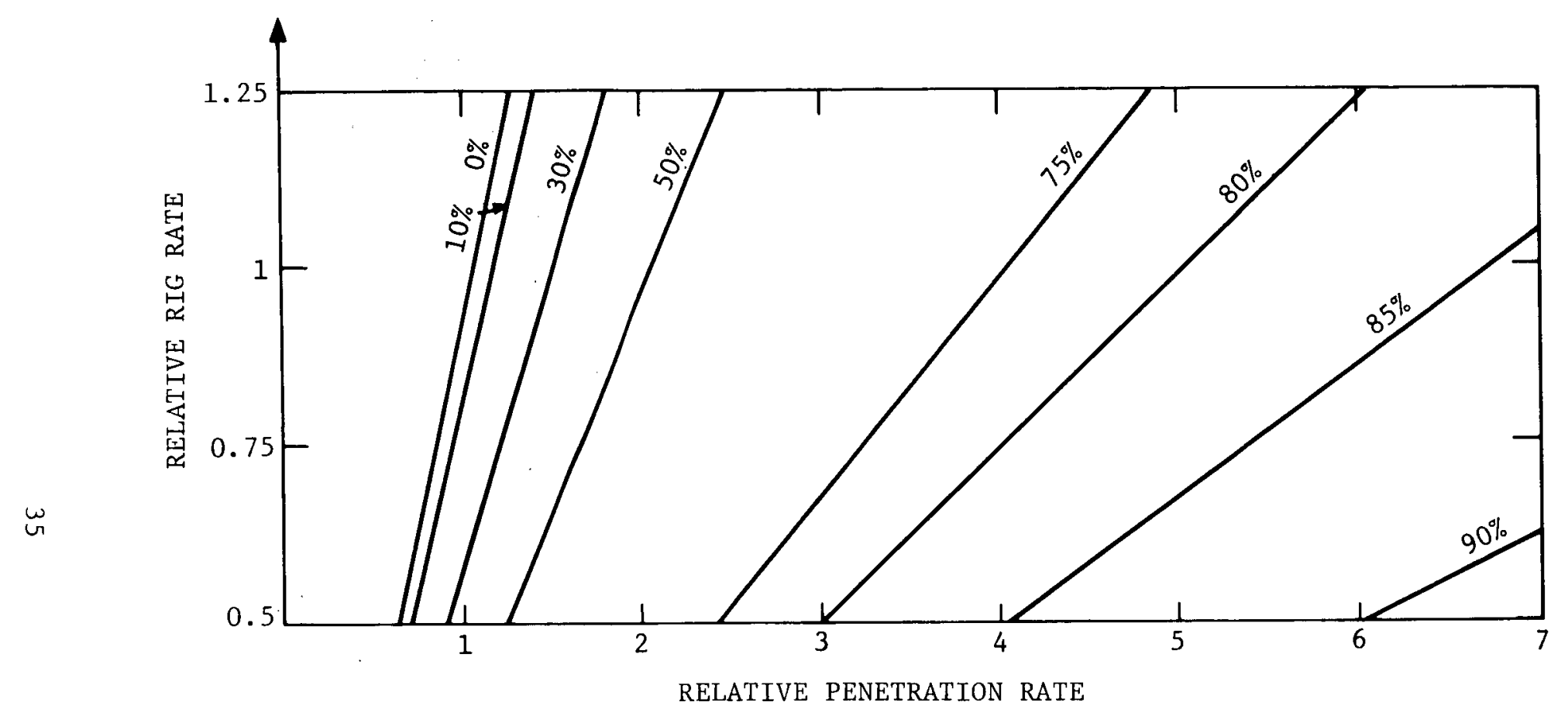

FIGURE 2-4

NORMALIZED INDIFFERENCE ROTATING COST SAVING CURVES

FOR $Z=10,000$ FEET, $B=\$ 2,000$ AND $L=12$ HOURS 


\subsection{Significance of Rotating Costs to Well Costs}

The preceding analysis is limited to that part of well costs associated with drilling and tripping. In addition to drilling and tripping the process of creating a finished well includes other timeconsuming activities (e.g., completion, logging, mobilization, demobilization) the costs of which have not been included in the above analysis. Table 2-III gives an example of the budget for a well at The Geysers.

Consideration of the various costs shows that approximately 25 percent are associated with tasks other than those associated with drilling and completion. These include road building, moving the rig, waste disposal, transportation, logging and miscellaneous costs. The remaining 75 percent of the cost of the well is devoted to drilling and completion. The relative fraction each of these might represent is likely to vary from well to well. We shall assume for the remainder of this analysis that non-rotating time consumes 10 percent of the well cost and that 65 percent of the well cost is associated with rotating time and completion costs. Thus, perhaps two-thirds of the total capital costs of the well are susceptible to being impacted by improved well technology. 
DRILLING AND COMPLETION COSTS AT THE GEYSERS[11]

\section{Cost of Completed Steam We1.1}

Build road, location, and cellar

$\$ 50,000$

Move rig in and out

65,000

Rig operating for 70 days

315,000

Air compressor rental

40,000

Fuel for rig and air compressors

34,000

Excessive drill pipe wear

25,000

Hardbanding drill pipe

3,000

Drill pipe and drill collar inspection

6,000

Water

15,000

Waste Disposal

20,000

20" Conductor pipe

4,500

13-3/8" Casing

52,500

9-5/8" Casing

67,500

Cement and Services

50,000

Rent 20" Hydril and Rotating Head

10,000

Rent shock sub and stabilizer

10,000

Rent monel drill collar and directional instruments

10,000

Drilling mud

30,000

Well head and muffler and flow line

20,000

Miscellanous transportation

10,000

Logging

8,000

Mud well logging

25,000

Bits (27)

55,000

Miscellanous

50,000

Direct supervision and overhead

28,000

$\$ 1,003,500$ 
$$
-
$$ 
3.0 ESTIMATING THE BENEFITS OF IMPROVED GEOTHERMAL WELL TECHNOLOGY This section provides estimates of the potential benefits of a government-sponsored research and development program in geothermal well technology. The benefits are expressed in terms of potential cost savings, from 1978 through 1990, resulting from the development of three types of geothermal resources: steam, liquid-dominated hydrothermal, and geopressured.

The expected benefits of the research and development program are a function of several factors: (a) the number of geothermal wells required, (b) the difficulty in drilling at each site or class of site, (c) the cost of each well, and (d) the extent to which improved technology can reduce the costs of drilling and completion. Consequently, computation of the potential savings in geothermal drilling and completion are based on these factors for each prospect and year. These savings, which are converted to present value, are used to establish a target $R$ and $D$ budget which has a benefit-to-cost ratio of 10 to 1 .

\subsection{Well Drilling Requirements and Schedules}

The first step in the determination of the well requirements for near-term geothermal resources by prospective development site (prospect) and year is a goal for power production at each site. The schedule presented in Table $3-I$ covers 37 current prospects which have been postulated to produce power by suitable conversion of steam, hydrothermal, or geopressured resources between 1978 and 1994 . 
TABLF 3-I

POWER ON-LINE SCHEDULE (MWe) [3]

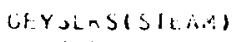

ERACLIMLA

Valles callulka

LAAAYY

DSAnl EY

KLLULVCL

LCI AAA.

CWSUL-L LIAT VALLEY

COVE FORT/SULPHURDALE

COLE

S (trini.)

SILAMTIMES

SURPKLIA VALLER

- chancle.

LLALH

LLALLASIEJ rannISH BR:LNEAL-LKaN JVIE. LASSE'S

KEINELY CLUNG

AL VURO

IATAGúna

CAF'cklis

ACALIA

CLrplis Chalji

SArtlhD

nELISER/LKATLL Critlk.

VAL.E

IHIEKMI

WATI KIVEN

GLASS HULiVIAIR.

PUNA

SPRINGS

n. YELLLCHSIUIVE

ISIAL

\begin{tabular}{|c|c|c|}
\hline 1.10 & עיl' & $1 \%, 0$ \\
\hline 211 & 1,00 & 215 \\
\hline u & 0 & $\mathrm{u}$ \\
\hline " & $u$ & i \\
\hline 0 & 0 & 0 \\
\hline J & 0 & $u$ \\
\hline$\checkmark$ & 0 & v \\
\hline .) & $u$ & $i$ \\
\hline 0 & 0 & i) \\
\hline$J$ & is & " \\
\hline 0 & 0 & u \\
\hline 0 & $u$ & 1 \\
\hline$v$ & $u$ & 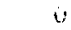 \\
\hline$\checkmark$ & 0 & 0 \\
\hline . & v & j \\
\hline J & 0 & 0 \\
\hline v & 0 & v \\
\hline 0 & v & 0 \\
\hline i) & 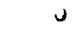 & 0 \\
\hline j & 0 & (1) \\
\hline j & 0 & u \\
\hline 0 & u & u \\
\hline$u$ & 0 & 0 \\
\hline 0 & 0 & 6 \\
\hline 0 & $i$ & 0 \\
\hline$u$ & u & 0 \\
\hline 0 & J & 6 \\
\hline 0 & 0 & 0 \\
\hline $\mathrm{C}$ & 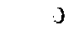 & u \\
\hline 0 & $u$ & i \\
\hline$v$ & 0 & 0 \\
\hline$J$ & 0 & () \\
\hline$u$ & $u$ & $u$ \\
\hline 0 & 0 & $u$ \\
\hline$j$ & 0 & 0 \\
\hline 0 & u & 0 \\
\hline 0 & 0 & 6 \\
\hline$\lambda$ & J & $u$ \\
\hline
\end{tabular}

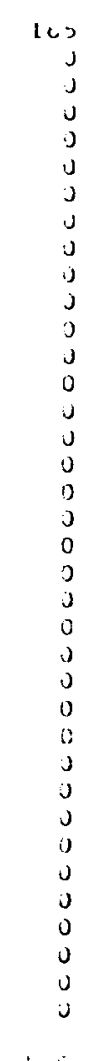

21
0
0
0
$u$
0
0
0
0
0
0
0
0
0
0
0
0
0
0
0
0
0
0
0
0
0
0
0
0
0
0
0
0
0
0
0
0
0
0

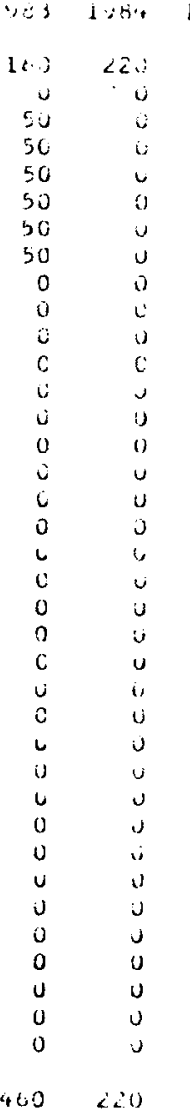

\begin{tabular}{|c|c|c|c|}
\hline 1.85 & 190 & | & 11008 \\
\hline 110 & 0 & ن & $v$ \\
\hline 0 & $<5$ & 0 & tuo \\
\hline 100 & は & 13 & idou \\
\hline 0 & 100 & u & lue \\
\hline 0 & bo & u & 100 \\
\hline 50 & 0 & 100 & 100 \\
\hline$u$ & (i) & 0 & 50 \\
\hline 0 & נו & u & 30 \\
\hline 50 & 20 & 20 & 130 \\
\hline 50 & 6 & 100 & 0 \\
\hline 50 & v & su & o \\
\hline 30 & 0 & 50 & ن \\
\hline lov & טנ 1 & $1 \mathrm{uv}$ & $1 \mathrm{Ju}$ \\
\hline 50 & $v$ & $i$ & jo \\
\hline jo & 0 & 0 & 30 \\
\hline 0 & Su & u & $5 J$ \\
\hline u & טג' & $u$ & i \\
\hline 0 & 0 & 50 & ن \\
\hline 0 & 0 & $>0$ & v \\
\hline 0 & 0 & 30 & u \\
\hline 0 & 0 & 50 & 0 \\
\hline$u$ & 0 & 30 & u \\
\hline u & 0 & $b 6$ & u \\
\hline v & $v$ & 56 & , \\
\hline 0 & 0 & so & 0 \\
\hline 0 & 0 & 50 & 0 \\
\hline 0 & 0 & 30 & J \\
\hline 0 & 0 & so & $J$ \\
\hline$u$ & $u$ & C & bo \\
\hline 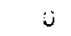 & 0 & i & ju \\
\hline u & $u$ & U & j.j \\
\hline u & 0 & 0 & 30 \\
\hline 0 & $u$ & $i$ & v \\
\hline 0 & $J$ & 0 & u \\
\hline 0 & 0 & 0 & 0 \\
\hline 0 & $\dot{u}$ & C & u \\
\hline 0 & $u$ & i & $\mathrm{J}$ \\
\hline
\end{tabular}

lyos 1440 14y1 1950 igy. 19y4

\begin{tabular}{|c|c|c|c|c|c|}
\hline i & $v$ & $u$ & ن ن & u & $J$ \\
\hline lus & <ul & $=\Delta i$ & <ub & 2000 & 200 \\
\hline 100 & 100 & 100 & $10 c$ & 100 & 100 \\
\hline$\iota$ & 100 & Iuv & 100 & 100 & ivo \\
\hline 0 & lou & ive & tou & 160 & lus \\
\hline 100 & 100 & 100 & 100 & 100 & 100 \\
\hline$\hat{u}$ & 100 & 100 & $1 C_{2}$ & 100 & 100 \\
\hline$v$ & luvi & 100 & 100 & 100 & 100 \\
\hline$i>0$ & 150 & $\theta$ & ¿ & 0 & 0 \\
\hline 0 & 100 & $v$ & c & 0 & 0 \\
\hline su & 50 & 100 & iul & Livo & 100 \\
\hline ijo & 100 & 100 & 100 & 100 & 100 \\
\hline 1.00 & 100 & I U v & 100 & 100 & 100 \\
\hline$v$ & u & J & $L$ & $u$ & $u$ \\
\hline 0 & 100 & 8 & C & 0 & 0 \\
\hline I) & 10u & ivo & 160: & 130 & 1 Jo \\
\hline$u$ & 100 & 50 & $\iota$ & u & 0 \\
\hline 0 & 50 & $10 \%$ & 100 & 100 & 100 \\
\hline 0 & 50 & (5) & lou & luo & $u$ \\
\hline ن & 100 & lue & luo & 100 & 100 \\
\hline 0 & 50 & 0 & $r$ & $u$ & 0 \\
\hline 0 & so & נט & si & 30) & 5u \\
\hline$u$ & so & be & bic & 50 & 50 \\
\hline 0 & 30 & 30 & 50 & so & j0 \\
\hline 0 & 50 & 50 & 50 & 0 & 50 \\
\hline 0 & jo & bu & 50 & 50 & 100 \\
\hline${ }^{\circ}$ & jo & 5u & su & 50 & 100 \\
\hline 0 & 0 & $v$ & 0 & $u$ & 0 \\
\hline 0 & 100 & iou & 106 & 100 & 100 \\
\hline$u$ & 50 & 50 & נu & su & 50 \\
\hline 0 & ن & ن & 100 & 100 & 100 \\
\hline 0 & 50 & ? & 0 & 0 & 0 \\
\hline$\dot{u}$ & bu & j & 9 & u & u \\
\hline 0 & $1 \cup 0$ & ¿ou & 200 & $<0$ & $2: 0$ \\
\hline 0 & 50 & 0 & U & 0 & o \\
\hline$J$ & 50 & $v$ & 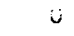 & 0 & v \\
\hline$v$ & 50 & $\therefore$ & $:$ & 0 & 0 \\
\hline 030 & $20>26$ & 2156 & 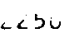 & $\therefore \angle b u$ & $22>0$ \\
\hline
\end{tabular}


For the next five years, only The Geysers prospect is expected to produce electric power. Electricity production from liquid-dominated hydrothermal areas is expected to begin in 1983. By 1986, geopressured resources are expected to contribute some electric power. Yearly additions of power will grow slowly from 1978 through 1989 and will reach a plateau by 1995 .

Realization of the power on-line schedule of Table 3-I implies a well drilling schedule which allows for a sufficient number of exploration, production, reinjection, and replacement wells to meet this power production goal. The requirements and schedules for each of these wells are discussed in the following paragraphs.

\subsubsection{Exploration Wells}

The number of wells to be drilled for exploratory purposes for the first plant at each prospect will be a function of current knowledge of the prospect. For this analysis, current knowledge was classified into three types with associated assumptions of drilling requirements :

- Type 1 - Exploration for the first plant has been completed.

- Type 2 - The reservoir of the prospect is reasonably well known but some exploration is still required. Approximately three sites within the prospect must be explored in order to identify the most appropriate site for a power plant. An average of 1.5 exploratory wells must be drilled at each site [14]. Thus, five exploratory wells will be required.

- Type 3 - Little or no exploratory drilling has occurred. An average of seven sites within the prospect must be explored (each with 1.5 wells) to find a suitable power plant site. Thus, 10 wells must be drilled. 
TABLE 3-II

REQUIREMENT FOR EXPLORATION WELLS

GEYSKRS(STEAN) SRAZLKIA

VALLLS Salliet. BLAWLE

KLLSEVEL

ut? hithe

MLAL - LLNL VALLEY

HEHEr

EASt de liryme)

STEAMALA

SIJPRRISE VALLEY

CTANULL

$\stackrel{\Delta}{N}$

CALCASIEJ PARKIS

GhulNEAU-Unaivivit

LASSEIV

KENEOY CCLNAYY

ALVLRO

Ma TALECKUA

Cambromis

CLRPUS CHISHI

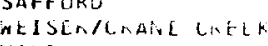

VALE

MAFI i IV

GLASS MLUJitali

PUNA

BAKER HOT SPRINGS

ne relicins] the

\begin{tabular}{|c|c|c|c|c|c|c|}
\hline $\begin{array}{l}\text { Reservoir } \\
\text { Type } \\
\text { (See Text) }\end{array}$ & 1310 & 197 & 1100 & $1 \cdots 1$ & $1 \times 1$ & $14(0)$ \\
\hline 1 & 5 & ; & s & 5 &. & $v$ \\
\hline 3 & j & $u$ & $\because$ & 17 & is & 0 \\
\hline 1 & $i$ & j & 0 & $\because$ & 5 & , \\
\hline $\mathrm{i}$ & $i$ & $\checkmark$ & $\because$ & i & 5 & 0 \\
\hline 2 & 5 & 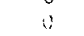 & 0 & 0 & 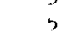 & 0 \\
\hline 1 & $c$ & $i$ & 0 & 5 & 0 & 5 \\
\hline 1 & i: & j & $\because$ & $i$ & 5 & 0 \\
\hline : & 5 & 3 & 0 & 0 & 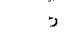 & 0 \\
\hline 3 & 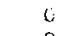 & j & $1 \mathrm{v}$ & v & 2 & 5 \\
\hline 3 & 0 & ij & 10 & 0 & i & 3 \\
\hline$\therefore$ & 0 & $a$ & 10 & 0 & is & 5 \\
\hline$i$ & 0 & $j$ & 0 & 6 & 2 & 5 \\
\hline 2 & 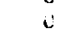 & 0 & j & u & $\xi$ & b \\
\hline 1 & v & 0 & 0 & ju & J & $\dot{i}$ \\
\hline j & ¿ & v & 16 & 0 & u & 0 \\
\hline 3 & 0 & 0 & 0 & 10 & j & u \\
\hline 3 & 0 & ) & $i$ & 10 & 0 & $\dot{i}$ \\
\hline 3 & i & j & 0 & 0 & 10 & 0 \\
\hline$\therefore$ & $i$ & $y$ & 0 & i & $1 u$ & u \\
\hline 3 & 0 & 0 & 0 & i & $1 u$ & 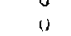 \\
\hline 2 & 0 & j & u & 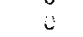 & Iu & 0 \\
\hline 3 & $i$ & 0 & 0 & 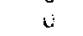 & iu & $i$ \\
\hline 1 & 0 & $j$ & 0 & $\checkmark$ & $1 \mathrm{c}$ & 0 \\
\hline 3 & 0 & 0 & v & ن & 10 & 0 \\
\hline 3 & 0 & 0 & 0 & $\checkmark$ & lu & 0 \\
\hline 3 & 0 & $j$ & 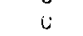 & 0 & 10 & j \\
\hline 3 & 6 & 0 & 0 & 0 & 10 & 3 \\
\hline 3 & c & 0 & ن & $u$ & iv & 0 \\
\hline 3 & $c$ & 3 & $i$ & 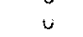 & 0 & lus \\
\hline 3 & 0 & u & 0 & u & $i$ & (i) \\
\hline 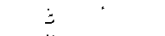 & 0 & $u$ & i) & 0 & 0 & 10 \\
\hline 2. & 0 & 0 & $j$ & $u$ & u & 5 \\
\hline 3 & 0 & $j$ & $j$ & u & 0 & 0 \\
\hline 3 & 4 & 3 & 3 & 0 & 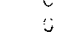 & 0 \\
\hline 3 & $i$ & 0 & 0 & $v$ & v & $i$ \\
\hline 3 & c & 0 & s & D & i) & v \\
\hline 3 & 4 & $v$ & 0 & 0 & 0 & 0 \\
\hline$I C T A L$ & 15 & 3 & 5: & + & 14\% & 70 \\
\hline
\end{tabular}

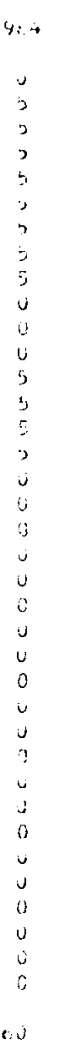

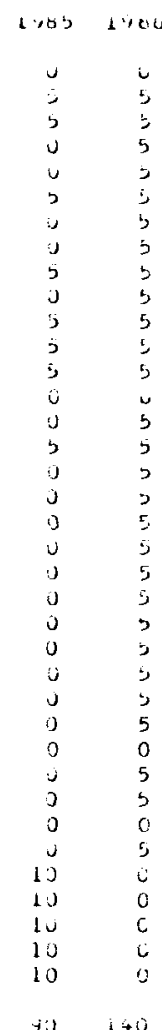

\begin{tabular}{|c|c|c|c|}
\hline u & 0 & $\because$ & 0 \\
\hline 5 & 3 & , & 5 \\
\hline 3 & 5 & כ & 5 \\
\hline 5 & 5 & $?$ & \\
\hline 3 & " & ') & 5 \\
\hline 5 & 2 & 5 & 5 \\
\hline 5 & 3 & 5 & 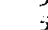 \\
\hline 0 & 0 & u & 0 \\
\hline 0 & 0 & $i$ & 0 \\
\hline 5 & ? & '3 & 5 \\
\hline 5 & ? & $?$ & 3 \\
\hline j & o & u & 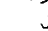 \\
\hline 0 & 0 & c) & 0 \\
\hline ' & ${ }^{i}$ & 's & 5 \\
\hline r & 4 & 3 & 5 \\
\hline 5 & 5 & ל & 0 \\
\hline 5 & , & ' & $=$ \\
\hline u & 0 & $u$ & 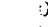 \\
\hline 5 & s & 3 & $b$ \\
\hline 3 & ? & 3 & 5 \\
\hline 5 & , & 5 & 3 \\
\hline 5 & f & , & 5 \\
\hline 5 & 5 & $b$ & 5 \\
\hline$?$ & 0 & $\dot{U}$ & 3 \\
\hline 5 & 5 & 5 & 5 \\
\hline b & 3 & , & 5 \\
\hline 3 & u & 3 & j \\
\hline 0 & $u$ & J & $j$ \\
\hline ', & 5 & 5 & , \\
\hline 3 & U & d, & a \\
\hline 3 & 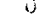 & $\dot{u}$ & 0 \\
\hline & & 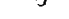 & \\
\hline & $i \ldots$ & 120 & \\
\hline
\end{tabular}

1 I AL

40

35

35

40

20

45

50

20

30

35 
The chosen number of sites within each prospect to be explored was derived from an informal paper on this issue provided by ERDA's Division of Geothermal Energy [15]. The logic developed by METREK for estimating numbers of wells and their timing follows.

For the purposes of scheduling, the exploratory wells were assumed to be completed five years prior to the goal for the first date of electric power production.

In this analysis, those plants to be brought on line after the first plant were assumed to be sited after an exploratory program similar to that of Type 2. That is, the reservoir will be known, but a specific drilling site must be selected. Therefore, five exploratory wells must be drilled to find a new site within a prospect. Because of the added knowledge of the reservoir after the first plant, the exploratory wells for subsequent plants need only precede the date of first power production by four years. Table 3-II illustrates the requirement for exploratory wells.

\subsubsection{Production and Reinjection Wells}

The determination of the number of production and reinjection (return) wells necessary to support a 50 MWe plant is based upon the estimated temperature of the resource, as well as the anticipated flow rate [1]. The probable requirements for production and reinjection wells are listed in Tables 3-III and 3-IV for each prospect and year. In computing these requirements, it has been assumed that 
TABLE 3-III

REQUTREMENT FOR PRODUCTION WELLS

No. OF WELLS REQUIRED TO SUPPORT A

GLYSLKSISILABA itRALiKI IA

SALILN SEA
VALLES CAALE:A

VALLES

oHakler

kClistriti

BeL

GLINL-LuHC VALIEY

COVE FORT/SULPHURDALE

HezE⿺辶:

Gerseins (lirutic)

LASI MLSA

$\vec{A}$

SI EAMBLA

LEALH

CALCASICU PARRISI

BRUAEAU- OTABDVIR

LASSL IV

KENELY

ALvitio
Aalablikua

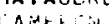

LAMERLI
ACALIA

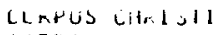

SAFF UKU
WEIStR/CHATE LRE

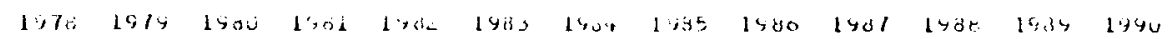

IITAL

TALL

TAEFMC.

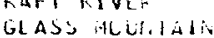

PUNA

BAKER HOT SPRINGS

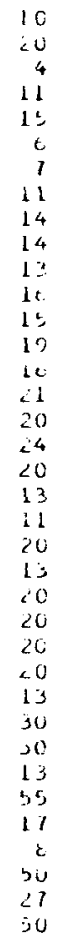

25
6
6
0
0
0
0
0
0
0
0
0
0
0
0
0
0
0
0
0
0
0
0
0
0
0
0
0
0
0
0
0
0
0
6
0
0

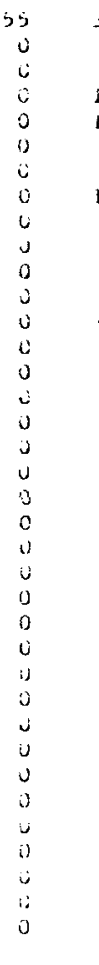

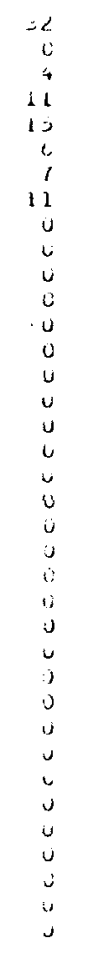

TI,TAL
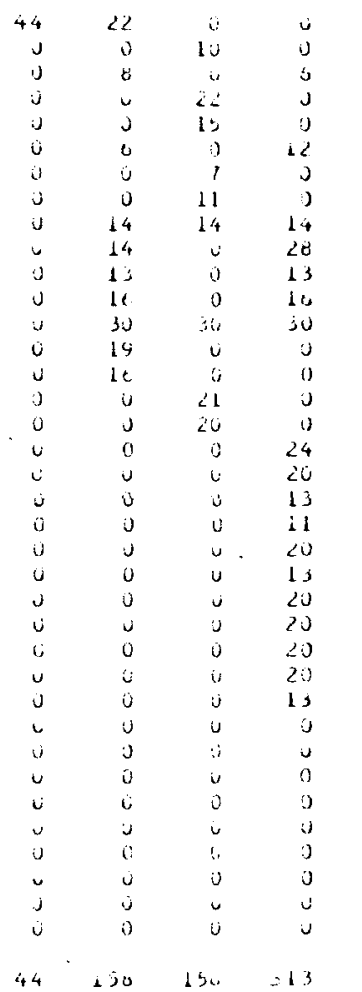

\begin{tabular}{|c|c|c|c|c|}
\hline$i$ & $u$ & 0 & $\dot{i}$ & $\mathrm{~s}$ \\
\hline 40 & 40 & 20 & (6) & 80 \\
\hline 6 & B & $\theta$ & 3 & $\theta$ \\
\hline 22 & $u$ & 22 & $\therefore$ & 22 \\
\hline 30 & $\mathrm{j}$ & 30 & נכ & j) \\
\hline Lo & 12 & $i_{i}$ & 12 & 12 \\
\hline & נJ & 14 & 14 & 14 \\
\hline 11 & $?$ & $\therefore$ & 24 & 22 \\
\hline 42 & 42 & 42 & (3) & 0 \\
\hline 0 & 0 & 20 & ) & $\mathrm{j}$ \\
\hline 0 & 13 & is & $i c$ & $\angle 0$ \\
\hline 0 & 32 & $j^{2}$ & $-3 \alpha$ & 32 \\
\hline 30 & 30 & 30 & 30 & 30 \\
\hline 15 & 0 & 0 & $\dot{u}$ & 0 \\
\hline IC & 0 & 32 & ) & 0 \\
\hline 21 & 42 & 42 & 42 & 42 \\
\hline u & 0 & - 40 & 20 & 0 \\
\hline 0 & 0 & 24 & 43 & $4 \overrightarrow{3}$ \\
\hline 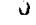 & 0 & $\angle 0$ & \& & 40 \\
\hline 0 & 0 & 20 & $<0$ & 20 \\
\hline 0 & 0 & 11 & 0 & 0 \\
\hline u & $u$ & 20 & 20 & $<u$ \\
\hline 0 & 0 & 13 & 1, & 1s \\
\hline 0 & 0 & 20 & (2) & 20 \\
\hline$i$ & i & 20 & iv & 20 \\
\hline 0 & 0 & 20 & $i 0$ & 20 \\
\hline$u$ & 0 & 20 & 20 & 20 \\
\hline 0 & $u$ & 0 & ? & $u$ \\
\hline O & 0 & tiu & 60 & t. \\
\hline 30 & 0 & 30 & $\therefore 1$ & 3. \\
\hline 13 & 0 & 0 & $u$ & 20 \\
\hline 35 & 0 & 35 & $u$ & $J$ \\
\hline 6 & $J$ & 11 & $\mathbf{J}$ & 0 \\
\hline $\boldsymbol{w}$ & 0 & $1 t$ & $\therefore$ & 32 \\
\hline 0 & 0 & $51]$ & $\mathrm{J}$ & 0 \\
\hline u & 0 & $? 7$ & « & i \\
\hline 0 & כ & & $\dot{v}$ & ن \\
\hline
\end{tabular}

241
330
64
121
$1>0$
84
63
99
108
70
104
160
240
18
84
210
80
144
100
91
22
80
58
83
80
80
80
13
210
120
39
10
17
80
50
27
50
3811
13 
TABLE 3-IV

No. OF WELLS REQUIRED TO SUPPORT A

REQUURRPAENT FOR RE-INJECTION WELLS

GLYSLCHS (STEAM) SKALUKIA

SALILN SEA

VALLES

BhAWLEY

BRAnLLY

BUUSCVEL

MCiNU-LUIVG VALLLY

COVE FORT/SULPHURDALE

HEBER

GEYSERS (tiYURU)

EAST MESA
SIEAMBUAT

SIEAMBUAT

- chanulea

LALCASICU PAKFISH

GRUNEAU-GXANLiVIÉ

LASSEN

KENEDY LIJUNIY

ALVLRO

PataGérida

CAMEKUN

CCakfus CMHISTI

SAFFUn CMTS

WLISEK/LRAIVE CAETK

VALE

IHEAMU:

rAFI KIVER

gLASS MEUINTALIH

PUNA

MT. HCOO

YCLLO

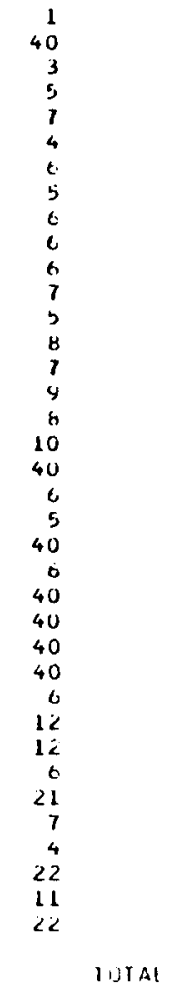


the production and reinjection wells for each power plant must be drilled two years prior to the date for power to go on line.

\subsubsection{Replacement Wells}

Production wells begin to lose power production capacity almost as soon as they are brought on line. For that reason, replacement wells must be brought on line to provide the heat input requirements throughout the plant's life. To estimate the schedule and number of replacement wells required by prospect, 5 percent of the production wells in service were assumed to be replaced each year at The Geysers [14]. For other prospects, a 10 percent yearly replacement rate was assumed [16].

Table 3-V summarizes the replacement well schedule. It was derived from the power on-line schedule and the number of production wells needed to produce that power. The replacement well drilling was assumed to begin in the first year of power production and to continue as needed.

\subsubsection{Total We1ls}

The rate of drilling for near-term geothermal resources will include the contribution from production, reinjection (return), replacement, and exploratory wells. A schedule which combines all these requirements is shown in Table $3-\mathrm{VI}$. It illustrates the total number of wells to be drilled by year at each prospect. 
REQUIREMENT FOR REPLACEMENT OF PRODUCTION WELLS

GEYSEKSISIEAM

SKAZLKIA

valles calveka

nLUSL VELT

BECWAn

GeNL-LGHG VALLEV

COVE FORT/SULPHURDAL

HEYSTKS

UASI MESA

SIEAMBUal

SUKPAISE VALLEY

LACH

CALCASIEU PATRIISH

KEAtior

matagorua

ClKruS CHIISOH

SAFFCKJ

VALE

TEKML

GLAS: MEUR iAI

PUNA

MI. HCGO

BAKER HOT SPRINGS

n. YtLLLinstive

\begin{tabular}{|c|c|c|c|c|c|c|c|c|c|c|c|c|c|}
\hline 1476 & $1 \times 7.4$ & 1480 & $1 \because 6 b$ & 1402 & 146.1 & $190+$ & 1483 & $1: 6 t$ & 1981 & 1980 & 1404 & 1990 & Ti,TAL \\
\hline$t$ & 10 & 13 & is & 10 & 20 & 22 & 23 & 23 & 23 & $\angle 3$ & 23 & 23 & 244 \\
\hline 0 & 0 & $v$ & $u$ & $\mathrm{c}$ & 0 & 6 & $u$ & 1 & 1 & 5 & 9 & 17 & 33 \\
\hline c & $u$ & 0 & 0 & 0 & 0 & 0 & 1 & 2 & 9 & 4 & 3 & 6 & 21 \\
\hline$c$ & 0 & 0 & 0 & 0 & l & 1 & $i$ & 3 & 3 & b & 5 & 7 & 26 \\
\hline 0 & 0 & $u$ & u & 0 & 2 & 2 & 2 & 4 & 4 & 7 & 7 & 10 & 38 \\
\hline C & 0 & 0 & 0 & 0 & 1 & 1 & 2 & $<$ & 3 & 4 & 5 & 0 & 24 \\
\hline $\mathrm{c}$ & 0 & $\mathrm{c}$ & u & $u$ & $i$ & $i$ & $i$ & 2 & 2 & 3 & 3 & 4 & 17 \\
\hline c & $u$ & 0 & 0 & 0 & $i$ & 1 & i & 2 & 2 & 3 & j & 5 & 18 \\
\hline c & 0 & 0 & 0 & 0 & 0 & 0 & 1 & $<$ & 3 & 7 & $1 i$ & 15 & 39 \\
\hline 0 & $j$ & 0 & u & 0 & 0 & $u$ & 1 & 1 & 4 & 4 & 4 & 7 & 21 \\
\hline 0 & 0 & 0 & 0 & 0 & 0 & u & i & 1 & 2 & 2 & 3 & 4 & 1s \\
\hline 0 & 0 & 0 & c & 0 & 0 & 0 & 2 & 2 & 4 & 4 & 7 & 10 & 29 \\
\hline c & 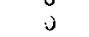 & $i$ & u & u & v & 0 & 3 & 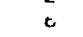 & $\therefore$ & 12 & 13 & 16 & 63 \\
\hline 0 & $J$ & 0 & 0 & 0 & 0 & 0 & 2 & 2 & 2 & 4 & 4 & 4 & 18 \\
\hline$c$ & jo & 0 & 0 & 0 & 0 & 0 & 2 & c & 2 & 4 & 4 & $i$ & 21 \\
\hline 0 & 0 & v & v & u & $u$ & is & 0 & 2 & 2 & 4 & d & 12 & 28 \\
\hline C & 6 & $i$ & v & 0 & i & u & u & 2 & 2 & 2 & 2 & 6 & 14 \\
\hline 0 & 0 & J & $u$ & 0 & v & $u$ & u & 0 & 2 & 2 & 2 & 4 & 10 \\
\hline$i$ & 3 & 0 & 0 & ن & 0 & 0 & u & c & 2 & 2 & 2 & 4 & 10 \\
\hline 0 & j & $i$ & u & v & u & u & $u$ & 0 & 1 & 1 & 1 & 4 & 1 \\
\hline 0 & 0 & 0 & 6 & $i$ & 0 & J & v & 0 & i & i & $i$ & 2 & 5 \\
\hline 0 & u & 0 & 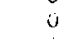 & u & 0 & $j$ & j & 0 & 2 & 2 & 2 & 4 & 10 \\
\hline$i$ & $u$ & $u$ & $u$ & u & $v$ & 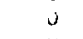 & u & 0 & 1 & $i$ & 1 & 2 & 3 \\
\hline 0 & 0 & 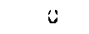 & 0 & 0 & 0 & $u$ & 0 & 0 & 2 & 2 & 2 & 4 & 10 \\
\hline 0 & 0 & 0 & 0 & u & $u$ & $u$ & 0 & 0 & 2 & 2 & 2 & 4 & 10 \\
\hline c & $u$ & \& & $u$ & 0 & $u$ & $u$ & 0 & 0 & 2 & 2 & 2 & 4 & 10 \\
\hline 0 & 0 & 0 & u & 0 & 0 & u & 0 & u & 2 & 2 & 2 & 4 & 10 \\
\hline $\mathrm{C}$ & 0 & 0 & u & 0 & 0 & 0 & u & 0 & $i$ & $i$ & I & I & 4 \\
\hline 0 & u & i & $u$ & $\mathrm{c}$ & $u$ & $u$ & 0 & $i$ & 0 & 3 & 3 & 9 & 15 \\
\hline 0 & 0 & 0 & $u$ & 0 & $u$ & 0 & v & 0 & 0 & 3 & 3 & b & 12 \\
\hline 0 & 0 & 0 & 0 & 0 & 0 & $v$ & $u$ & 0 & 0 & 1 & 1 & 1 & 3 \\
\hline 0 & $u$ & 0 & $u$ & u & 0 & i & i & $u$ & 0 & b & 0 & 12 & 24 \\
\hline 0 & 0 & 0 & 0 & 0 & 0 & 0 & 0 & 0 & 0 & 0 & ن & 2 & 2 \\
\hline $\mathrm{c}$ & 0 & i & u & u & 0 & u & $j$ & 0 & 0 & j & 0 & 2 & 2 \\
\hline 0 & 0 & $\ddot{0}$ & v & i & u & i & $u$ & i & u & 0 & 8 & 5 & 5 \\
\hline$r$ & 0 & 0 & 0 & 0 & 0 & i & v & C & 0 & j & $j$ & 1 & 3 \\
\hline 0 & 0 & 0 & 0 & 0 & 0 & $v$ & 0 & v & 0 & 0 & J & 5 & 5 \\
\hline 6 & 10 & (1) & 15 & 14 & $2 t$ & $\Leftrightarrow \Rightarrow$ & 43 & 59 & dy & $1<0$ & 147 & 243 & 829 \\
\hline
\end{tabular}


T'ABLE 3-VI

ESTMMATED TOTAL NUMBER OF WELLS REQUIRED TO SUPPORT POWER ON-LINE SCHEDULE

GirstridalaAis, CA Uinclikld, TX

SALLITS SLA, CA MRALY, NV Hanahlir, CA

muCSEVELT, UT

oliinawe, NV

Cl.SL, CA

COVE FORT/SULPHURDALE, UT H:LHLF, CA

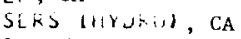

SASI YtSA, CA

jumptise Vill ir, ca

Chanultr, AZ

$\stackrel{\infty}{\infty}$

CALLASILE PAM KISH, LA

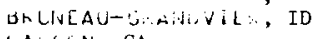

LADSEN, CA

AlNeur CQ OR

satalcrioja,

Namautiruá, TX

ALALIA, LA

LEKF'US LHATII TX

SAFFLEJ, AZ

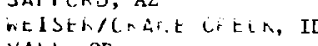

VALt, OR

KATI KIVE

GLAS, RLition, ID

PUNA, HI

जI . HC.U, OR

BAKER HOT SPRINGS, WA

\begin{tabular}{|c|c|c|c|c|c|c|c|c|c|c|c|c|c|}
\hline 1,7 & $\therefore t$ & $1 \% 0$ & AUd & $1 \times 0.2$ & 1 1,0s & Isin, & (2) & $\because s d \theta$ & 1031 & $1 \cdots 3:=$ & $! \because \ldots:$ & liyu & $1 . \mathrm{AAL}$ \\
\hline 74 & إ & $i$ & 3 & « & .44 & $c<$ & $<3$ & $\therefore$ & s & $-j$ & -3 & 2 &, 29 \\
\hline c & 0 & $\dot{u}$ & $1 \mathrm{u}$ & 0 & 0 & s) & s & $i<i$ & lac & Liu & $\therefore$ & $\therefore 02$ & 1 sud \\
\hline L & u & 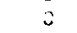 & $1<$ & , & 19 & it & 11 & $\angle 1$ & 22 & 23 & $\therefore$ & (2) & 184 \\
\hline 6 & 0 & 6 & 16 & , & 1 & so & 1 & $4 i$ & o & 42 & $4<$ & 44 & 237 \\
\hline 5 & u & ij & $c<$ & 3 & 2 & $\therefore$ & 2 & 53 & $;$ & $\therefore 0$ & $x$ & by & 294 \\
\hline$i$ & $v$ & 0 & 12 & 2 & 16 & : & 21 & ¿I & 20 & $\therefore$ & 3.1 & 31 & -09 \\
\hline $\mathrm{C}$ & 3 & 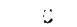 & 13 & $;$ & 1 & 15 & 1 & $2 J$ & 7 & 34 & 34 & 3 & 16, \\
\hline 5 & 0 & 0 & io & $\because$ & 1 & ci. & l & $<3$ & 7 & +4 & $4 ;$ & 42 & 202 \\
\hline$c$ & $i$ & 16 & u & 5 & 25 & $c 3$ & $\therefore c$ & 41 & c3 & .7 & 11 & (1) & 314 \\
\hline 0 & 0 & 10 & i & J & $\angle 5$ & 0 & 4 & 0 & 4 & $\leftrightarrow$ & 4 & 7 & 141 \\
\hline$u$ & $\dot{u}$ & is & 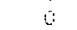 & $u$ & 24 & $\therefore$ & $\therefore 3$ & $c$ & 20 & $<0$ & is & +1 & 210 \\
\hline 1) & j & $i$ & u & $\because$ & 28 & $v$ & 90 & 7 & 55 & 5 & $s_{0}$ & $\mathrm{cl}$ & 294 \\
\hline 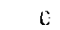 & 0 & 5 & 0 & , & 45 & $4 \%$ & $\therefore 0$ & il & 54 & 57 & tu & 03 & 433 \\
\hline 0 & J & 1) & $v$ & v & $\therefore 7$ & : & $\because$ & $<1$ & 2 & $\rightarrow$ & 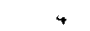 & , & $7 \%$ \\
\hline 0 & $i$ & 10 & u & is & is & ; & 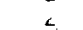 & ji & 2 & bo & 4 & $j$ & 133 \\
\hline 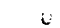 & 0 & $\mathrm{v}$ & $i \mathrm{c}$ & u & 0 & ; & $;$ & 1 & 6.7 & 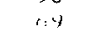 & $7 \mathrm{~s}$ & $t i$ &, 73 \\
\hline 0 & j & i & $1 \because 2$ & 8 & 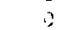 & Li, & J & $l$ & 1 & $=4$ & $\because$ & $c$ & 140 \\
\hline 0 & v & 8 & 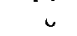 & $1 \mathrm{u}$ & v & 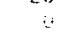 & $j+$ & 5 & $i$ & 41 & 7 & 17 & 249 \\
\hline 0 & 0 & (3) & 0 & ij & 0 & u & 00 & $b$ & $i$ & is 7 & 17 & 124 & 340 \\
\hline 0 & $j$ & u & $u$ & is & $i$ & $"$ & 19 & 5 & 0 & 44 & 4. & +7 & 175 \\
\hline c & 3 & ن & $u$ & 1: & 0 & u & 10 & 5 & l & 17 & $i$ & 2 & 32 \\
\hline$c$ & 0 & $c$ & c & 10 & $j$ & 0 & t.j. & 5 & 7 & 47 & ci $i$ & 09 & 205 \\
\hline 0 & j & ن & ju & 10 & 3 & (1) & 14 & 5 & 0 & $\begin{array}{l}15 \\
25\end{array}$ & $\therefore$ & 26 & 110 \\
\hline u & is & 0 & u & $\therefore \therefore$ & 0 & j & ou & b & 7 & 87 & $\therefore 7$ & $\theta x$ & 205 \\
\hline $\mathrm{c}$ & 0 & 0 & J & 10 & 0 & 0 & bo & 3 & 7 & 0.7 & 1 & 69 & 285 \\
\hline$u$ & u & 0 & u & is & u & 0 & oJ & 5 & $l$ & i7 & +7 & 69 & 235 \\
\hline$c$ & J & $j$ & 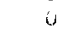 & io & u & $\because$ & ou & 5 & 1 & $c l$ & it & c"; & $\therefore 85$ \\
\hline 0 & J & 0 & $u$ & 10 & u & $\therefore$ & 1\% & $u$ & I & 1 & 1 & 1 & 33 \\
\hline$i$ & j & $i$ & u & 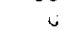 & iv & 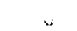 & $u$ & 41 & 3 & 2 & $\therefore$ & 96 & 344 \\
\hline$i$ & ن ن & 0 & $j$ & 3 & 10 & j & 0 & +1 & ; & $\because j$ & $=0$ & 53 & 215 \\
\hline 0 & i) & 0 & u & $j$ & iv & $i$ & 0 & 19 & ju & 0. & 0 & 44 & BS \\
\hline$c$ & u & j & 0 & ن & 3 & $i$ & j & 01 & 0 & 32 & 0 & is & 180 \\
\hline 0 & 0 & $i$ & 0 & 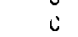 & 0 & 8 & 10 & $i$ & 0 & 24 & 0 & 2 & 36 \\
\hline 0 & $u$ & 3 & . & ") & u & i & (:) & u & 5 & 21 & 53 & 55 & 152 \\
\hline c & i & 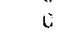 & 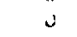 & is & 0 & $j$ & iv & c & $j$ & 12 & 3 & 5 & 37 \\
\hline c & $u$ & 0 & v & 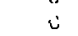 & 3 & i & 13 & 0 & 0 & is & J & , & 51 \\
\hline$i$ & $j$ & 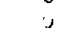 & i & . & v & $\therefore$ & is & v & ) & $i 2$ & , & 5 & 3 \\
\hline ; & 1 & 2,4 & $A$ & 211 & , ll & 年 & .73 & $\therefore 17$ & 503 & $\therefore$ is & $15+0$ & $: 10\}$ & 0659 \\
\hline
\end{tabular}




\subsection{Well Costs by Prospect*}

Minimal data are available on the costs of geothermal wells. No data exist for many of the geothermal prospects cited in this document because they have yet to be drilled. Further, only 1 imited use can be made of the few examples of published costs. Several possible reasons explain this limitation:

- The data may have been obtained from a government-sponsored drilling operation. While government sponsorship may guarantee a complete disclosure of the schedule and costs of the well, such operations often are experimental and include frequent interruptions for logging and testing not normally undertaken in commercial production drilling. As a result, the costs of the government-sponsored wells are often justifiably higher than those for commercial production wells. In many cases (such as Raft River or the hot dry rock experiments in New Mexico), these wells may be classified as "wild-cats," (first of its kind in an area, for which high costs are expected because of all the unknowns). Therefore, the costs of these wells are not valid estimates of the costs of future production wells at these sites.

- The costs for drilling and completion are not separated from other costs often associated with the well, such as licensing, environmental study and control, and legal costs.

- The applicability of the data to current costs is a strong function of the actual time of drilling. Reportedly, oil and gas wells have doubled in cost in the last four years. As a result, the credibility of any drilling cost data before 1975 must be questioned [10].

In spite of the scarcity of data, some up-to-date well cost data exist for selected sites. The data include:

*All analyses in this and subsequent sections are carried out in 1977 dollars. 
- The Geysers [3] - $\$ 1,003,000, *$

- Salton Sea [4] - $\$ 400,000$,

- Brawley [4] - $\$ 400,000$,

- Heber [4] - $\$ 400,000$,

- East Mesa [4] - $\$ 400,000$,

- Raft River [10] - \$670,000,

- Cameron [7] - $\$ 2,662,000$,

- Kenedy County [8] - $\$ 2,590,000$, and

- Corpus Christi [9] - $\$ 2 ; 000,000$.

The data for the first six sites represent actual well costs. The data for the last three. sites are careful estimates derived from quotations for equipment and services.

These data are used both for estimated well costs and estimated savings in Section 3.4 as well as for a guide in estimating drilling costs for the other prospects. The characteristics of the geological formation, the probable depth of the wells for each prospect, and the reservoir temperature were used to estimate well costs for those prospects with no data.

For each prospect, a depth to the top of the reservoir was determined either from U.S. Geological Survey data or by comparison with other, similar prospect geologies [6]. In addition, 500 meters was added to each well depth to account for drilling into the reservoir.

*A breakdown of these data appears in Table 2-III. 
The geological classifications were lised to define the type and hardness of rock found at each prospect as described in section 4.1 .

It was assumed that down-hole pumps would be necessary at all binary conversion cycle plants (except the very high-temperature highflow rate plant at Salton Sea). Down-hole pumping would also be employed at sites with formation temperatures below $200^{\circ} \mathrm{C}$ for which the flash cycle would be used. We further assumed that the oversized wells needed to accommodate the down-hole pumps would cost fifty percent more than regular-sized wells at the same sites. Estimates of the well costs were then derived from the formation hardness, temperature well depth data, and an estimation of the footage costs in geothermal drilling at various depths [17]. The footage cost data are summarized in Table 3-VII. This table lists the probable cost per foot in 1977 dollars for each type of formation hardness, for both the shallow ( $<5000$ feet) and deep $(>5000$ feet) segments of a well. Results of the calculations appear in Table 3-VIII, along with the input data.

The existing data on well costs offer an opportunity to check the reliability of the method described above. When a comparison was made between the cost-estimating methodology and actual production well costs, a root mean square error of 8 percent was found. Thus, the drilling cost-estimating methodology appears to provide reasonable cost estimates, especially when the unpredictable nature of drilling costs is considered. 
TABLE 3-VII

FOOTAGE COSTS FOR GEOTHERMAL DRILLING AS A

FUNCTION OF ROCK TYPE AND WELL DEPTH[17]

\begin{tabular}{|l|c|c|}
\hline \multirow{2}{*}{$\begin{array}{c}\text { ROCK } \\
\text { HARDNESS }\end{array}$} & \multicolumn{2}{|c|}{ COST/FOOT $(1977$ DOLLARS $)$} \\
\cline { 2 - 3 } & $<5000$ FEET & $>5000$ FEET \\
\hline Soft & 80 & 160 \\
Medium & 100 & 120 \\
Medium-Hard & 125 & 250 \\
Hard & 200 & 400 \\
\hline
\end{tabular}


TABLE 3-VIII

CHARACTERISTICS OF THE PROSPECTS

\begin{tabular}{|c|c|c|c|c|c|c|c|c|}
\hline Notes & Prospect & $\begin{array}{c}\text { Reservoir } \\
\text { Temperature } \\
\quad\left({ }^{\circ} \mathrm{C}\right) \\
\end{array}$ & $\begin{array}{r}\begin{array}{r}\text { Depth to } \\
\text { Reservoir } \mathbf{k m}^{*}\end{array} \\
\end{array}$ & $\begin{array}{c}\text { Average } \\
\text { Classification }[20]\end{array}$ & $\begin{array}{c}\text { Depth to } \\
\text { Reservo1r Plus } \\
0.5 \mathrm{~km} \\
\end{array}$ & $\begin{array}{l}\text { Probable Cost Per } \\
\text { Exploration, Pro- } \\
\text { duction and Re- } \\
\text { placement Well } \\
\quad\left(\$ \times 10^{3}\right) \\
\end{array}$ & $\begin{array}{l}\text { Probable Cost } \\
\text { Per Reinjection } \\
\text { Well }\left(\$ \times 10^{3}\right) \\
\end{array}$ & $\begin{array}{l}\text { Wel1 cost } \\
\text { Reference } \\
\end{array}$ \\
\hline 4 & Geysers (steam), CA & $\approx 240$ & 2.0 & Medium & 2.5 & 1003 & 1003 & 10,11 \\
\hline 3,4 & Brazoria, TX & 146 & 4.0 & Soft & 4.5 & 1962 & 1962 & 5 \\
\hline 2 & Salton Sea, CA & 340 & 1.0 & Soft & 1.5 & 400 & 400 & 4 \\
\hline & Valles Caldera, NM & 240 & 1.0 & Hard & 1.5 & 984 & 984 & 5 \\
\hline & Brady, NV & 214 & 0.5 & Hard & 1.0 & 656 & 656 & 5 \\
\hline 2 & Brawley, CA & 260 & 1.5 & Soft & 2.0 & 400 & 400 & 4 \\
\hline & Roosevelt, UT & 230 & 0.8 & Med1um-Hard & 1.3 & 533 & 533 & 5 \\
\hline & Beowawe, NV & 240 & 1.0 & Hard & 1.5 & 984 & 984 & 5 \\
\hline & coso, CA & 220 & 1.0 & Medium-Hard & 1.5 & 615 & 615 & 5 \\
\hline & Mono-Long Valley, CA & 220 & 1.0 & Med Ium-Hard & 1.5 & 615 & 615 & 5 \\
\hline 1 & Cove Fort/Sulphurdale, U & UT 200 & 1.5 & Med fum-Hard & 2.0 & 1523 & 1015 & 5 \\
\hline 1 & Heber, CA & 190 & 1.0 & Soft $t$ & 1.5 & 600 & 400 & 4 \\
\hline 4 & Geysers (hydro), CA & no data & 2.0 & Medium & 2.5 & 1141 & 1141 & 5 \\
\hline 1 & East Mesa, CA & 180 & 1.0 & Soft & 1.5 & 600 & 400 & 4 \\
\hline & Steamboat, NV & 210 & 0.3 & Med 1 um-Hard & 0.8 & 328 & 328 & 5 \\
\hline 1 & Surprise Valley, CA & 175 & 1.0 & Medium-Hard & 1.5 & 923 & 615 & 5 \\
\hline 1,4 & Chandler, AZ & 178 & 2.0 & Medium & 2.5 & 1711 & 1140 & 5 \\
\hline 1,4 & Leach, NV & 170 & 2.0 & Med i um-Hard & 2.5 & 2138 & 1426 & 5 \\
\hline 3,4 & Calcasieu Parrish, LA & 156 & 4.0 & Sof $t$ & 4.5 & 1962 & 1962 & 5 \\
\hline 1,4 & Bruneau-Grandview, ID & 200 & 2.0 & Medfum-Hard & 2.5 & 2138 & 1426 & 5 \\
\hline & Lassen, CA & 240 & 1.0 & Med ium-Hard & 1.5 & 615 & 615 & 5 \\
\hline 3,4 & Kenedy County, TX & 168 & 4.0 & Sof $t$ & 4.5 & 2590 & 2590 & 8 \\
\hline 1 & Alvord, OR & 200 & 1.5 & Hard & 2.0 & 2437 & 1625 & 5 \\
\hline 3,4 & Matagorda, $\mathrm{TX}$ & 146 & 4.0 & Sof $t$ & 4.5 & 1962 & 1962 & 5 \\
\hline 3,4 & Cameron, LA & 140 & 4.0 & Sof $t$ & 4.5 & 2662 & 2662 & 7 \\
\hline 3.4 & Acad 1a, LA & 164 & 4.0 & Soft. & 4.5 & 1962 & 1962 & 5 \\
\hline $\begin{array}{l}3.4 \\
3.4\end{array}$ & Corpus Christi, TX & 169 & 4.0 & Sof $t$ & 4.5 & 2000 & 2000 & 9 \\
\hline $\begin{array}{l}1,4 \\
1,4\end{array}$ & Saf ford, AZ & 200 & 2.0 & Med Ium-Hard & 2.5 & 2138 & 1426 & 5 \\
\hline 1,4 & We1ser/Crane Creek, ID & 160 & 1.0 & Med fum-Hard & 1.5 & 923 & 615 & 5 \\
\hline 1 & Vale, OR & 160 & 1.0 & Soft & 1.5 & 591 & 394 & 5 \\
\hline 1 & Thermo, UT & 200 & 1.5 & Med lum & 2.0 & 1219 & 812 & 5 \\
\hline 1 & Raft River, ID & 140 & 1.5 & Soft & 2.0 & 910 & 607 & 10 \\
\hline 4 & Glass Mountain, Ci & 210 & 2.0 & Medium-Hard & 2.5 & 1426 & 1426 & 5 \\
\hline 4 & $\begin{array}{l}\text { Puna, HI } \\
\text { H }\end{array}$ & 275 & 2.0 & Hard & 2.5 & 2281 & 2281 & 5 \\
\hline & Mt. Hood, OR & 125 & 1.0 & Medfum & 1.5 & 738 & 492 & 5 \\
\hline 1,4 & Baker Hot Springs, WA & 165 & 2.0 & Medium-Hard & 2.5 & 2138 & 1426 & 5 \\
\hline 4 & w. Yellowstone, WY & no data & 2.0 & Soft & 2.5 & 912 & 912 & 5 \\
\hline
\end{tabular}

NOTES - 


\subsection{Cost Reduction Profile}

\subsubsection{Gross Savings From Expected Technology Improvements}

The cost reduction profile, as defined in this section, is made up of a set of assumptions concerning the possible cost reductions resulting from successful government and industrial research and development efforts in geothermal well technology. Three general types of cost savings are assumed:

- Cost savings resulting from industry efforts which occur without investment of government money or without costsharing with government. These savings may result, for example, from transfer of technology from the oil and gas industry to geothermal industry or from specific industry research on geothermal drilling technology.

- Cost savings resulting from investment of government money in improved conventional technology, generally by materials research and substitution.

- Cost savings resulting from investment of government money in development of new technology not yet in commercial use by either the oil and gas or geothermal industry.

Most of the manufacturers, contractors, and service companies in the well construction industry generally perceive the geothermal market to be small and uncertain. The number of geothermal wells required to meet the postulated power on-line schedule does not exceed 200 wells annually until 1982, and never quite exceeds an annual rate of 2,000 wells before 1990 . Compared to the more than 40,000 domestic oil and gas wells drilled annually, the geothermal industry could be expected to amount to about 0.5 to 5 percent of the total market through 1990 . 
Reportedly, well component manufacturers and drilling contractors are in a seller's market, and they are expected to remain so for many years as the demand for oil and gas increases. Additionally, since the industry tends to invest in research on improvements or products expected to materialize within three to five years, long-term payoffs are discounted heavily. Based on these considerations, METREK assumed that industry, on its own, would only invest in a modest way until the size of the geothermal market became a considerable fraction of the total well drilling market.

The relatively small anticipated market for customized geothermal well technology and the understandably moderate incentives for independent industrial participation are among the major reasons for a strong government role to accelerate technology improvement through support of industrial developments. For the purposes of this analysis, METREK assumed that government participation in addition to that of industry could improve conventional technology significantly through the mid-1980s.

In addition to efforts designed to improve conventional technology, it is anticipated that novel drilling and completion technologies can be expected to emerge in about a decade. Therefore, the overall cost reduction scenario can be viewed as a two-part process: improvements in conventional technology until about 1987 followed by a relatively sharp increase in performance from novel drilling techniques. 
Figure 3-1 illustrates the assumed cost reduction profile related to government/industry research in geothermal drilling and completion technology between 1978 and 1990. Combined industry and government-sponsored materials substitution in conventional technology is assumed to account for a 46 percent decrease in rotating costs by 1987. Government-sponsored advanced technology research was assumed to reduce costs in a linear fashion beginning in 1987 and, if successful, to reach a savings (relative to 1977 costs) of 70 percent by 1990. The dashed line in the figure illustrates the assumed saturation in the rate of savings improvements for conventional drilling methods. Additional evidence exists of the reasonableness of the savings which might result from conventional technology over the next 10 years.

The various cost analysis curves depicted in Section 2 and Appendix A illustrate the relatively modest gains needed in either bit lifetime or penetration rate to achieve about a 50 percent saving in rotating costs. In most cases, a doubling of the penetration rate, with no associated increase in bit lifetime or a doubling of bit lifetime and an associated 50 percent increase in the penetration rate, would result in the desired rotating cost savings. A number of researchers have suggested that improvements of this scale are within the capacity of conventional technology and can be expected within 10 years. Completion costs are not likely to be susceptible to similar cost reductions. 


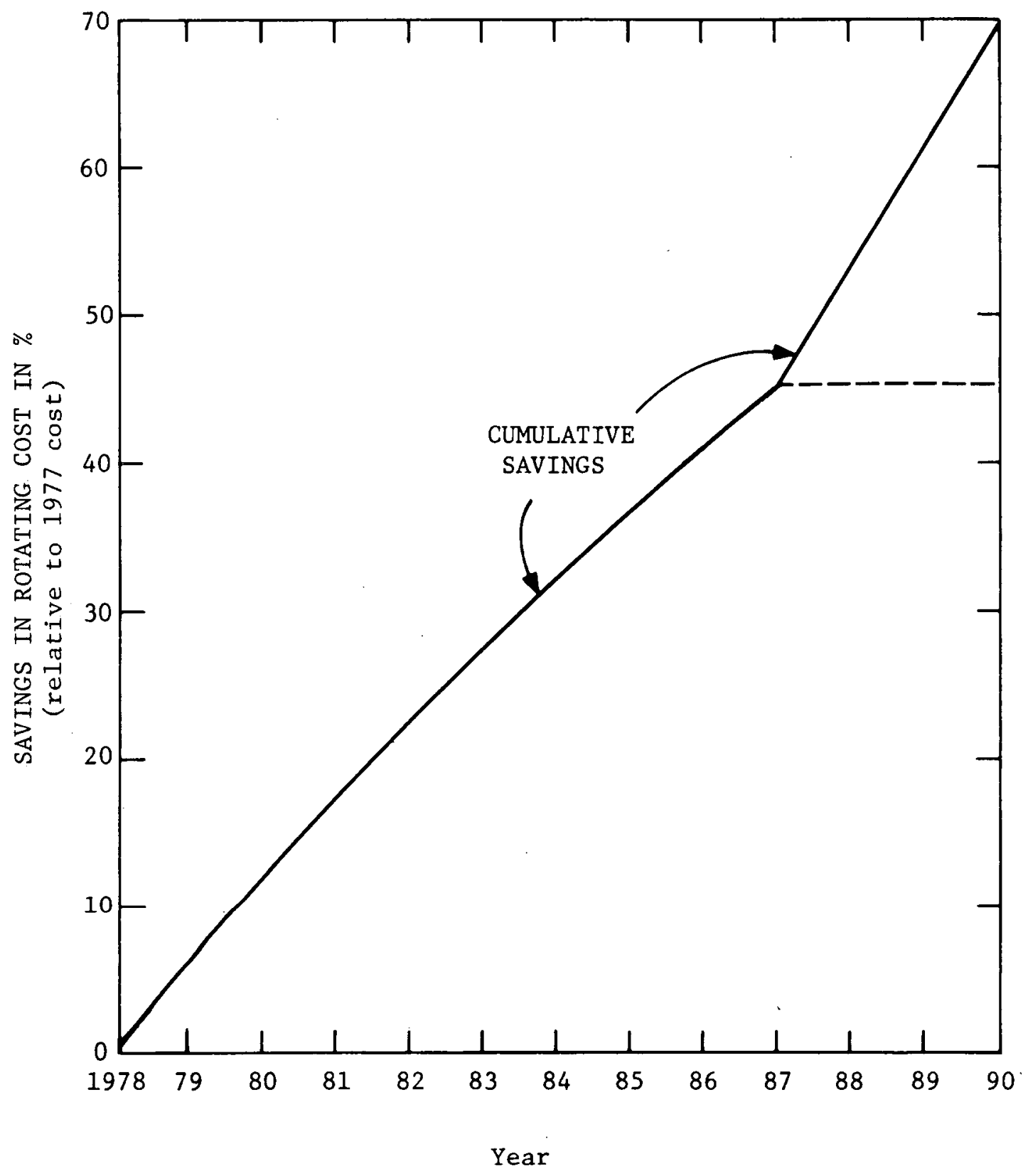

FIGURE 3-1

ASSUMED ROTATING COST SAVINGS BY YEAR 
It has been assumed that little use of novel drilling techniques would be made in the geothermal drilling industry in the next 10 years. However, beginning in 1987, the novel techniques may be able to produce a well at the least cost per foot. Therefore, for the period from 1988 to 1990 , cost savings were assumed to be controlled by the advanced technology curve, which is linear and reaches savings of 70 percent by 1990 .

The postulated cost reduction profile (Figure 3-1) for the period from 1978 to 1990 , as modified below by additional cost assumptions, will be used in Section 3.4 to compute the expected savings from planned research. At this point, the profile represents little more than a set of assumptions about possible achievements in cost reduction from successfully executed government and industrial research and development. The design and execution of a national effort to achieve the postulated cost reduction profile remain to be accomplished. Furthermore, the savings which will be computed assume that new technology can be used to reduce all elements of the capital cost of the we11. As noted in Section 2.3, the costs which may be impacted by the R\&D program may represent only two-thirds of the well cost. This point is reflected in the discussion of section 3.4 .

\subsubsection{Adjusting For the Expected Extra Costs of the New Technology}

The discussion of the cost reduction profile has largely sidestepped the probability that the advanced technology, which allows the greater savings, will have higher costs than those common today. 
The additional costs will probably involve materials, processes, and labor. In any case, savings expected from the new technology, as depicted in Figure $3-1$, should be modified to account for these additional costs. The measure of performance of the new technology will be defined as: $\left\{\frac{1}{1-\text { fractional savings }}\right\}$. Therefore, performance in 1978 is defined by 1.0 . In 1990, when the fractional saving is assumed to be 0.7 , the performance is 3.33 .

The added cost of using new technology can be estimated through the use of a formula applied to industrial engineering problems [18]. The capacity of facilities of different sizes is related to the cost of the facility by this formula:

$$
I=I_{B}\left(\frac{Q}{Q_{B}}\right)^{M}
$$

where

$$
\begin{aligned}
& I \quad=\text { cost of facility; } \\
& I_{B} \quad=\text { cost of base facility; } \\
& Q \quad=\text { capacity of the facility; } \\
& Q_{B} \quad=\text { capacity of base facility; and } \\
& M \quad=\text { power factor, generally between } 0 \text { and } 1 . \\
& \text { Equation (10) may have exponent values (M) which vary widely for }
\end{aligned}
$$
individual elements of a large and complex system. However, as these elements are brought together to achieve a production goal, a value of $M=0.6$ can describe the cost-production relationship with an accuracy of approximately 30 percent. For the purposes of this analysis, such an uncertainty would be acceptable. 
Equation (10) is employed by substituting the improved performance figure for capacity, by analogy. Therefore, technological advances which decrease the cost by 70 percent (equivalent to a performance of 3.33) could be expected to cost $(3.33)^{0.6}=2.06$ times as much as the nominal. Since the performance is 3.33 times as great, the resultant new cost per unit of performance is $\frac{2.06}{3.33}=0.618$. Thus, the 70 percent gross savings will result in a net savings of 38.2 percent. Figure 3-2 illustrates the impact of the cost of new technology on the potential savings. Essentially, the savings to be achieved are reduced by a factor of two by the increased costs.

The net savings profile will be used in Section 3.4 to estimate the cost savings to be achieved by 1990 .

\subsection{Potential Savings from Improved Technology}

The potential cost savings in geothermal well drilling and completion resulting from improved technology are expected to total approximately $\$ 3$ billion through 1990. Table 3-IX presents these savings by prospect and year assuming that all well costs can be reduced. If it assumed that two-thirds of the well costs can be impacted by new technology, the effective savings would be reduced to $\$ 2$ billion. Since this effective savings impact is estimated by performing a simple multiplication, the remainder of this analysis will present the gross savings. The well drilling schedule, the well drilling costs, and the net cost reduction profile all were used to compute these savings. All calculations of savings accounted for the 


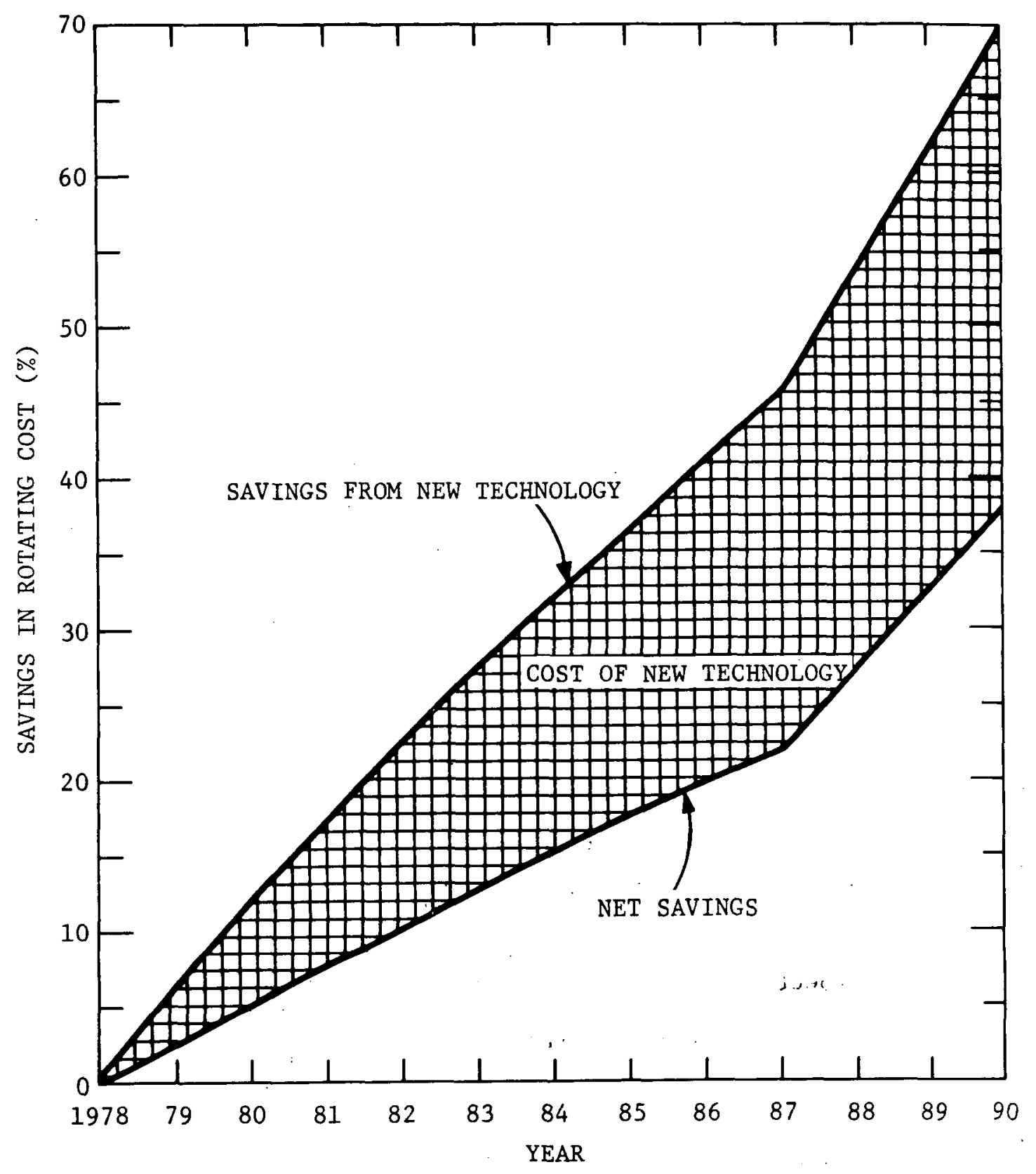

FIGURE 3-2

GROSS AND NET SAVINGS BY YEAR 
TABLE 3-IX

MAX IMUM EXPECTED COST SAVINGS BY YEAR AND PROSPECT

(million of dollars)

\begin{tabular}{|c|c|c|c|c|c|c|c|c|c|c|c|c|c|c|}
\hline & 1583 & $1+1+1$ & $14: 0$ & ixad & WW: & lyoj, & 1334 & 1\%ob & 1,00 & 1407 & 1980 & 1489 & 1590 & TOTAL \\
\hline NLI SAVARUS $(\ldots)$ & $v .0$ & $\therefore$ & $\ldots$ & 1.4 & 5.1 & $1<.1$ & 14.4 & $1 x .4$ & .14 .2 & 21.0 & $<0.5$ & 32.0 & 38.2 & \\
\hline uersexs(s)tati), CA & ט.J & 1... & 3.7 & 4.1 & $0 . \%$ & 5.3 & 3.2 & $3 . ; 7$ & 4.4 & 5.0 & 6.1 & 7.4 & 0.8 & 59.7 \\
\hline DKALCFIA, TX & v. & 0.0 & 100 & 1.5 & 0)$. & $v .0$ & 5.4 & 1.1 & 47.3 & 53.4 & 130.6 & $15 \% .5$ & $19 c .4$ & 599.7 \\
\hline SALILA SLA, CA & 0.0 & j.u & 0.0 & 0.4 & 0.2 & 0.4 & 3.5 & 1.1 & 1.0 & 1.9 & 2.4 & 3.1 & 3.6 & 16.4 \\
\hline VALLES GALUERA, MM & u. & 10.0 & ن.J & 1.2 & 0.5 & 4.1 & 5.4 & 0.2 & 1.0 & 1.7 & 11.0 & 13.2 & 16.5 & 57.3 \\
\hline LhAUY, NV & u.u & 1.0 & u.u & 1.1 & 0.3 & U. & 2.7 & 0.2 & 3.7 & 1.3 & 9.7 & 11.8 & 14.8 & 48.7 \\
\hline GRAGLEY, CA & 0.0 & 0.0 & 0.0 & 0.4 & 0.0 & 0.8 & 0.3 & 1.8 & 2.1 & 2.4 & 3.1 & 3.0 & 4.7 & 19.5 \\
\hline RLLSEVVELI, UT & 0.0 & 1.0 & v.u & 0.5 & 0.3 & 0.1 & 1.5 & 0.1 & 2.0 & 0.8 & 4.8 & 5.8 & 7.1 & 23.0 \\
\hline DCUnARE, NV & 0.0 & 0.0 & 0.0 & 1.2 & i. & 0.1 & s. & 0.2 & 4.3 & 1.5 & 10.4 & $1<.6$ & 15.0 & 49.7 \\
\hline Cuse, CA & 0.0 & 0.0 & 0.3 & 0.0 & 0.5 & 1.5 & $\therefore$ & 2.1 & 7.4 & 8.4 & 10.4 & 2.2 & 3.5 & 40.3 \\
\hline MCNUL-LUNG VALLEY, CA & 0.0 & 0.0 & 0.3 & $u=0$ & 0.0 & 1.4 & 0.0 & 4.3 & 0.1 & 0.5 & 7.2 & 0.8 & 1.6 & 17.3 \\
\hline COVE FORT/SULPHURDALE, UT & 8.0 & U. & 0.1 & 0.0 & 0.0 & 4.1 & 0.0 & 5.9 & 1.3 & 7.9 & 9.7 & 20.0 & 23.0 & 75.5 \\
\hline he Gek, CA & 0.0 & 0.0 & 0.0 & 0.0 & 0.1 & 2.0 & .0 & 3.0 & $\therefore 0$ & 7.1 & 8.7 & 11.1 & 14.0 & 40.9 \\
\hline GeYstis WHYCKU,, CA & 0.0 & 0.0 & $u .3$ & 0.0 & 0.6 & 0.2 & 1.4 & 4.3 & $1 \mathrm{i} .2$ & 13.3 & 17.2 & $<1.9$ & 27.5 & 114.8 \\
\hline CASI MLSA, CA & 0.0 & U.J & u. 0 & 0.0 & 0.0 & 2.0 & $\therefore 4$ & 0.2 & 3 & 0.3 & 0.0 & 0.0 & 0.4 & 8.5 \\
\hline STEAMBLAR, NV & $i .0$ & 0.0 & 0.2 & 0.0 & 0.0 & 0.9 & 3.2 & 0.1 & 1.9 & 0.1 & 4.3 & 3.4 & 0.9 & 4.1 \\
\hline SURPFISE VALLEY, CA & 1.0 & ... & 0.3 & 0.7 & 0.0 & 0.0 & +3 & 0.8 & 6.0 & $1<.2$ & 15.4 & 19.8 & 25.0 & 84.1 \\
\hline CHANULLK, AZ & w. & 0.0 & U.J & 1.3 & 0.0 & 0.0 & 0.2 & 0.0 & 2.3 & 2.6 & 23.4 & 15.0 & 3.9 & 55.1 \\
\hline LEACH, NV & 0.0 & 3.0 & 0.0 & 0.0 & 2.1 & 0.0 & 0.0 & $1 i .1$ & 2.1 & 3.2 & 21.3 & 40.0 & ל. & 144.0 \\
\hline CALCASIEU PAH.t ISH, LA & 0.0 & 0.) & u.d & 0.0 & $1 . \div$ & 0.0 & 0.0 & 19.9 & $1 . y$ & 2.0 & 34.8 & 42.1 & $y<.9$ & 196.5 \\
\hline ONUNEAU-GaAisuVter, ID & 0.0 & 0.0 & u.j & 0.0 & 2.1 & 0.0 & 7.0 & 0.1 & 2.1 & 2.8 & 22.7 & $<7.4$ & 35.1 & 98.2 \\
\hline LASSEIH, CA & 1) .0 & 0., & 3.0 & 0.0 & 0.0 & v.u. & 0.0 & 1.7 & 0.0 & 0.1 & $2 .:$ & 0.2 & 1.5 & 0.4 \\
\hline hENEUY CLANTY, TX & 0.0 & 3.3 & 0.0 & 0.0 & 2.5 & 0.0 & 3.0 & 20.3 & 2.5 & 3.9 & 40.0 & 35.3 & 0.3 .3 & 205.0 \\
\hline$A(\vee O K J), O R$ & 0.0 & ¿.o & u.j & 0.0 & $2 .$. & 0.0 & 0.0 & 7.0 & $\ldots 3$ & 3.2 & 14.9 & 17.4 & $\angle \therefore=3$ & 70.0 \\
\hline MATAGUIIUA, TX & U.0 & j.u & 0.0 & 0.0 & 1.4 & 0.0 & 10.0 & $13 . x$ & 1.4 & 3.0 & 34.6 & 42.1 & 51.7 & 155.3 \\
\hline CAintriLN, LA & i.J & 0.0 & 0.0 & i.u & 2.0 & 0.0 & 3.0 & 27.0 & 2.0 & 4.0 & 47.3 & 37.1 & 70.2 & 210.7 \\
\hline ACAL 1 L, LA & 0.0 & u. & ن. & 0.0 & 1.9 & 0.0 & $\ddot{u} .0$ & 19.9 & 1.4 & 3.0 & (8. & 42.1 & 31.1 & 155.3 \\
\hline Clanplus Lnidsil, TX & 0.0 & 0.0 & 0.0 & 0.0 & $1 .$. & 3.0 & 0.0 & 20.3 & 1.9 & 3.0 & $35 .:$ & $420 y$ & 52.7 & 158.3 \\
\hline SAttit 0, AZ & ט.) & c.u & 0.0 & 0.0 & 2.1 & j.o & 0.0 & 0.1 & j.i & 0.5 & u.t. & 0.7 & 7.8 & 10.7 \\
\hline ne 1 Stidchine dWLEN, ID & 0.0 & 0.0 & 0.0 & 0.0 & 0.0 & 1.1 & 0.0 & c.o & $l . i$ & 1.0 & 20.5 & 24.8 & 1. & 86.8 \\
\hline VALE, OR & 0.0 & 0.0 & 0.0 & 0.0 & 0.0 & $\therefore .1$ & 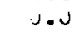 & 0.0 & 4.9 & 0.0 & 7.2 & 8.7 & 11.1 & 33.2 \\
\hline THEKMU, UT & 0.0 & 0.0 & 0.0 & 0.0 & c.u & 1.5 & 0.0 & 0.0 & 4.0 & 0.0 & 1.9 & 2.3 & 10.0 & $28 .$, \\
\hline rAET + IVLK, ID & u.u & 0.0 & 0.0 & 0.0 & 0.0 & 0.4 & 0.0 & 0.0 & 9.4 & 0.0 & 13.2 & 1.2 & 2.8 & 26.9 \\
\hline 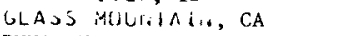 & 1.0 & a.) & (i.) & 0.0 & u. & 0.0 & 0.0 & 2.4 & 0.0 & 0.0 & 9.1 & 0.0 & 1.1 & 12.0 \\
\hline PUNA, HI & 3.0 & 1.0 & 0.0 & 0.0 & a. & u.u & u.u & 3.4 & 0.0 & $\therefore 5$ & 11.5 & 39.7 & 47.4 & 110.4 \\
\hline MI. Huti.j, OR & 0.0 & 0.0 & 0.0 & 0.0 & 3.0 & u.u & 0.0 & 1.2 & 0.0 & 0.0 & 14.1 & 0.0 & 1.4 & 16.1 \\
\hline BAKER HOT SPRINGS, WA & 0.0 & 3 & 0.0 & 0.0 & J.: & u.u & 0.0 & 3.5 & 0.0 & 0.0 & 19.5 & $\ldots$ & 2.5 & 25.5 \\
\hline n. YELLI,nJTtARE, MT & 0.0 & 0.0 & ن.u & 0.0 & u. & u.u & נ.c & 1.5 & u. 0 & 0.0 & 77.4 & 0.0 & 1.7 & 20.7 \\
\hline IOHALL & $\because 0$ & 1.2 & 3.7 & $1<\cdot<$ & 30. & si.. 1 & +1.6 & $\angle i 3 . t^{\prime}$ & $15 \% .7$ & $15+.1$ & till. 4 & 159.9 & $+x 2.9$ & 3091.1 \\
\hline
\end{tabular}

"Computed by applying net savings percentage to total well costs. To the extent that only a fraction of the well cost can be impacted by new technology, the expected savings will be correspondingly smaller. 
different costs for production and reinjection wells for several of the prospects where downhole pumps and, therefore, larger diameter wells were assumed to be used.

\subsection{Targeting a Federal Research Program through Benefit/Cost Analysis}

The cost savings of geothermal drilling and completion can be used to target a reasonable research expenditure needed to achieve the projected savings. The level of government support for a geothermal well technology program should be determined by a realistic ratio of the size of the potential savings to the cost of the research.

For the purposes of establishing a target research budget, a benefit-to-cost ratio of 10 to 1 was selected. That is, for every dollar invested by the government in research, 10 dollars of savings would be expected to result. In this section, the computed expected savings are converted to present value (discounted) to establish the present value of the research budget. Present-value savings are used because the research investment and the resulting savings do not occur in the same years.

As discussed in the following paragraphs, designing a research program based on such a benefit/cost analysis does not necessarily guarantee that the investment will produce the desired savings. However, this approach can be used to establish a reasonable upper bound on program expenditures.

The procedure used to establish a target for a research budget has three steps: 
- adjust the yearly cost savings (Table 3-IX) to reflect uncertainty in the development of novel drilling methods,

- compute the yearly contribution to the total well technology budget by taking a $10: 1$ benefit-to-cost ratio, and

- convert the yearly estimates of savings to present value and compute a total.

Uncertainty in the eventual capability of novel drilling methods to provide the savings predicted for the years 1988,1989 and 1990 in Table 3-IX requires that an adjustment be made in computing the target research budget. For that reason, the net savings in those years were reduced to what could be expected by applying the net savings percentage postulated for 1987 ( 21.6 percent). This is equivalent to assuming that conventional technology will represent the state of the art through the last four years of the decade. In the event that novel methods do achieve the greater savings predicted in Table 3-IX, justification for the R\&D program would be even more secure. Thus, while we are willing to use the estimated net savings of Table 3-IX in determining the benefit of new technology, it seems appropriate to be conservative in computing the appropriate benefit base from which the R\&D budget is to be computed as shown in Table 3-X.

The selection of an appropriate discount rate for use in the present value analysis is not straightforward. Industry generally uses the minimum attractive rate of return of investment to discount future benefits. Typically, the minimum attractive rate of return is composed of two components, the cost of borrowed money and the cost of equity capital. The cost of equity capital is higher than 
the cost of borrowed money because of greater uncertainty surrounding returns to equity capital. The extra cost represents a premium necessary to attract money for high-risk investments [19].

Historically, government economic studies have used discount rates determined by the cost of borrowed money [19]. Such an approach can be criticized because:

- It fails to consider the opportunity cost of potentially preferable investments.

- Estimates of the eventual benefits may be inaccurate and the risk of this error should be used to raise the discount rate.

- The benefactors of the investment are not distributed uniformly among the contributors (the taxpayers). Therefore, the expected rate of return should exceed the cost of money.

- The interest rates charged to government agencies for borrowed money do not completely define the adverse effects of the borrowing. A common result of increased government borrowing is increased inflation rates.

Each of these four points suggests that the benefits resulting from government-supported projects should be as heavily discounted as those from industry-supported projects.

Because of the many problems associated with selecting any one appropriate discount rate, the expected benefits of the proposed budget were converted to present value using several possible discount rates, which range from 0 to 15 percent. These calculations are presented in Table 3-X for each discount factor for the years from 1978 to 1990. The present-value savings are expressed in 1977 dollars to avoid the influence of inflation. 
TABLE 3-X

CONVERSION OF EXPECTED SAVINGS STREAM TO PRESENT VALUE

(in million of 1977 dollars)

Projected

Saving

Benefit Base

(10:1 benefit

to cost ratio

applied to pro-

jected savings)

2

Present Value

a Discount Rate

$$
0 \%
$$

$4 \%$

$6 \%$

$8 \%$

$10 \%$

$15 \%$

$\begin{array}{rrrr}\text { Total } & 1978 & 1979 & 1980 \\ 3097.1 & 0.0 & 1.2 & 5.7\end{array}$

$\begin{array}{rr} & 0.0 \\ 229.1 & 0.0 \\ 188.3 & 0.0 \\ 155.7 & 0.0 \\ 129.3 & 0.0 \\ 108.0 & 0.0 \\ 90.6 & 0.0 \\ 59.8 & 0.0\end{array}$

0.6

1.2

3.1

$3.0 \quad 4.8$

$21.3 \quad 15.8$

15.4

56.4

51.3

56.1

$\begin{array}{lllllllllllll}0.1 & 0.6 & 1.2 & 3.1 & 3.0 & 4.8 & 21.3 & 15.8 & 15.4 & 56.4 & 51.3 & 56.1\end{array}$

$0.1 \quad 0.6 \quad 1.1$

2.9

2.7

$2.7 \quad 4.3 \quad 18.5$

$18.5 \quad 13.5$

$12.9 \quad 46.3$

41.3

33.3

$0.1 \quad 0.6,1.1$

$0.1 \quad 0.5 \quad 1.0$

2.6

$2.2 \quad 3.4 \quad 14.2$

$11.5 \quad 10.8 \quad 38.1$

$31.5 \quad 27.0 \quad 27.9$

$\begin{array}{lll}0.1 & 0.5 & 1.0 \\ 0.1 & 0.5 & 0.9\end{array}$

2.3

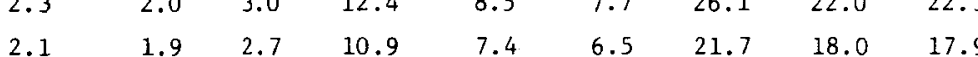

$\begin{array}{llllllllllll}0.1 & 0.5 & 0.8 & 1.8 & 1.5 & 2.1 & 8.0 & 5.2 & 4.4 & 13.9 & 11.0 & 10.5\end{array}$

* Note that in: 1988,1989 and 1990 , the projected saving is based on the projected net savings rate of 1987 (21.6\%) to account for the uncertainty in the savings which might result from novel technology. 
According to the results of this benefit/cost analysis, a reasonable target research budget for geothermal well technology would range from $\$ 60$ million (with a 15 percent discount rate) to almost $\$ 230$ million (with no discounting). With a 10 percent discount rate, which would account for the cost of money and for investment risk, a total government investment with a present worth of $\$ 90$ million would be appropriate.

It should again be noted that these calculations are based on the assumption that all capital costs of a well will be reduced by new technology. As was shown in section 2.3 , the fraction of reducible costs might be two-thirds. In that case, and assuming a 10 percent discount rate, a $\$ 60$ million budget target would be appropriate. 


\subsection{CURRENT PROBLEMS IN GEOTHERMAL DRILLING AND THEIR COST IMPACT}

The development of a geothermal resource requires several stages of effort including exploratory drilling, reservoir testing and confirmation, and energy extraction and conversion. Virtually each of these steps involves the drilling of wells under often difficult conditions. Further, the wells must be drilled to considerable depth, normally several kilometers (up to about ten thousand feet). This section describes the basic components and techniques required or used in such drilling, as well as their limitations. The high costs incurred in geothermal drilling because of the difficult conditions are also summarized.

Section 4.1 describes the characteristics of the geological formations encountered in exploratory and developmental drilling, particularly from the point of view of formation hardness and temperature.

Sections 4.2 through 4.8 are devoted to a discussion of the technology currently used in geothermal exploration and development, including methods; components, logging, exploratory drilling and drilling fluids. Throughout, attention is directed to the limitations in conventional methods and hardware and to the commonly used techniques for solving these problems.

This section has been assembled from two basic sources: the "conventional wisdom" found in the technical literature and from visits and conversations with geothermal drilling experts. 


\subsection{The Drilling Environment}

To date a great majority of the practical or research drilling done for geothermal resource development has relied upon the drilling technology utilized in the oil and gas industry. The equipment and methods have been adapted from an industry which regularly drills into sedimentary formations (principally shale and limestone) or other geological formations that are consistent with the locations of oil and gas resources $[20,21]$. Geothermal resources more commonly exist in areas where more difficult rock formations exist. Hydrothermal resources, for example, are likely to be found in resource areas dominated by young volcanic formations or tectonically active areas [21]. Geopressured resources are associated with sedimentary formations having alternating sand and shale strata.

Table 4-I illustrates the characteristics found in drilling in a number of areas of the U.S. known to have a hydrothermal resource. The hardness specified for each prospect refers to the conditions found in the overburden rock through which much of the drilling occurs. A more complete listing of this type occurs in Section 3 where it is used as part of the drilling cost model. Table 4-II defines some additional formation types which have been encountered in exporatory or developmental drilling around the world. Those conditions are not unlike those found in the U.S. Table 4-III depicts the various types of geothermal resources and their typical geological formations and associated drilling problems. Generally, 
TABLE 4-I

GEOLOGY OF SELECTED GEOTHERMAL SITES[2]

\begin{tabular}{|c|c|c|c|}
\hline $\begin{array}{l}\text { DEPTH TO TOP } \\
\text { RESERVOIR (M) }\end{array}$ & PROSPECT & $\begin{array}{l}\text { RELATIVE* } \\
\text { HARDNESS }\end{array}$ & TYPE OF ROCK \\
\hline 1000 & HEBER, CA & $\mathrm{s}$ & SANDY DELTAIC SEDIMENTS \\
\hline 800 & ROOSEVELT H.S., UT & $\mathrm{M}-\mathrm{H}$ & GRANITE AND RECENT VOLCANICS \\
\hline 1000 & VALLES CALDERA, NM & $\mathrm{H}$ & $\begin{array}{l}\text { IGNEOUS ROCK TYPES--CALDERA } \\
\text { VOLCANICS }\end{array}$ \\
\hline 1500 & BRAWLEY, CA & S & $\begin{array}{l}\text { SEDIMENT/SILTSTONE AND } \\
\text { SANDSTONE }\end{array}$ \\
\hline 500 & BRADTY, H.S., NV & $\mathrm{H}$ & BASALT AND ALLUVIUM \\
\hline 1000 & BEOWAWE, NV & $\mathrm{H}$ & BASALT AND ALLUVIUM \\
\hline 1000 & SALTON SEA, CA & s & $\begin{array}{l}\text { SHALE-SILTSTONE CAPROCK } \\
\text { UNDERLAIN BY ARKOSIC SAND }\end{array}$ \\
\hline 300 & STEAMBOAT SPRINGS, NV & $\mathrm{M}-\mathrm{H}$ & $\begin{array}{l}\text { GRANITE AND METAMORPHIC } \\
\text { ROCK }\end{array}$ \\
\hline 1000 & COSO, H.S., CA & $\mathrm{M}-\mathrm{H}$ & ALLUVIUM AND GRANITE ROCK \\
\hline 1000 & LONG VALLEY, CA & $\mathrm{M}-\mathrm{H}$ & RHYOLITIC VOLCANICS \\
\hline 1000 & SURPRISE VALLEY, CA & $\mathrm{M}-\mathrm{H}$ & ALLUVIUM AND IGNEOUS ROCK TYPES \\
\hline 1500 & COVE FORT-SULPHURDAIE, UT & $\mathrm{M}-\mathrm{H}$ & SEDIMENTS AND RECENT VOLCANICS \\
\hline $\begin{array}{l}1000 \\
:\end{array}$ & MORGAN SPRINGS, CA & M & MOSTLY ANDESITES AND DACITES \\
\hline 1000 & EAST MESA, CA & H & DELTAIC RIVER SEDIMENTS \\
\hline \multicolumn{3}{|c|}{ * Refers to hardest rock type in group } & LEGEND: $\begin{array}{l}\mathrm{S}=\text { SOFT } \\
\mathrm{M}=\text { MEDIUM } \\
\mathrm{H}=\text { HARD }\end{array}$ \\
\hline
\end{tabular}


TABLE 4-II

GEOTHERMAL DRILLING CHARACTERISTICS OF SELECTED

INTERNATIONAL SITES[22]

LOCATION

Larderello

The Geysers

New Zealand

Japan

Pathe, Mexico

Cerro Prieto, Mexico

Niland, California

Iceland

Northern Taiwan
RESOURCE

steam

s team

hot water

hot water

hot water

hot water

hot water
ROCK TYPE

fractured limestone

fractured graywacke

acid volcanics

fractured middle tertiary volcanics

river delta sediments

fractured cavernous basaltic lavas

acid volcanics sedimentaries 
TABLE 4-III

EXPECTED SEQUENCE OF COMMERCIAL MATURITY OF THE FIVE TYPES OF GEOTHERMAL RESOURCES AND THEIR GEOLOGICAL

CHARACTERISTICS $[23,24,25,26]$

1. Hydrothermal - Involves higher temperature than in petroleum drilling (up to $350^{\circ} \mathrm{C}$ ). Usually found in formations of hard abrasive volcanic rock although Imperial Valley resources are in sedimentary rock.

2. Geopressured - Regularly detected in coastal areas of Gulf of Mexico when drilling for oil or gas. Usually found in sedimentary basins at considerable depth (up to 25,000 feet).

3. Hot Dry Rock - Advances for hydrothermal can be directly applied for this resource. Less dangerous to drill than drilling into steam or superheated water due to less corrosion, erosion and hazard from high velocity flow.

4. Magma

- Top of resource usually a.t depths greater than $3 \mathrm{~km}$. Drilling to $3-6 \mathrm{~km}$ and at $650^{\circ}-$ $1200^{\circ} \mathrm{C}$ as would be required is not now possible. Collapse of the hole will be a major problem along with introduction of heat exchange equipment. Sticking of the drill pipe is also to be expected.

5. Normal

Gradient - Must be drilled to considerable depth. Can utilize advances for hydrothermal. 
the features of a reservoir which impact drilling cost include the required depth of the well, the required diameter of the well (which is determined by the temperature and probable flow rate of the wel1) and the approximate hardness of the overburden rock. Considerable attention is given to the impact of formation characteristics on drilling cost in Section 3 .

The end result of all of these factors is that drilling and completion of the well may progress very slowly. The penetration rate achieved in a particular formation is, of course, a function of a number of factors but is dominated by the way the rock hardness and abrasiveness affect the bit performance. The compressive strength of the rock and its elastic properties are also influential. The elastic properties (which may crudely be defined as ranging from easily-drilled brittle to the more difficult plastic) vary with the stress imposed on the formation. Both shale and sandstone may be brittle near the surface and become harder to drill as the pressure and depth increase [20]. Furthermore, these formations become unstable in the presence of water or steam and may collapse, trapping the drill pipe.

In addition to overburden geology, the geology of the reservoir itself is of interest. A classification system has been developed related to the difficulty in drilling into the reservoir.

The classifications are related to the natural permeability of the formation and are: 


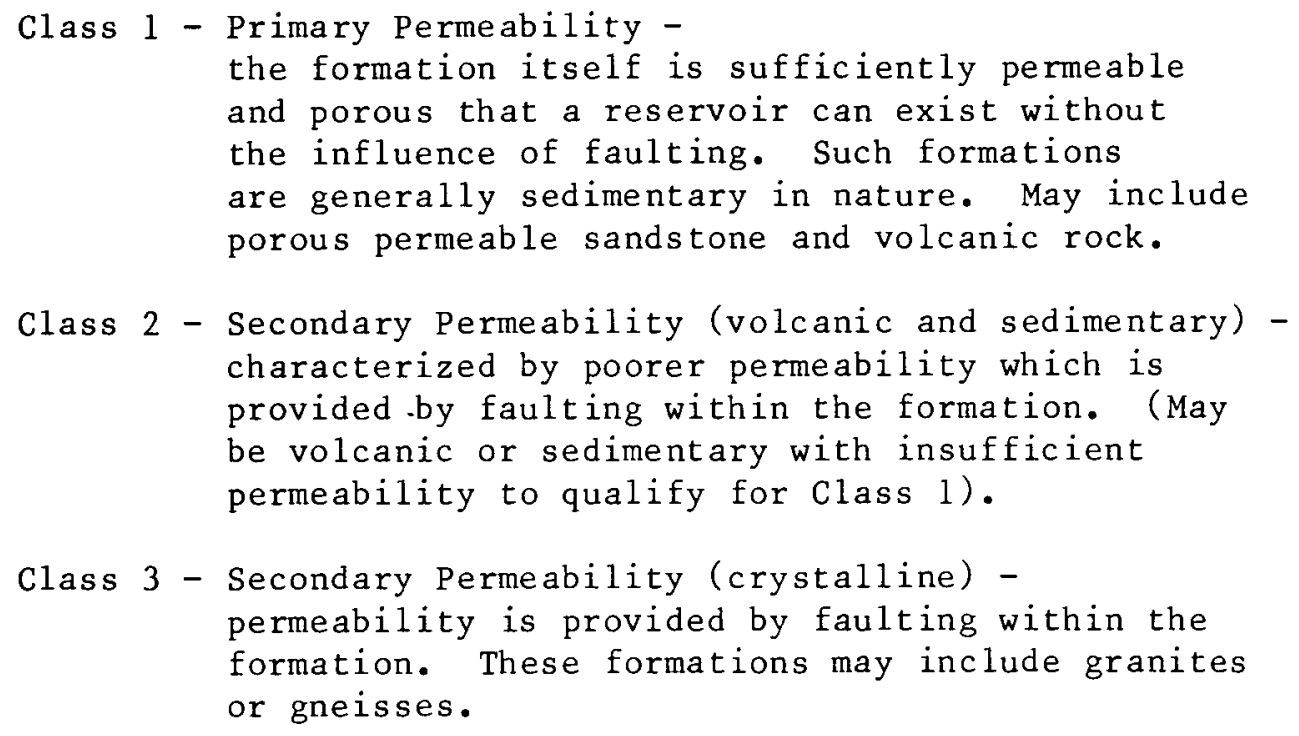

Table 4-IV illustrates the application of the system to 37 reservoirs, along with information on other site-specific factors (total dissolved solids, reservoir temperature and depth of the top of the reservoir). Many of the areas exhibit reservoir geology that falls into more than one class. Of particular note are the caldera formations, which exhibit characteristics that place them in each of the classes, depending on the site chosen for drilling.

\subsection{The Components of Conventional Drilling Technology}

The conventional drilling technology used in oil, gas and most geothermal exploration and development efforts is based on the use of the rotary drill string and roller bit. In principle, the operation of such a drilling system is relatively simple: the pipe sections and bit are rotated by a motor on the derrick, while the drill cuttings are carried from the hole by the circulation of either a drilling fluid (mud) or compressed air. Figure 4-1 illustrates the 
TABLE 4-IV

GEOLOGICAL CLASSIFICATION OF RESERVOIRS[27]

\begin{tabular}{|c|c|c|c|c|c|c|}
\hline SITE & $\underline{\operatorname{TDS}}$ (PPM) & $\begin{array}{c}\text { RESERVOIR TEMP. } \\
\left({ }^{\circ} \mathrm{C}\right)\end{array}$ & $\begin{array}{l}\text { DEPTH TO RESERVOIR } \\
\text { (USGS-ESTIMATE) } \\
\text { (KM) }\end{array}$ & $\begin{array}{r}\text { CLASS } 1 \\
\text { PRIMARY PERM. }\end{array}$ & $\begin{array}{c}\text { CLASS } 2 \\
\text { SECONDARY PERM. } \\
\text { VOLCANIC AND SEDIM. } \\
\end{array}$ & $\begin{array}{l}\text { CLASS } 3 \\
\text { SECONDARY PERM. } \\
\text { CRYSTALLINE } \\
\end{array}$ \\
\hline Brawley, CA. & Low-Moderate & 200 & 1.5 & $\mathrm{x}$ & $\mathrm{x}$ & \\
\hline Coso H.S., CA & 2000 & 220 & 1.0 & $\mathrm{x}$ & $\mathrm{x}$ & $\mathrm{x}$ \\
\hline East Mesa, CA & 2500 & 180 & 1.0 & $\mathrm{x}$ & $\mathrm{x}$ & \\
\hline Geysers, CA (steam) & -- & $\sim 240$ & -- & & $\mathrm{x}$ & \\
\hline Glass Mountain, CA & -- & $>200$ & -- & $\mathrm{x}$ & $\mathrm{x}$ & $\mathrm{x}$ \\
\hline Heber, CA & $14,000-25,000$ & 190 & 1.0 & $\mathrm{x}$ & $\mathrm{x}$ & \\
\hline Lassen, CA & -- & $\sim 240$ & 1.0 & $\mathrm{x}$ & $\mathrm{x}$ & \\
\hline Long Valley, CA & $1,000-2000$ & 220 & 1.0 & $\mathrm{X}$ (MOAT) & $\mathrm{X}$ (DOME) & $x(R I M)$ \\
\hline Puna, HI & -- & 275 & -- & & $\mathrm{x}$ & \\
\hline Salton Sea, CA & $250,000-330,000$ & 340 & 1.0 & $x$ & $\mathrm{x}$ & \\
\hline Surprise Valley, CA & 1500 & 175 & 1.0 & $\ddot{x}$ & $\mathrm{x}$ & \\
\hline Alvord, $\mathrm{OR}$ & 3000 & 200 & 1.5 & & $\mathrm{x}$ & \\
\hline Baker H.S., WA & -- & 165 & - & $\mathrm{x}$ & $\hat{\mathrm{x}}$ & $\mathrm{x}$ \\
\hline Valles Caldera, NM & 6000 & 240 & 1.0 & $X$ (MOAT) & $\mathrm{X}$ (DOME) & $\hat{x}(\mathrm{RIM})$ \\
\hline Brady H.S., NV & 2450 & 214 & 0.5 & 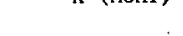 & $\mathrm{x}$ & \\
\hline Roosevelt H.S., VT & 7800 & 230 & 0.8 & & & $\mathrm{x}$ \\
\hline Beowawe, NV & 1200 & 240 & 1.0 & & $\because$ & ? \\
\hline Cove Fort/Sulphurdale, UT & -- & 200 & 1.5 & & & $\dot{x}$ \\
\hline Geysers (Hydro), CA & -- & - & - & & $\mathrm{x}$ & \\
\hline Sțeamboat H.S., NV & 2500 & 210 & 0.3 & & $\mathrm{x}$ & $\mathrm{x}$ \\
\hline Chandler, AZ & $62,000-\pi$ & 178 & -- & ? & $?$ & ? \\
\hline Leach, NV & $\sim 800$ & 170 & -- & $\mathrm{x}$ & $\mathrm{x}$ & . \\
\hline Bruneau/Grandview, ID & -- & 150 & -- & $\mathrm{x}$ & $\mathrm{x}$ & \\
\hline Saf ford, $A Z$ & -- & 100 & -- & ? & $?$ & ? \\
\hline & & 200 measured & & & & \\
\hline Weiser/Crane Creek, ID & $1,000-1,200$ & 160 & 1.0 & & $\mathrm{x}$ & \\
\hline Vale H.S., OR & $1,0,--$ & 160 & 1.0 & $\mathrm{x}$ & $\mathrm{x}$ & \\
\hline Thermo, UT & -- & 200 & 1.5 & & $\mathrm{x}$ & $\mathrm{x}$ \\
\hline Raft River, ID & $\sim 2000$ & 140 & 1.5 & $\mathrm{x}$ & $\mathrm{x}$ & \\
\hline Mt. Hood, OR & -- & 125 & 1.0 & $\mathrm{x}$ & $\mathrm{x}$ & $\mathrm{x}$ \\
\hline West Yellowstone, WY & -- & -- & -- & $\mathrm{x}$ & & \\
\hline Brazoria County, TX & -- & 146 & -- & $\mathrm{x}$ & & \\
\hline Calcasieu. Parish, LA & - & 156 & -- & $\hat{x}$ & & \\
\hline Kenedy County, TX & -- & 168 & -- & $\hat{\mathrm{x}}$ & & \\
\hline Matagorda County, IX & -. & 146 & -- & $\mathrm{x}$ & & \\
\hline Acadia, LA & -- & 164 & -- & $\mathrm{x}$ & & \\
\hline Corpus Christi County, TX & -- & 169 & -- & $\mathrm{x}$ & & \\
\hline Cameron, LA & -- & 140 & -- & $x$ & & \\
\hline
\end{tabular}

«possible contamination from salt based drill mud. 


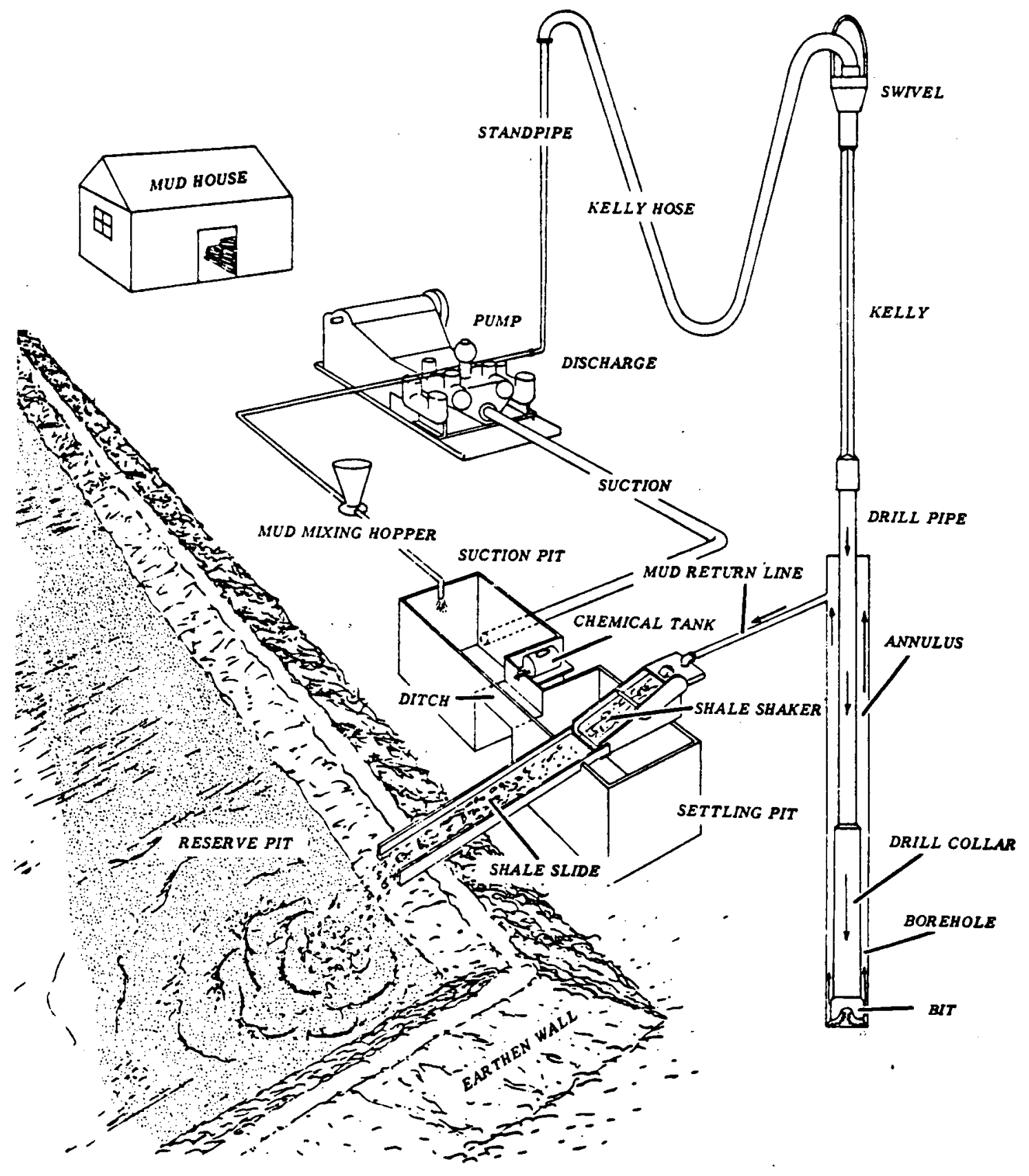

FIGURE 4-1

ROTARY RIG FLUID CIRCULATION AND MUD TREATING SYSTEM [28] 
basic components of such a drilling effort. As drilling proceeds, the traveling block and the drill pipe and bit it supports gradually move downward. Since drill pipe, which is threaded together to form the drill strings, comes in standard 30-foot lengths, every 30 feet of progress means an interruption to add another section of pipe. The process thus proceeds until the drill bit is worn out. At that time, the entire drill string is brought out of the hole, disassembled into 90-foot units and stored while the bit is replaced. This procedure, along with reassembling the drill string, is known as "roundtripping" and may occupy up to forty-five minutes per thousand feet of drill pipe.

In addition, it may be necessary to place in the well bore tubing (or "casing") for the purpose of stabilizing the wall of the well or preventing loss of drilling fluids (commonly called lost circulation) into the highly fractured formation. The casing is usually fixed in place by pumping cement in between it and the well wall.

Once the hole has achieved the proper depth, direction (which is often difficult to control) and diameter, completion of the well may rarely include the placing of a production tubing inside the casing and installation of control valves. The production tubing serves to carry the working fluid to the surface without exposure of the well or casing to the potentially degrading brine. After a period of use, the production tubing may be conveniently replaced without 
threatening the integrity of the well. This common oil well practice will probably be a rarity in geothermal wells.

A number of other tools and techniques are used in the drilling process. These include the initial use of "slim" holes (about 4" in diameter) to determine heat flow and sediment loads and to provide water for use in the major drilling process. Such drilling also allows for proper design of the casing required for the larger wells. Down-hole motors, driven by the flow of drilling mud or by electric power, are used in directional drilling, either to turn the well toward the producing zone, to put it back on course after faults and density changes in the formation have deflected the hole, or to create a productive well after drilling a dry hole. Because the use of a down-hole motor also eliminates the need to rotate the drill string, excessive wear on the drill pipe is avoided. In rare cases, down-hole motors are used for straight-hole drilling.

Logging of the well provides knowledge of temperature of the formation, direction of the well bore, and faulting of the rocks in the vicinity of the well, as well as other features of the well bore and local geology.

Were the technology available, completion of a geothermal we11 might benefit from a process common to the oil and gas industry, fracturing. Such a process is useful when the formation is insufficiently fractured to provide the needed flow rates. Under these conditions, large expandable rubber and steel cylinders (called 
packers) are placed above and below the desired producing zone and expanded to plug the well bore. The upper packer allows the introduction of pressurized fluids into the area between the packers. When everything goes according to plan, the hydraulic pressure on the fluids is raised until the formation fractures. In order to prop these fissures open, material such as sand may be introduced into the fracturing fluid and pumped into the region. The packers can then be removed and production can begin.

During the drilling process, a so-called blow-out preventer is placed at the top of the well. This unit is designed to control any excess pressure which may materialize within the well. Generally control of well pressures is achieved by maintaining an appropriate mud density. The blow-out preventer provides a safety margin for both the well and the crew.

There are a number of other elements in the drilling process. These will be discussed in subsequent sections. The practical aspects of drilling with the methods described above are complicated considerably, however, by efforts to provide safe and economical drilling. Efforts to provide effective drilling depend to a great extent on the characteristics of the formation, as discussed in Section 2.1, along with a number of tangible and intangible factors, which are summarized in Table $4-V$. 
TABLE $4-\mathrm{V}$

FACTORS WHICH DETERMINE PENETRATION RATE[After 20]

1. Personnel efficiency

a. Competence

(1) experience

(2) spectal training

b. Psychological factors

(1) company-employee relations

(2) pride in job

(3) chance for advancement

2. Rig efficiency

a. State of repair, preventive maintenance

b. Proper size

c. Ease of operation, degree of automaticity, and power equipment

3. Formation characteristics

a. Compressive strength

b. Hardness and/or abrasiveness

c. State of underground stress (overburden pressure, etc.)

d. Elasticity - brittle or plastic

e. Stickiness or balling tendency

f. Permeability

g. Fluid content and interstitial pressure

h. Porosity

i. Temperature

4. Mechanical factors
a. Weight on bit.
b. Rotating speed
c. Bit type

5. Mud properties
a. Density
b. Solid content
c. Flow properties
d. Fluid loss
e. Surface tension-wettability

6. Hydraulic factors-essentially bottom hole cleaning 


\subsection{Drilling Fluids}

The role of drilling fluids in the geothermal environment is as in the case of oil and gas drilling; that is, the fluid provides cooling for the bit and other down-hole components, is a means for carrying cuttings out of the hole, supports the hole walls hydrostatically, prevents formation fluids from entering the hole during drilling, and assists in monitoring formation temperature while drilling $[29,30]$.

The major limitations imposed on such fluids in geothermal drilling is associated with the elevated temperatures of the formations. Furthermore, the frequency with which drilling fluid escapes into the geological formation after passing through the bit (lost circulation) is very high. A problem of this type adds to the complexity of selecting materials due to cost factors.

Drilling muds typically begin to perform badly at temperatures exceeding $150^{\circ}$ to $170^{\circ} \mathrm{C}[29,31]$. As the temperature rises, the mud viscosity increases, resulting in an altered flow rate as the mud solidifies [31]. In addition, mud may accumulate within the hole, forming a barrier lining that may severely limit the potential flow rate in the productive formation [26,32] or creating a cement-like material if exposed to alkaline soils. The components of these typical low-temperature drilling muds include bentonite or other clay-based materials [31]. 
At elevated temperatures, a chrome-lignite/chrome-1ignosulphonate compound is used to retard jelling. Addition of special materials to mud may solve a specific problem but have other consequences:

- they may make it difficult to dispose of the mud (due to the addition of materials containing toxic heavy metal ions);

- chemical additives may induce voltage that could impede effective logging, and

- costs are increased.

For example, adding substances to raise the operating temperature of the mud requires the addition of a suspender which must be flocculated. Flocculants, which assist in suspending and dispersing the material in the mud are, unfortunately, temperature-sensitive. In addition, at elevated temperatures, a cooling system may still be required.

In those cases when drilling muds do not perform adequately, air, natural gas and/or water may be used in its place [32, 33]. The utilization of air as a drilling fluid is a common method in lowpressure strata [26]. The major difficulty with air drilling is its inability to control pressures in the well (as a mud does) so that blow-outs are more likely.

In addition to the complications of elevated temperature, the formation may be fractured to the extent that drilling mud is lost through the wall of the hole during the circulation process. 
A solution for the control of lost circulation may be found by the introduction of cement or casing at the appropriate depth. This is by no means a simple solution however, since the formation may have the strength to support the weight of the mud but not of the cement, which may be 50 percent more dense. This difficulty requires the performance of pressure tests to guarantee that an effective cementing can be performed [31].

An alternative method of controlling circulation losses is the introduction of organic materials into the suspect part of the hole. These materials allow continued drilling but decompose when exposed to hot water and steam, or when acid is put down the hole for that purpose.

Careful selection of drilling fluid is also required to avoid damage to the formation resulting from the flow of the mud into the fissures that provide the path from the formation to the well bore. In most cases, muds can be used while drilling the overburden but must be abandoned in favor of water or air drilling as the producing zone is approached. Future advances in foam might offer an alternative drilling fluid that has some advantages since foam is relatively insensitive to zones which could cause lost circulation. However, a delicate balance is needed in foam drilling to obtain a foam which is easy to defoam (break down) for cleaning and, further, easy to refoam (rebuild). Foam drilling also reduces wear on the drill stem as compared with air drilling. 
0i1-based muds are virtually insensitive to temperature. However, they are difficult to use because of environmental considerations (see Appendix B). Oil-based muds also cost more than most other muds. Their use is quite rare.

\subsection{Limits of Other Materials and Equipment}

In addition to the adverse effect of the geothermal environment on drilling fluids, other materials may exhibit unsatisfactory performance.

Elastomers (rubber-1ike materials) form a small but very important component of the materials needed for successful drilling. These products are used wherever flexible seals are needed, whether it is in drill bits and drilling motors (to control loss of lubricating fluid) or in packers (to seal off a section of the well). Unfortunately, virtually all of the currently available elastomers are degraded by exposure to temperatures exceeding approximately $150^{\circ} \mathrm{C}$. As a result, the equipment which uses these materials also becomes subject to failure. The relatively small market for these materials has impeded research for'higher-temperature products.

Some of the drilling equipment which is degraded in performance due to elastomer failure are:

- Packers - application of packers even in a cased hole requires some use of elastomers. When one considers that in oil and gas drilling an approximately 20 percent failure rate exists for packer applications in cased holes, it is evident that the'higher failure rate to be expected in a geothermal environment would be unacceptable. In uncased holes, an even larger packing element is required and failure rates will be very high. 
- Blow-out preventers - cooling of these units is often required to assure that they survive and protect the well and drilling crew.

- Bits - a discussion of their performance and dependence on elastomers appears in another section.

Cements also represent a problem in a high-temperature environment. The use of retarders, chemical agents which control the rate of hardening of the cement, can achieve the desired results, but only if the user has good information on the temperature in the part of the hole to be cemented as well as the parts of the hole through which the cement must pass. Use of too little retarder results in the cement hardening before reaching its destination. Too much means that the cement may never set.

\subsection{Logging}

Logging (taking a variety of measurements along the hole depth for the purpose of inferring the location and properties of the several strata) in a geothermal environment is generally difficult due to the following factors:

- In many cases, hole stability is a function of time. Delaying any step in the drilling or completion process might lead to wall collapse, particularly in sedimentary formations.

- High temperatures prevent the use of conventional logging tools.

- The formation being drilled may not be familiar to the specialized service company which does the logging.

Research in logging methods is continuing to evolve but is limited by the apparent size of the market. It is probable, however, 
that the need for caliper and directional logs will increase. The primary role of caliper logs is for fracture mapping and use in conjunction with other instruments for flow measurements [34]. Caliper logs would be used before setting a packer in an uncased formation, such as for fracturing the formation or installing a down-hole pump. Directional logs will be in more demand as the frequency of directional drilling increases.

The temperature limitations in logging which exist today can be avoided by the use of a thermally insulated protective container, or the use of cooling fluid and insulation together and development of tolerant components (particularly in the area of electronics). 4.6 Drill Bits

The bits used in geothermal drilling fall into two main types: roller bits, including those with sealed bearings and those with unsealed bearings, and drag bits.

Sealed roller bearing bits normally utilize elastomer seals and appropriate lubricants for the friction surfaces. The cutting surfaces could be either machined and hardened steel or tungsten carbide buttons inserted into steel cones.

Open bearing roller bits rely on the drilling fluid for cooling and lubrication of friction surfaces. They, too, might have machined or inserted cutting elements.

Drag bits commonly use diamond cutting elements to cut away the rock face, whereas roller bits break up the rock by exposing it to high forces. 
The importance of drill bit performance is reflected by its considerable control of drilling economy. While bits may comprise 5 to 15 percent of the cost of the well, they may influence a somewhat larger percent of the rotating costs because of downtime incurred in changing them, as is shown in section 2. The technical problems that limit bit life include: bearing and seal failure, loss and wear of tungsten carbide inserts, gauge wear (gradual reduction in the outer diameter of the gauge row of cutter teeth) resulting in a tapered hole which requires reaming, or loss of diamonds.

The lifetime of sealed bearing bits might be up to 300 hours under ideal conditions. In drilling at The Geysers, unsealed bits are used and last about 20 hours. In cooler formations, and with the use of drilling mud rather than air, 60 to 70 hours might be expected. Drilling rates may range up to 30 feet/hour in some geothermal applications, for example at The Geysers.

Diamond bits drill considerably slower because they are used in hard formations where roller bits do not perform as well. Diamond bits often exhibit longer life than roller bits and may be economical in deep, hard formations due to the need for fewer round trips in spite of the added cost of diamond bits.

\subsection{Down-hole Motor's}

Two basic types of down-hole motors are used in drilling. They are the positive displacement type and turbines. (A new electric motor is now being tested.) 
The positive displacement type runs at approximately $350 \mathrm{rpm}$ and has an upper temperature limit of $130^{\circ} \mathrm{C}$. These units are limited in temperature by the elastomer stator. Their performance with roller cone bits is only marginal since the motor rotates at about five times the speed at which these bits work best.

Turbines work at even higher speeds, and work well with diamond bits. Turbines are more immune to temperature effects but their relatively short bearing life means that they can only be used practically for directional drilling applications. The use of down-hole motor drives for straight holes is considered too expensive under current conditions of their performance and economics [35].

\subsection{Influence of Technology Limits on Drilling Costs}

Several incentives exist for the improvement of drilling technology. Among these are reduction of costs, resultant reduction of on-line power costs, encouragement of more extensive exploration for resources, safety, availability of major equipment (such as drill rigs), and improved capability to drill in difficult formations. Generally, drilling can be expected to represent the most expensive aspect of resource exploration and assessment. This section briefly summarizes the ways in which technology limits influence the costs encountered in geothermal driliing. The specific drilling costs encountered in geothermal drilling are discussed in Section 3. In addition, the influence of well costs on electric costs is discussed in Section 1. 
Current experience suggests that the use of conventional drilling technology for geothermal resources is two to four times as expensive as drilling to the same depth for oil or gas $[26,32,36,37,38]$. In the case of a hot well, decreased bit life, reduced pipe life and/or the need for high quality equipment (pipe, cement, casings, muds) at increased expense can be expected [36].

Experience in areas such as the Imperial Valley [20] suggests that the considerable increase of geothermal drilling costs over that of oil and gas drilling may be, to a great extent, associated with increased temperatures of operation. In the Imperial Valley, the formations are sedimentary (as in oil and gas drilling) but are at elevated temperature. At The Geysers, where elevated temperatures are also associated with volcanic rock and difficult terrain, costs over oil and gas drilling may reach a factor of four [38]. Typically, it is thought that at The Geysers half of the increase results from temperature and half from the geology and topography.

of all of the drilling involved in obtaining output from the resource, exploratory drilling can be expected to be the most expensive. To a great extent this results from the large number of holes which must be drilled, uncertainty in the type of formations which will be encountered, the requirement for regular inspection of the drill bit and stem, extraction of core samples for study, logging and so forth.

The drilling of "slim" holes ( $\langle 4$ " diameter) generally reduces costs and provides effective data for mapping heat flow, as well as 
providing water to be used during drilling of production wells. Slim hole exploratory drilling is reportedly practiced by at least one large geothermal resource developer.

Genera11y, it can be expected that each of the technology limits cited in this Section will contribute to the escalation of the drilling costs.

Some factors which influence cost and are not related directly to equipment include: selection of an appropriate contractor, the costs of licensing and other institutional costs, and higher than average expense for transportation of equipment of support contractors to often poorly accessible geothermal drill sites. It has been estimated that the typically remote locations of geothermal drilling adds 10 to 15 percent to the cost of drilling compared to the costs of drilling similar wells in areas relatively close to a major source of drilling equipment and personnel.

In addition, controlling environmentally dangerous materials, landscaping to prevent land slides and disposal of waste also raise costs, although such costs are also encountered in oil and gas drilling as well. 


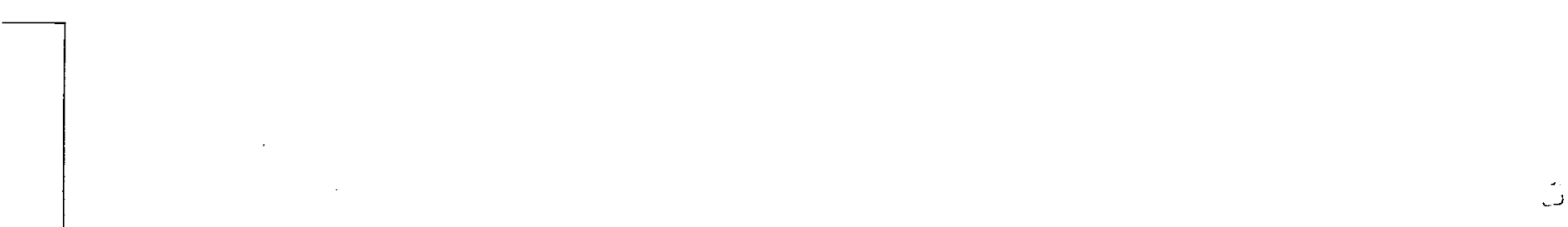




\subsection{RESEARCH AND DEVELOPMENT REQUIREMENTS}

Section 4 depicted several features of geothermal drilling along with the associated problem areas and general cost impact of these limitations. It is the purpose of this section to convert those limitations into general, or if possible, specific research requirements. Site-specific requirements are identified for the few prospects which have been drilled.

The availability of information on site-specific development needs is small. Only in the areas that have been drilled can specific statements be made concerning the drilling and completion problems which were encountered. Furthermore, the availability of this information is limited since commercial development and drilling firms do not normally make this information public. The combination of these influences reduces drastically the number of prospects for which a meaningful drilling history can be obtained for use in defining site-specific and multi-regional drilling problems.* When reviewing the drilling problems which are commonly encountered, it is interesting to note that among them temperature and its perverse influence on equipment performance dominate. This,

\footnotetext{
*As the geothermal research, development and demonstration program pursued by the Division of Geothermal Energy and other federal agencies becomes more mission-oriented, increasing emphasis is being placed on the crucial needs of individual prospective development sites or small groups of very similar sites. Less emphas is is placed on problems which would benefit many sites (multi-regional), but which are not crucial to any.
} 
along with the occurrence of the type of problems which occur in conventional oil field drilling, result in an opinion that only about 20 percent of drilling problems are site-specific and 80 percent will be encountered at all sites.

Research requirements following from Section 4 have been assembled into a set of discussions. The discussions depict, with as much detail as possible, current problems, the motivation for improved performance, a standard for the new product, the components or materials requiring improvement, site-specific needs, and the well characteristics which impose the performance limit. Three major topics are identified: equipment, methods and materials. The discussions appear in Sections $5.1,5.2$ and 5.3 .

The general conclusions drawn are discussed below:

(1) The most effective near-term approach to improved performance is through materials substitution in conventional equipment. These developments are best pursued cooperatively with the industry.

(2) One way to overcome the currently limiting features of geothermal drilling is to develop radically new approaches. These might provide economical drilling that does not involve muds, cements, lubricants, elastomers or other materials which do not work well at elevated temperature. An alternative but unlikely possibility is the gradual increase in the performance capabilities of each of these materials.

(3) Government-sponsored initiatives in the following areas could greatly enhance information transfer and commercialization of either improved conventional equipment or novel technology: (1) the development of testing equipment, procedures and facilities appropriate to the characteristics of the geothermal environment, and (2) the encouragment of mechanisms for field testing new technology with minimal risk to commercial drillers. 
(4) Drilling problems can be identified as multi-regional or site-specific. Approximately 80 percent of drilling and completion problems will be encountered at any geothermal drilling site. Approximately 20 percent of the problems are site-specific.

(5) Cross-fertilization of technology may occur some 10 years hence as oil and gas wells encounter higher temperatures and can begin to utilize geothermal equipment. Furthermore, such events would greatly expand the market for high temperature equipment.

(6) Site-specific drilling problems will generally be associated with the following features of the reservoir:

- formation temperature,

- salinity of the brine,

- incidence and concentration of $\mathrm{H}_{2} \mathrm{~S}$

- amount, direction and type of formation fractures, and

- formation pressure.

(7) In addition, local environmental restrictions will represent site-specific limitations on drilling. Lastly, the cost of drilling is affected by the location of the drilling site, relative to areas of major oil and gas exploration and development, since the availability of equipment and manpower may be affected.

\subsection{Research Needs for Equipment}

\section{1 .1 Drill Bits}

Current Problems - Bits used in geothermal drilling exhibit accelerated wear in bearings, frequent breakage of roller cones, cutter teeth and bearings, loss of tungsten carbide inserts and gauge wear. These limits are dominated by temperature effects on materials. Motivation for Improvement - Improving bits to the point where they perform as well as in oil and gas applications would significantly reduce rig time, tripping requirements, mud maintenance 
requirements, and the need for reaming. Review of the cost analysis curves of Section 2 and Appendix A clearly demonstrates the relatively small improvement in penetration rate needed to effect a large reduction in footage costs.

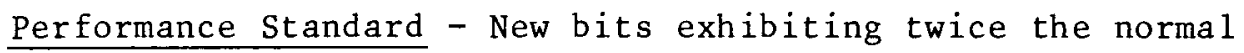
penetration rate as well as lifetimes ranging up to 5 times nominal would result in rotating cost savings of 75 percent.

Components Requiring Improvement - Significant returns could result from improvements in seals and bearings, particularly in terms of increases in bit lifetimes.

\section{$\therefore \quad 5.1 .2$ Packers}

Current Problems - Packers are generally limited to use in relatively cool parts of the well. In addition, they work best when used inside a casing rather than in the we1l-bore. Failure of packers in high-temperature environments is common due to decomposition of the packing material.

Motivation for Improvement - Packers are required for fracturing of the formation, use of down-hole pumps, well testing and completion procedures. Blow-out preventers (which work much the same way as a packer) are also used at the surface for control of steam flow from the well.

Performance Standard - Operation at $275^{\circ} \mathrm{C}$ would satisfy most applications with the exception of hot dry rock, with the added requirement that the lifetime of the unit be essentially infinite for 
completion applications (where pressures and temperatures are nearly static). The lifetime must also be increased for dynamic applications.

Components Requiring Improvement - The main limitation is

imposed by the requirement for a large packing element (for applications where no casing is in the well) and high-temperature durability. The development of an elastomer-free packer would be an attractive goal, since elastomer development is not expected to meet the required performance goals.

\subsubsection{Down-hole Motors}

Current Problems - The life of downhole motors is limited by high-temperature environments. These units are rarely used in straight-hole drilling in spite of their many attractive features. Major weaknesses occur in elastomeric seals and in bearings. The motors are not generally compatible with roller cone bits due to their relatively high rotation speeds.

Motivation for Improvement - Development of appropriate steering tools (based on real-time logging-techniques) and more durable motors could provide an ideal drilling method. Motors reduce the chance of pipe twist-off, provide potentially more power to the rockface, and are convenient for directional drilling [34]. Directional drilling has many applications such as: straightening a crooked hole, turning the hole to reach the reservoir, and drilling multiple wells from a single pad.

Performance Standard - Both the lifetime and load capacity of down-hole motors need improvement. A 200-hour bearing lifetime, 
which is a reasonable goal, will require advances in bearing technology to make the motors less susceptible to destruction by drilling fluids, dynamic stresses and high temperatures. Lower rotation speeds, compatible with roller cone bit performance, is also an essential requirement.

\section{1 .4 Tubular Goods}

Current Problems - The lifetime of these products is limited, particularly in cases where air drilling is used. This is, for example, a problem at The Geysers, where drill pipe life is shorter than that experienced in other drilling. Pipe must be replaced or repaired frequently.

Motivation for Improvement - Longer life and higher reliability in drill pipe will have a positive impact on drilling costs. Perhaps more important, the likelihood of twist-off will be reduced. Performance Standard - A measure of the quality of pipe in a particular environment is the frequency with which it must be repaired or replaced. A reduced need for welded-on hard banding or replacement would represent an advance. The Geysers also imposes a requirement for anti-corrosive metallurgy in the pipe. This, too, appears to be a site-specific problem (it is less of a problem in the Imperial Valley).

\subsection{Methods}

\subsubsection{Keeping Hole Straight}

Current Problems - The highly faulted formations and density variations encountered in much of geothermal drilling cause the well 
to deviate from vertical. The bit may also follow surfaces where the rock hardness changes from soft to hard.

Motivation for Improvement - A crooked hole imposes considerable drag on the drill pipe, increasing the possibility of twist-off. The drag also limits the power which can be delivered to the bit.

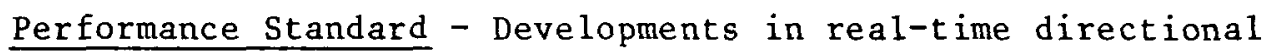
logging and down-hole motors could provide the capability to monitor and correct unwanted deviations.

\subsubsection{Directional Drilling}

Current Problems - As noted in the previous section, there are difficulties with holes which deviate from straight or nearlystraight. Directional drilling to correct these deviations therefore would be an attractive capability. In addition, the capability does not now exist to make instantaneous steering corrections while drilling directionally in order to direct the well toward a producing zone. Such drilling requires the concurrent development of long-lived downhole motors and better logging methods.

Motivation for Improvement - Effective completion of wells requires the ability to drill into the producing zone. In addition, directional drilling allows the opportunity for drilling multiple wells from a single pad. Applications would be found in hot dry rock drilling where two adjacent well bores must reach the same fracture zone: Performance Standard - As in Section 5.2.1, the standard is to be able to drill directionally with instantaneous steering control, 
either to correct a deviated hole or to attempt to drill into the producing formation.

\subsubsection{Lost Circulation Control}

Current Problems - Loss of drilling fluid can result in loss of control of the well (including blow-out), twist-off of drill string and costly replacement of lost fluids. Organic packing materials, as used in oil and gas drilling, are not entirely satisfactory when used in the geothermal environment.

Motivation for Improvement - Improved methods of lost circulation control will improve safety, lower costs and increase productivity in geothermal drilling.

Performance Standard - Control methods must be capable of surviving in the geothermal environment, be easily removed for production and leave no residue to plug the formation. Additives to or constituents of drilling fluids must be amenable to removal or degradation after use so that no permanent damage to the environment will result.

\subsubsection{S1im Hole Drilling}

Current Problems - Slim holes (less than 4" in diameter) offer an economical alternative to the production-size well bores which reportedly are used as the norm in explorațory drilling. Slim holes are limited in the depth which they can achieve.

Motivation for Use - Expanded use of slim hole drilling could provide relatively inexpensive exploration wells from which data 
on temperature, stratigraphy, heat flow, and dissolved solids in the formation water could be obtained. In addition, these wells can be used as a source of water during drilling of the larger wells. They also allow development of completion schedules for casing and cementing by revealing the formation structure. They have been effectively used at The Geysers, Hawaii and Roosevelt Hot Springs.

\section{2 .5 Well Control}

Current Problems - Two major problems exist in dealing with geothermal wells which are similar to the problems encountered in oil and gas drilling. They are blow-outs and well-bore collapse. A major difference is that the techniques used for control in lowtemperature applications are somewhat limited in their usefulness to the geothermal driller. Both blow-out preventers and the cement which might be used for casing the well are poor performers in a high-temperature environment. Motivation for Improvement - Safety and cost concerns motivate the need for improved methods of high-temperature blow-out control as well as preventing collapse of the well. The latter point is particularly important in wells drilled in shale or other formations which may decompose and collapse on exposure to the water in drilling fluid or water that flows into the well bore during drilling. The likelihood of well collapse is site-specific, and can be expected in sedimentary areas like the Imperial Valley and in the geopressured shales. 
Performance Standard - Well-control methods must be adequate to deal with the environment found in geothermal drilling and provide the same safety as is provided in oil and gas drilling.

\subsubsection{Control of $\mathrm{H}_{2} \mathrm{~S}$ Effects}

Current Problems - Exposure of metals and elastomers to hydrogen sulfide causes decomposition, embrittlement and subsequent failure. It is also a health hazard for the drilling crew [34].

Motivation for Improvement - Control of $\mathrm{H}_{2} \mathrm{~S}$ as it is found during drilling would contribute to solving the problem of reduced life of components.

Performance Standard - Section 5.3 discusses some specific limitations of materials when exposed to $\mathrm{H}_{2} \mathrm{~S}$.

\subsection{Materials}

\subsubsection{Cement}

Current Problems - Preparation of cement for geothermal applications requires careful selection of component materials, depending on the temperatures to be encountered. An improper ratio of ingredients may cause the cement to set before reaching the desired part of the we11, not set at all, or decompose as it ages. Motivation for Improvement - The effective completion of a well requires both the permanent installation of casing and the implementation of other essential steps, all of which rely on a successful cementing job. This includes the installation of cement plugs to form a basement for kicking off into the formation. 


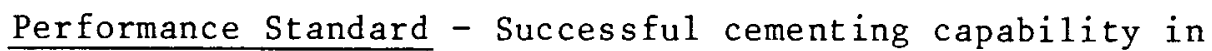

a geothermal environment requires increased temperature tolerance. Cement whose hardness approaches that of the local rock is needed to form a base for starting directional drilling. Cement hardness limits have created problems for attempted directional drilling at Roosevelt and Mono. Cements whose characteristics are not strongly influenced by temperature are also needed.

\subsubsection{Stee1}

Current Problems - Limits on the durability of steels can be related to the site-specific incidence of $\mathrm{H}_{2} \mathrm{~S}$. Its effects are embrittlement and corrosion. Additional problems are encountered in assembling bonds between steel and elastomers, as in packers. The temperature encountered in many geothermal wells approaches the annealling temperature of a common steel (\$4142) so that high-temperature hardness and fracture toughness are poor.

Motivation for Improvement - More appropriate steels will improve the lifetime and performance of a number of important drilling tools, thereby reducing cost. Available specialty steels should be screened for applicability to the geothermal environment.

\subsubsection{Elastomers}

Current Problems - Major problems exist with temperature-induced decomposition of elastomers as well as difficulties in bonding it to steel, poor lifetime in an abrasive environment and embrittlement on exposure to $\mathrm{H}_{2} \mathrm{~S}$. Elastomer decomposition in seals and packers is one of the greatest limitations on the performance of present drilling 
equipment. The current outlook for producing elastomers adequate for the geothermal environment is not encouraging. Alternative materials and designs are also being investigated.

Motivation for Improvement - Elastomers represent a small but important component in almost every drilling tool. Improving their performance could have a significant impact on drilling costs. Performance Standard - Elastomers must be able to survive for extended periods at the high temperatures characteristic of the geothermal environment. Increasing the upper limit on operating temperatures from about $175^{\circ} \mathrm{C}$ to about $275^{\circ} \mathrm{C}$ is required. Success is deemed unlikely, though an incremental improvement of about $20^{\circ} \mathrm{C}$ may be achieved.

\section{3 .4 Lubricants}

Current Problems - Many tools that utilize sealed, lubricated bearings are incapable of operation under the high temperatures in the geothermal environment. Lubricant failure exposes the bearings to abrasive materials. The lubricants themselves, however, tend to decompose after extended periods at a high temperature. Motivation for Improvement - Many of the lifetime and failure problems encountered in geothermal drilling are related to bearing and/or lubricant failure. The combined improvement in steels, elastomers and lubricants which protect the bearings would significantly contribute to the life and performance of many drilling tools. Performance Standard - Increased operating temperatures represent the major goal for lubricant development. 


\section{REFERENCES}

1. J. Gupta, W. Jacobsen, J. Leigh, R. Trehan, "Site-Specific Analysis of Geothermal Development." MITRE/METREK Report MTR-7586 Vol. II, October 1977.

2. F. Williams, A. Cohen, R. Pfundstein and S. Pond, "Site-Specific Analysis of Geothermal Development - Data Files of Prospective Sites," MITRE/METREK Report MTR-7586, Vol. III, October 1977.

3. Adapted from data provided by the Division of Geothermal Energy, January 1977. The schedule was originally prepared for program planning purposes.

4. John H. Cromling, "Geothermal Drilling Procedures and Costs," in Special Study Guide No. 4, Financial Aspects of Geothermal Resources Development, Geothermal Resources Council, Davis, California, April 1976.

5. Uses the cost estimation procedure discussed in Section 3 .

6. U.S. Department of the Interior, Geological Survey, "Geothermal Resources File (Geotherm) Revision 8", Reston, Virginia, January 1977.

7. A.L. Podio, et al, Proceedings of the Second Geopressured Geothermal Energy Conference, Vol. III, Reservoir Research and Technology, p. 24 and Appendix II, pages 7, 13, 19, The University of Texas at Austin, February 1976. Note that cost is a strong function of final production tubing diameter.

8. Reference 7, Appendix I, p. 67.

9. Reference 7, p. 24. Note that the reference is to Nueces County, which encompasses Corpus Christi.

10. Extracted from data provided in personal communication with M. Newsom, Sandia Laboratories, July 1977. The data also included costs for earlier Raft River wells drilled in 1975. They were $\$ 847 \mathrm{~K}$ for a 5000 -foot well and $\$ 802 \mathrm{~K}$ for a 6500 -foot well. As is noted in the text, these earlier wells are often excessively expensive due to frequent testing and experimentation and have been ignored in this analysis.

11. Bill Glass, "1977 Drilling Methods and Costs at The Geysers" presented to the Geothermal Resources Council at San Diego, California, May 1977 (provided by C. Carwile, May 20, 1977). 
REFERENCES (Continued)

12. M. Newsom, et a1, "The Down-hole Replaceable Drill Bit--Progress Report and Program Plan," Sandia Laboratory, Albuquerque, New Mexico, 1976.

13. H.M. Dodd, "An Economic Analysis of Downhole Replaceable Drill Bit Systems" Sandia Report SAND 76-0301, September 1976.

14. R. Trehan, et a1, "Analysis of Geothermal Energy Development Scenarios," METREK Division of The MITRE Corporation, MTR-7220, p. 89, November 1976.

15. ERDA-DGE, "A Position Paper on Resource and Reservoir Assessment and its Impact on Federal Plans for Development of Geothermal Energy Over the Near-Term," undated.

16. Private communication from S. Goldstein, July 1977. Specifically, his information, derived from Delbert Pyle of Union Oil Company, is that one replacement well must be drilled every year for each 100 MWe on-1ine at The Geysers. Since approximately 20 production wells are needed for 100 MWe at The Geysers, this data indicates a 5 percent replacement rate.

17. Developed during meetings at Sandia Laboratories on July 7, 1977. Participants included M. Newson, C. Huff and J. Polito of Sandia and E. Friedman and S. Goldstein of MITRE/METREK.

18. D.F. Rudd and C.C. Watson, Strategy of Process Engineering, Wiley, New York, p. 116-124, 1968 .

19. E.L. Grant and W.G. Treson, Principles of Engineering Economy, The Ronald Press, New York, p. 459-464, 1970.

20. C. Gatlin, Petroleum Engineering; Drilling and Well Completions, Prentice-Ha11, 1960 .

21. W. de Dufour, "An Overview of Hydrothermal Resource Development Activities and the Associated Potential Environment Problems," MITRE/METREK Working Paper 11997, February 14, 1977.

22. C. Banwe11, "Geophysical Methods in Geothermal Exploration," in Geothermal Energy: Review of Research and Development, (H. Armstead, ed.), The Unesco Press, Paris, 1973. 


\section{REFERENCES (Continued)}

23. D. Peck, "Recoverability of Geothermal Energy Directly from Molten Igneous Systems," in Assessment of Geothermal Resources of the United States - 1975, (White and Williams, eds.), Geological Survey Circular 726, Branch of Distribution, USGS, Arlington, VA.

24. N. Scheve, "Geothermal Hot Dry Rock Program," ERDA, Division of Geothermal Energy, January 1976.

25. J. Colp and G. Brandvold, "The Sandia Magma Energy Research Project: in Proceedings of the Second United Nations Symposium on the Development and Use of Geothermal Resources. Available from U.S. GPO Stock No. 060-000-00005-1.

26. , "Definition Report; Geothermal Energy Research and Development and Demonstration Program," ERDA, Division of Geothermal Energy, October 1975.

27. Developed in consultation with W. Laughlin and J. Rowley of Los Alamos Scientific Laboratory, April 1977. Further supplemented by R. Pfundstein of the MITRE/METREK staff.

28. Ad Hoc Committee on Technology of Drilling for Energy Resources, "Drilling for Energy Resources," National Academy of Sciences, Washington, D.C., 1976.

29. C. Urbain, "Tapping Geothermal Formations in E1 Salvador Calls for Innovations," Oil and Gas Journal, August 25, 1975.

30. J. Anderson, "The Vapor-Turbine Cycle for Geothermal Power Generation," in Geothermal Energy: Resources, Production, Stimulation, P. Kruger and C. Otte (editors), Stanford University Press, Stanford, California, 1973.

31. K. Matsuo, "Drilling for Geothermal Steam and Hot Water," in Geothermal Energy: Review of Research and Development, (H. Armstead, ed.), The Unesco Press, Paris, 1973.

32. "Program Definition for the Development of Geothermal Energy," Vols. I, II and III, Jet Propulsion Laboratory, August $26,1975$.

33. E. Berman, Geothermal Energy, Noyes Data Corporation, Park Ridge, New Jersey, 1975. 
REFERENCES (Concluded)

34. J. Polito, Sandia Laboratories, private communication, September 1977.

35. W.C. Maurer, J.D. Nixon and L.W. Matson, "New Turbodrill for Geothermal Drilling," submitted to the 12th Inter-Society Energy Conversion Engineering Conference, August 28-September 2, 1977.

36. J.H. Altseimer, "Technical and Cost Analysis of Rock-Melting Systems for Producing Geothermal Wells," Los Alamos Scientific Laboratory Report LA-6555-MS. Available through NTIS, November 1976.

37. W.M. Dolan, letter to $\mathrm{Dr}$. James Bresee, Director, Division of Geothermal Energy, ERDA, November 29, 1976.

38. J. Rowley, "Geothermal Energy Development," Physics Today, January 1977.

39. As noted in Appendix B, removal of the drill string from the hole is said, by a number of experts, to take 0.8 hours per 1000 feet. Reassembly and replacement takes 0.3 hours per 1000 feet. 
APPENDIX A

COST ANALYSIS CURVES 
The cost analysis discussion of Section 2 defined the governing equations and provided an example of the cost reductions which might result from improving bit lifetime, penetration rate or both. This appendix extends that work and illustrates the normalized indifference curves for a number of depths. Bit costs were selected to be $\$ 2000$ and $\$ 10,000$.

The rotating cost is given by [12]:

$$
F=\frac{C\left[L+v\left(D+\frac{Z}{2}\right)\right]+B}{R \cdot L}
$$

where

$$
\begin{aligned}
& C=\text { rig rate } \\
& \mathrm{L}=\text { bit lifetime, hr } \\
& \nu=\text { average tripping rate, hr/ft [39] } \\
& \mathrm{D}=\text { starting depth for drilling, ft (below ground level) } \\
& Z=\text { total depth drilled, ft } \\
& \text { B }=\text { bit cost, } \$ \\
& \mathrm{R}=\text { instantaneous penetration rate (i.e., drilling rate), ft/hr. } \\
& \text { From Equation 1, the rotating cost is shown to be a function } \\
& \text { of seven parameters: } C, L, V, D, Z, B \text { and } R \text {. The average tripping } \\
& \text { rate is controlled by manul efforts in bit hoisting and drill } \\
& \text { pipe assembling and threading where very little improvement can be } \\
& \text { expected. For all practical purposes, the average tripping rate } v \text { is, } \\
& \text { therefore, constant. The incremental change in rotating cost due to } \\
& \text { small changes in the remaining parameters (i.e., R, L, C, D, Z and B) }
\end{aligned}
$$
is : 
$\frac{d F}{F}=K_{R}\left(\frac{d R}{R}\right)+K_{L}\left(\frac{d L}{L}\right)+K_{C}\left(\frac{d C}{C}\right)+K_{D}\left(\frac{d D}{D}\right)+K_{Z}\left(\frac{d Z}{Z}\right)+K_{B}\left(\frac{d B}{B}\right)$

where $K_{R}, K_{L}, K_{C}, K_{D}, K_{Z}$, and $K_{B}$ are the cost sensitivity coefficients and are defined in section 2 of this report.

In general, the coefficients, $K$, are found by noting that:

$$
\mathrm{dF}=\left(\frac{\partial \mathrm{F}}{\partial \mathrm{R}}\right) \mathrm{dR}+\left(\frac{\partial \mathrm{F}}{\partial \mathrm{L}}\right) \mathrm{dL}+\ldots
$$

and that

$$
\frac{\mathrm{d} F}{\mathrm{~F}}=\left(\frac{\partial \mathrm{F}}{\partial \mathrm{R}}\right) \frac{\mathrm{dR}}{\mathrm{F}}+\left(\frac{\partial \mathrm{F}}{\partial \mathrm{L}}\right) \frac{\mathrm{dL}}{\mathrm{F}}+\cdots
$$

Rearranging we get

$$
\frac{d F}{F}=\left(\frac{\partial F}{\partial R}\right) \frac{R}{F}\left(\frac{d R}{R}\right)+\left(\frac{\partial F}{\partial L}\right) \frac{L}{F}\left(\frac{d L}{L}\right) \cdots
$$

Therefore

$$
\begin{array}{ll}
K_{R}=\left(\frac{\partial F}{\partial R}\right) \frac{R}{F} & \\
K_{L}=\left(\frac{\partial F}{\partial L}\right) \frac{L}{F} & \text { etc. }
\end{array}
$$

Each coefficient represents the effect on the incremental change in rotating cost when one of the parameters is increased by some small amount. The sensitivity coefficient $K_{R}$, for example, can be used to determine the incremental change in rotating cost $K_{R}\left(\frac{d R}{R}\right)$ as a result of a change in instantaneous drilling rate equal to $\left(\frac{d R}{R}\right)$. Figures A-1 through A-4 illustrate the normalized indifference curves for values of: 


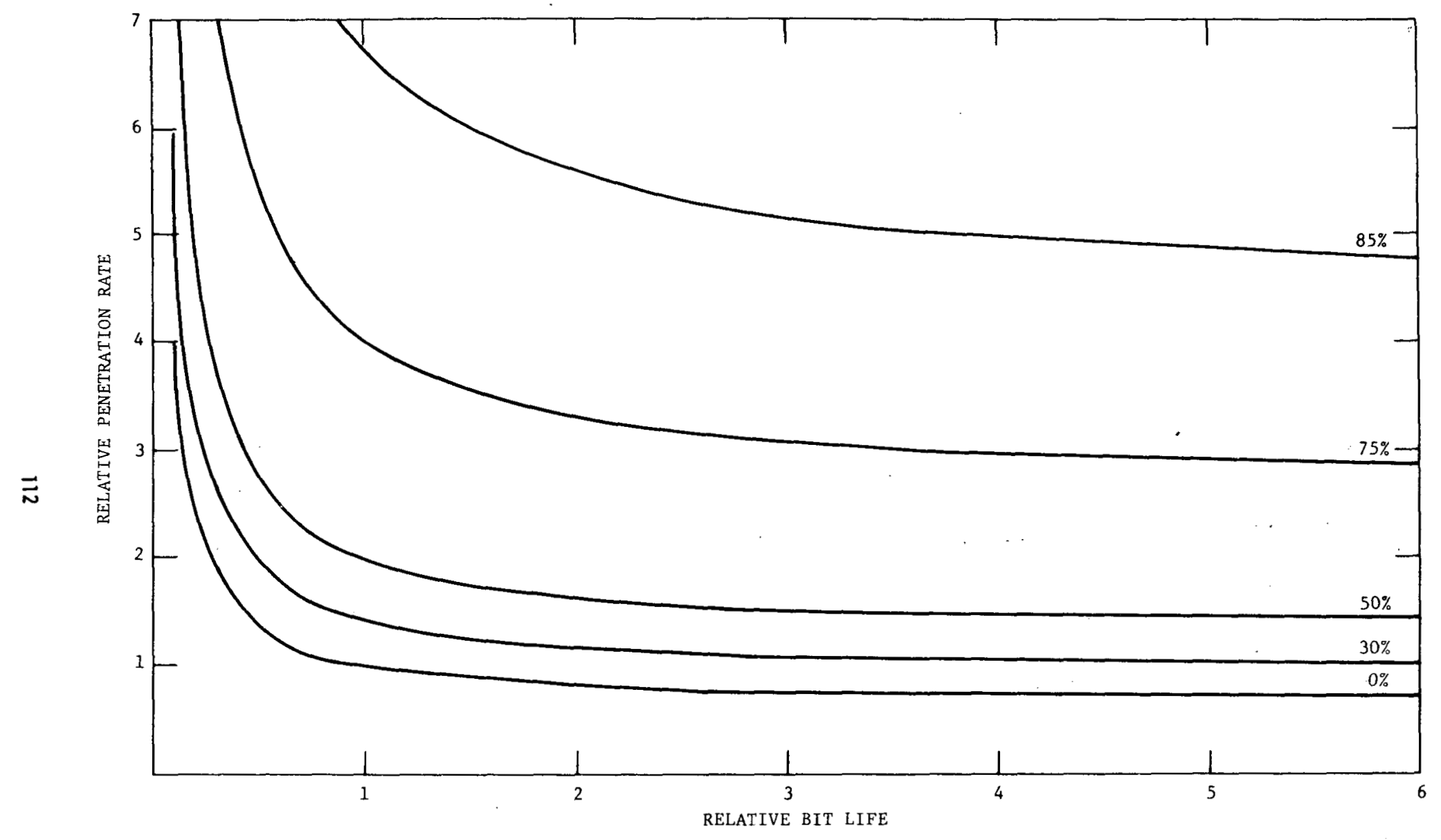

FIGURE A-1

NORMALIZED INDIFFERENCE CURVES FOR $Z=2,000$ FEET

$\mathrm{C}=400 \$ / \mathrm{HOUR}, \mathrm{B}=\$ 2,000$ AND $v=0.0011 \mathrm{HOUR} / \mathrm{FOOT}$ 


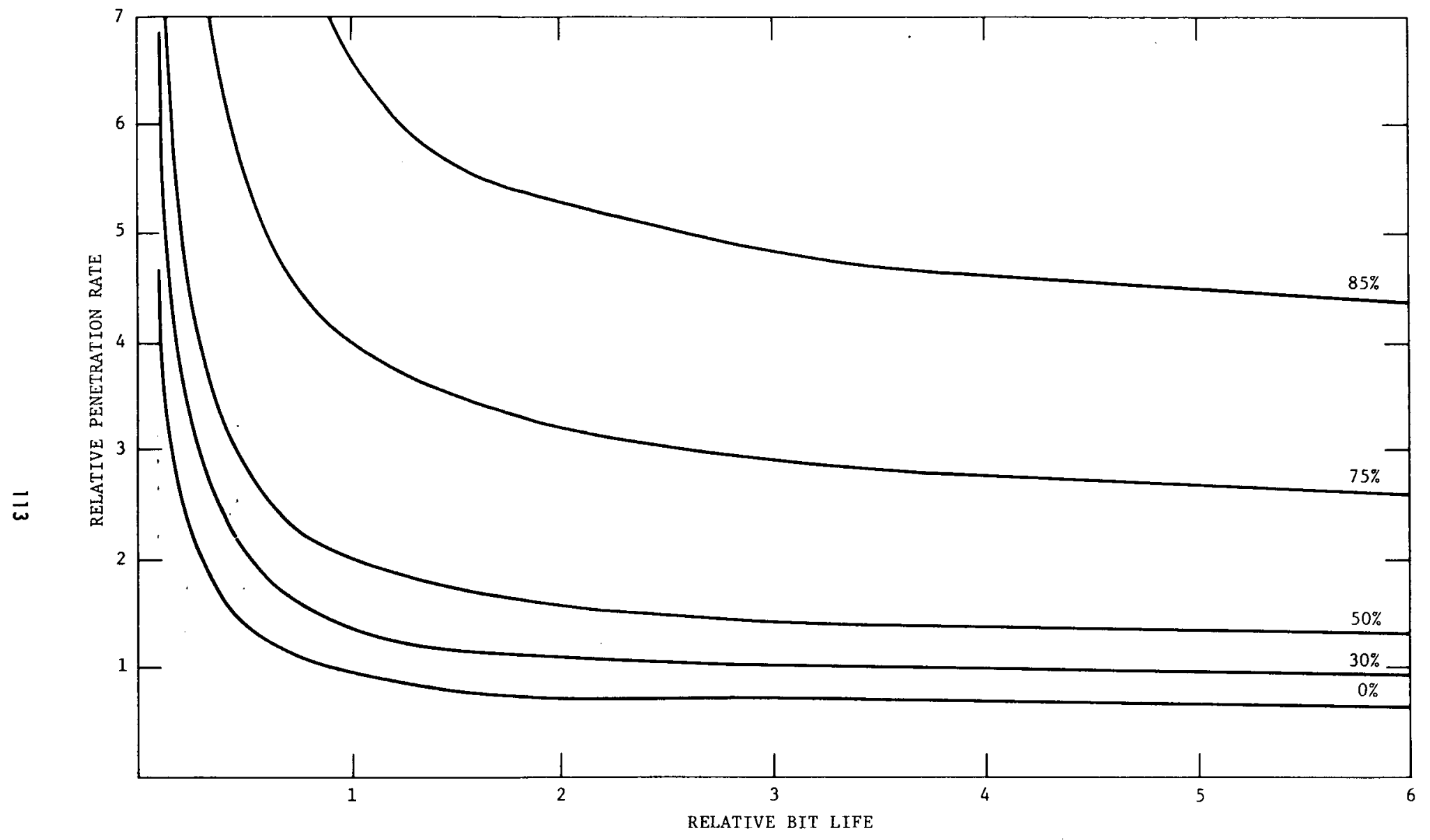

FIGURE A-2

NORMALIZED INDIFFERENCE CURVES FOR $Z=6,000$ FEET

$\mathrm{C}=400 \$ / \mathrm{HOUR}, \mathrm{B}=\$ 2,000$ AND $v=0.0011 \mathrm{HOUR} / \mathrm{FOOT}$ 


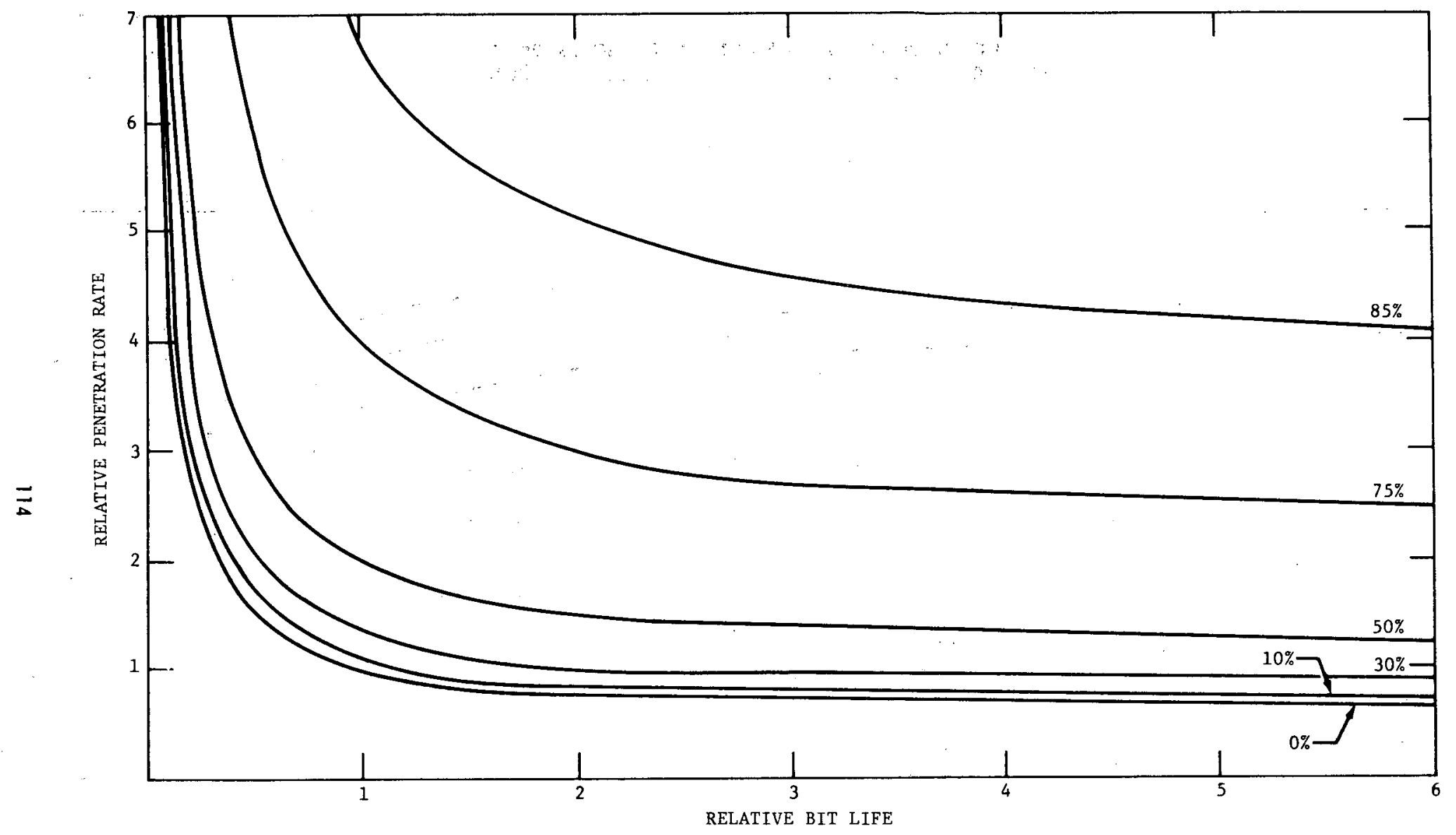

FIGURE A-3

NORMALIZED INDIFFERENCE CURVES FOR $Z=10,000$ FEET,

$\mathrm{C}=\mathbf{4 0 0} \$ / \mathrm{HOUR}, \mathrm{B}=\$ 2,000$ AND $v=0.0011 \mathrm{HOUR} / \mathrm{FOOT}$ 


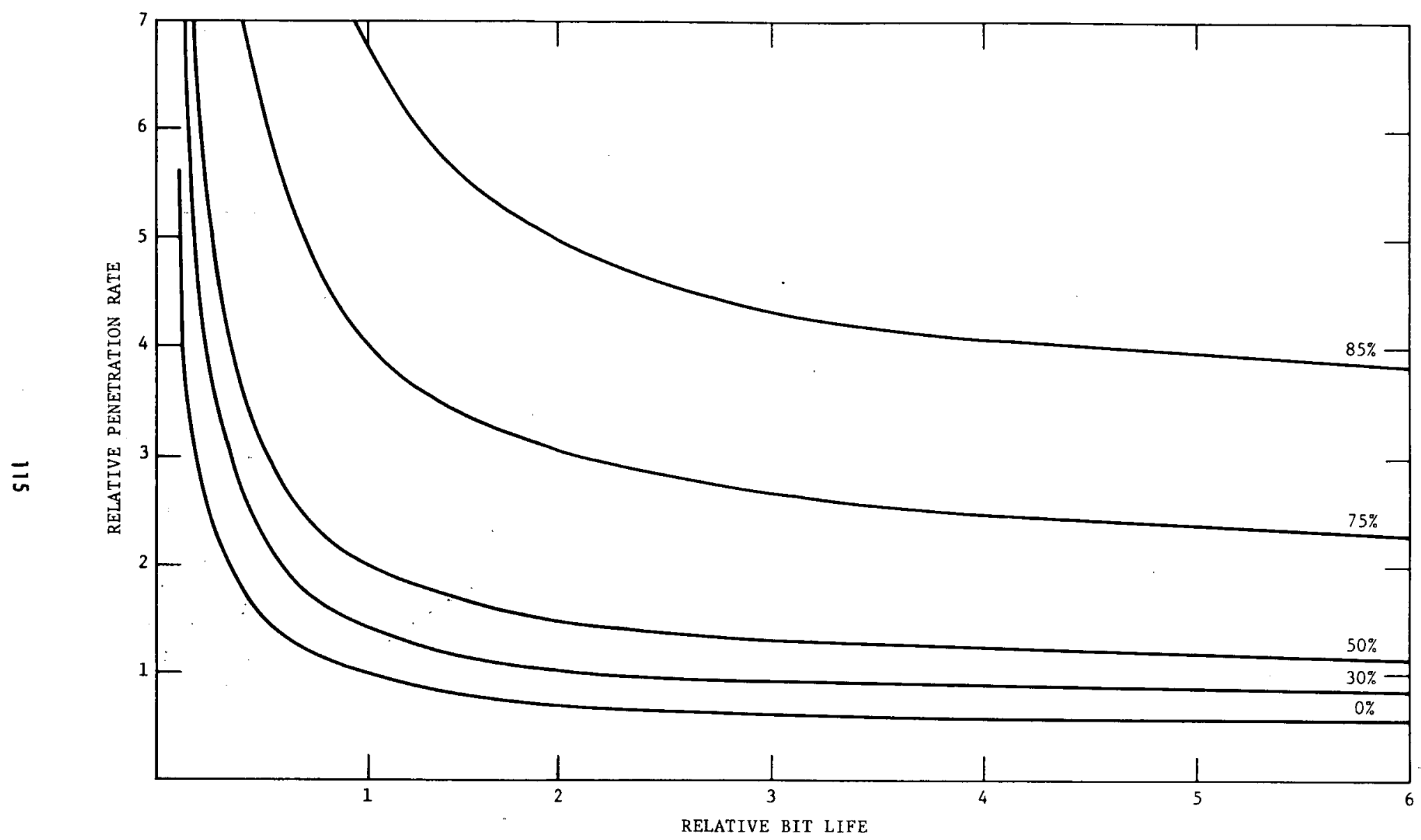

FIGURE A-4

NORMALIZED INDIFFERENCE CURVES FOR $Z=14,000$ FEET

$\mathrm{C}=\mathbf{4 0 0} \$ /$ HOUR, $\mathrm{B}=\$ 2,000$ AND $v=0.0011 \mathrm{HOUR} / \mathrm{FOOT}$ 
$C=\$ 400 /$ hour

$B=\$ 2000$

$v=0.0011$ hour $/$ foot and

$Z$ ranging from 2000 to 14,000 feet.

Figures A-5 through A-9 were computed with values of:

$C=\$ 400 /$ hour

$B=\$ 10,000$

$v=0.0011$ hour $/$ foot and

$Z$ ranging from 2000 to 18,000 feet. 


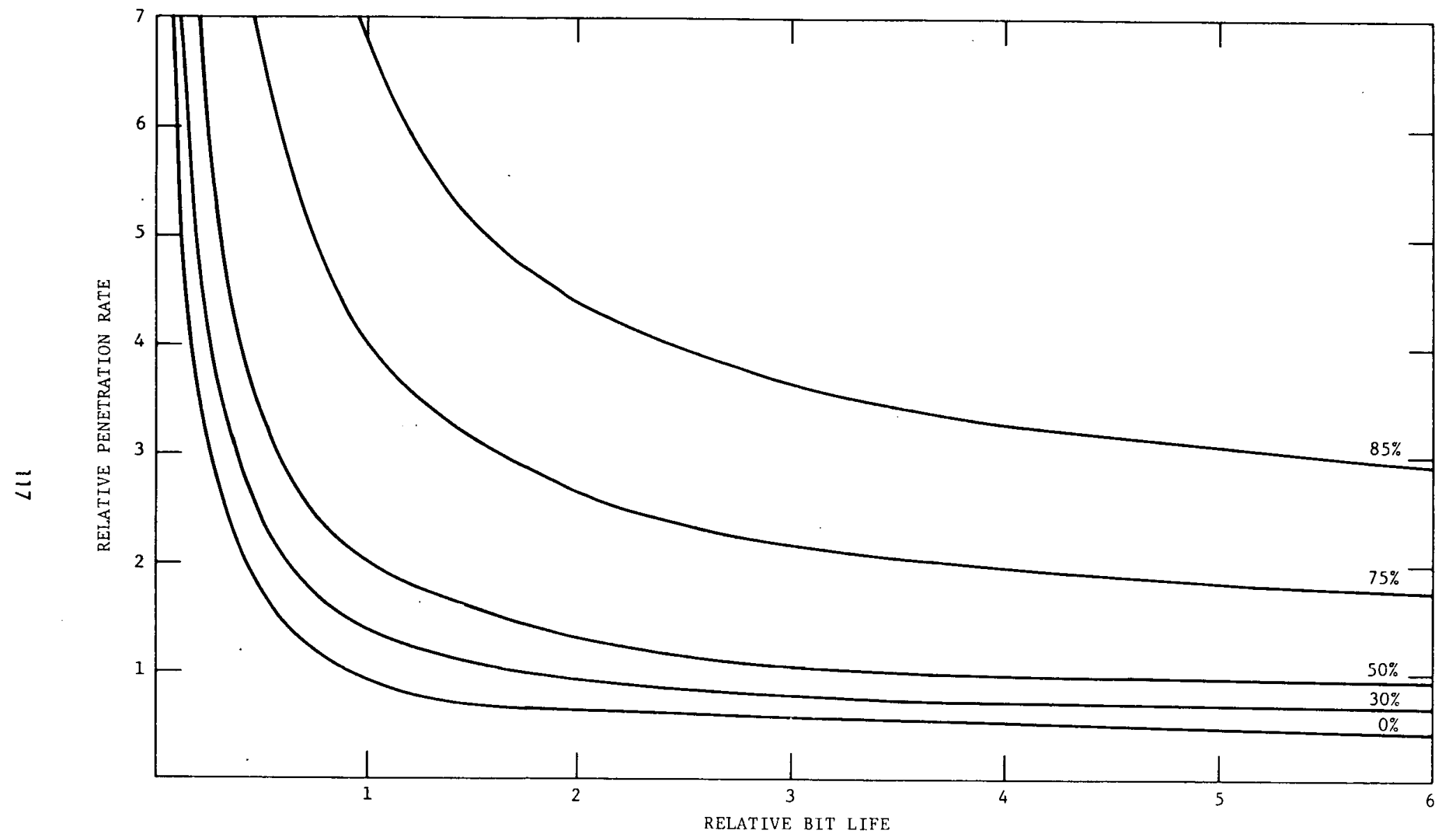

FIGURE A-5

NORMALIZED INDIFFERENCE CURVES FOR $Z=2,000$ FEET

$\mathrm{C}=\mathbf{4 0 0} \$ / \mathrm{HOUR}, \mathrm{B}=\$ 10,000$ AND $v=\mathbf{0 . 0 0 1 1} \mathrm{HOUR} / \mathrm{FOOT}$ 


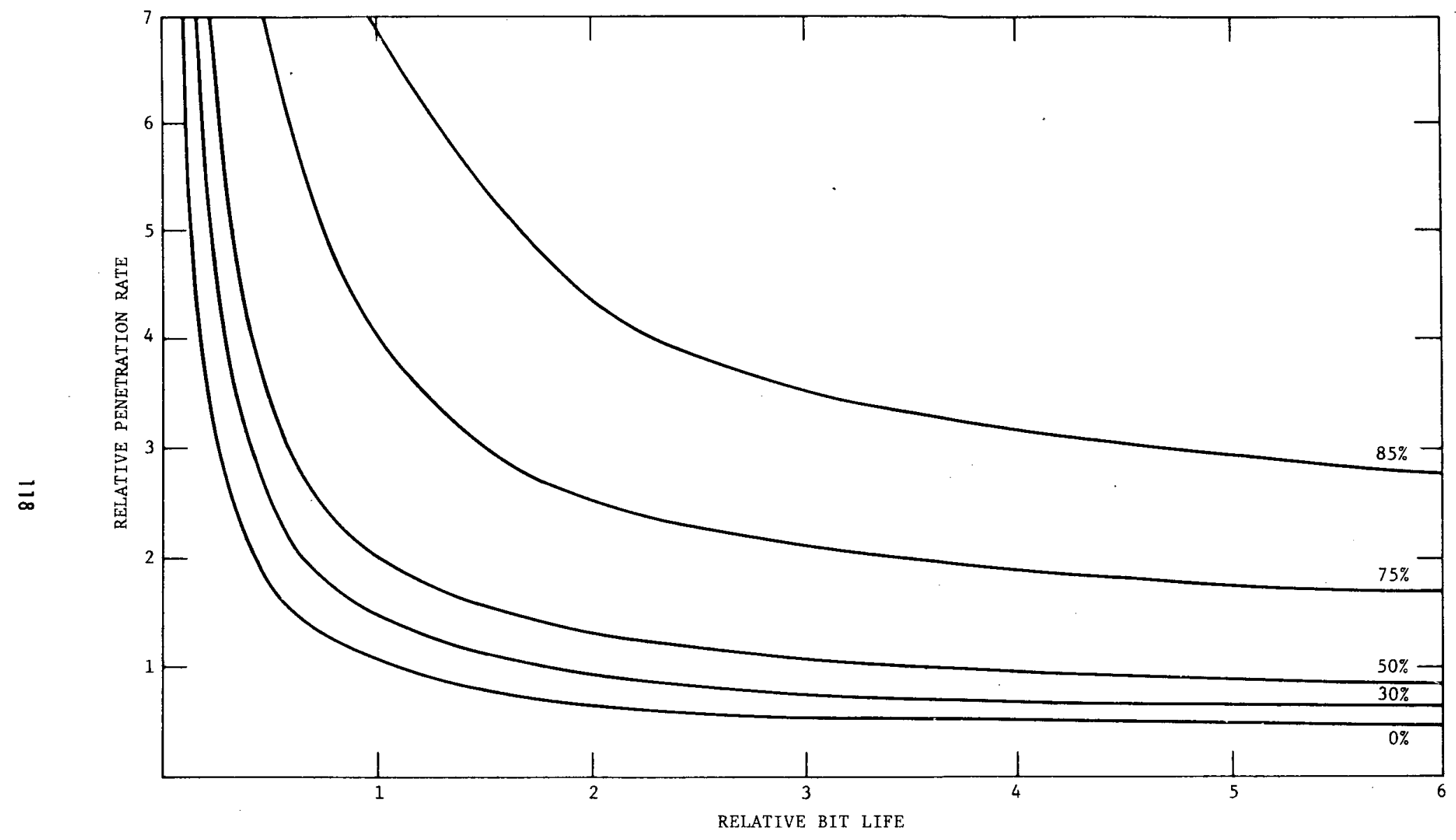

FIGURE A-6

NORMALIZED INDIFFERENCE CURVES FOR $Z=6,000$ FEET, $\mathrm{C}=400 \$ / \mathrm{HOUR}, \mathrm{B}=\$ 10,000$ AND $v=0.0011 \mathrm{HOUR} / \mathrm{FOOT}$ 


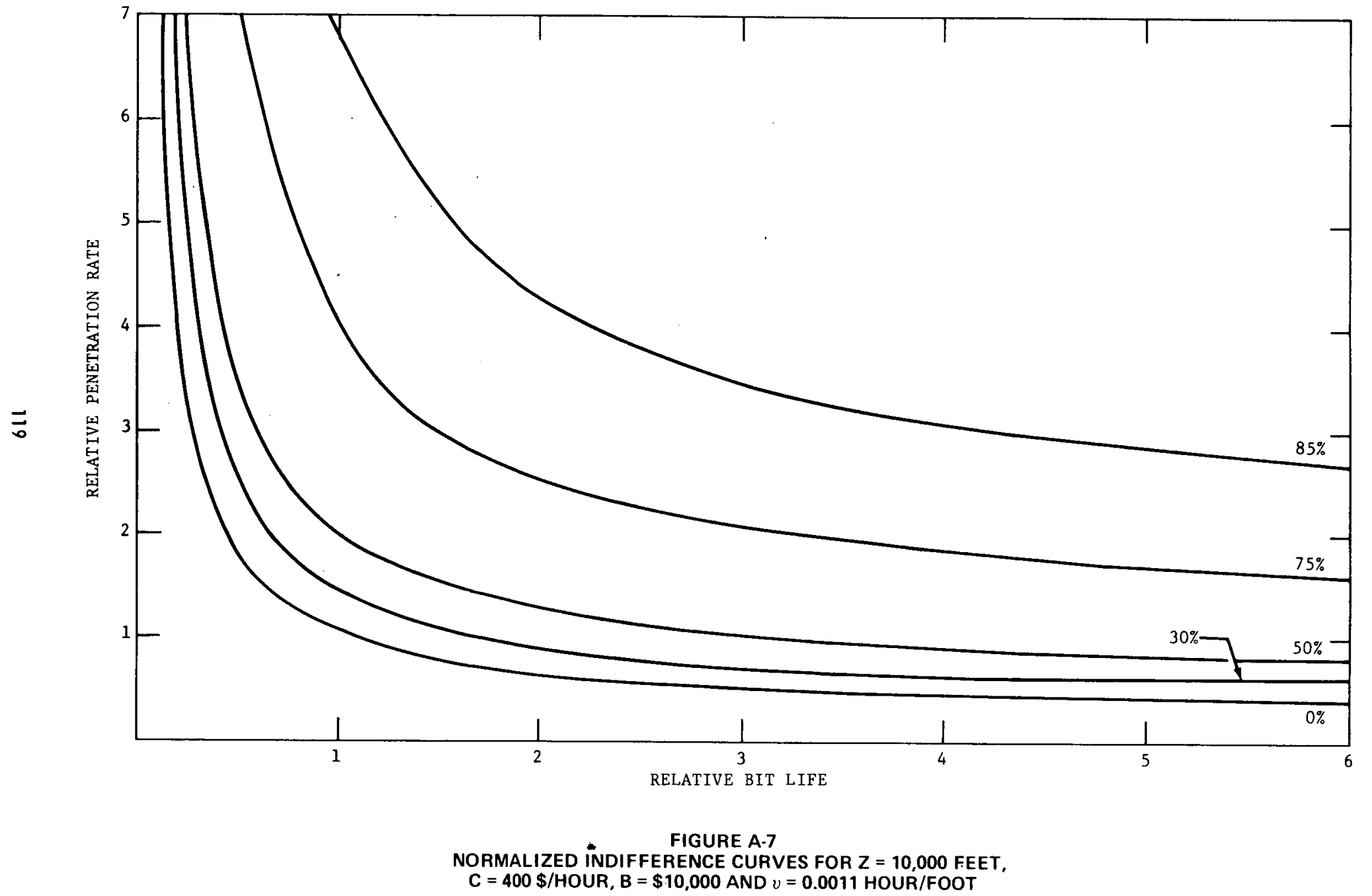




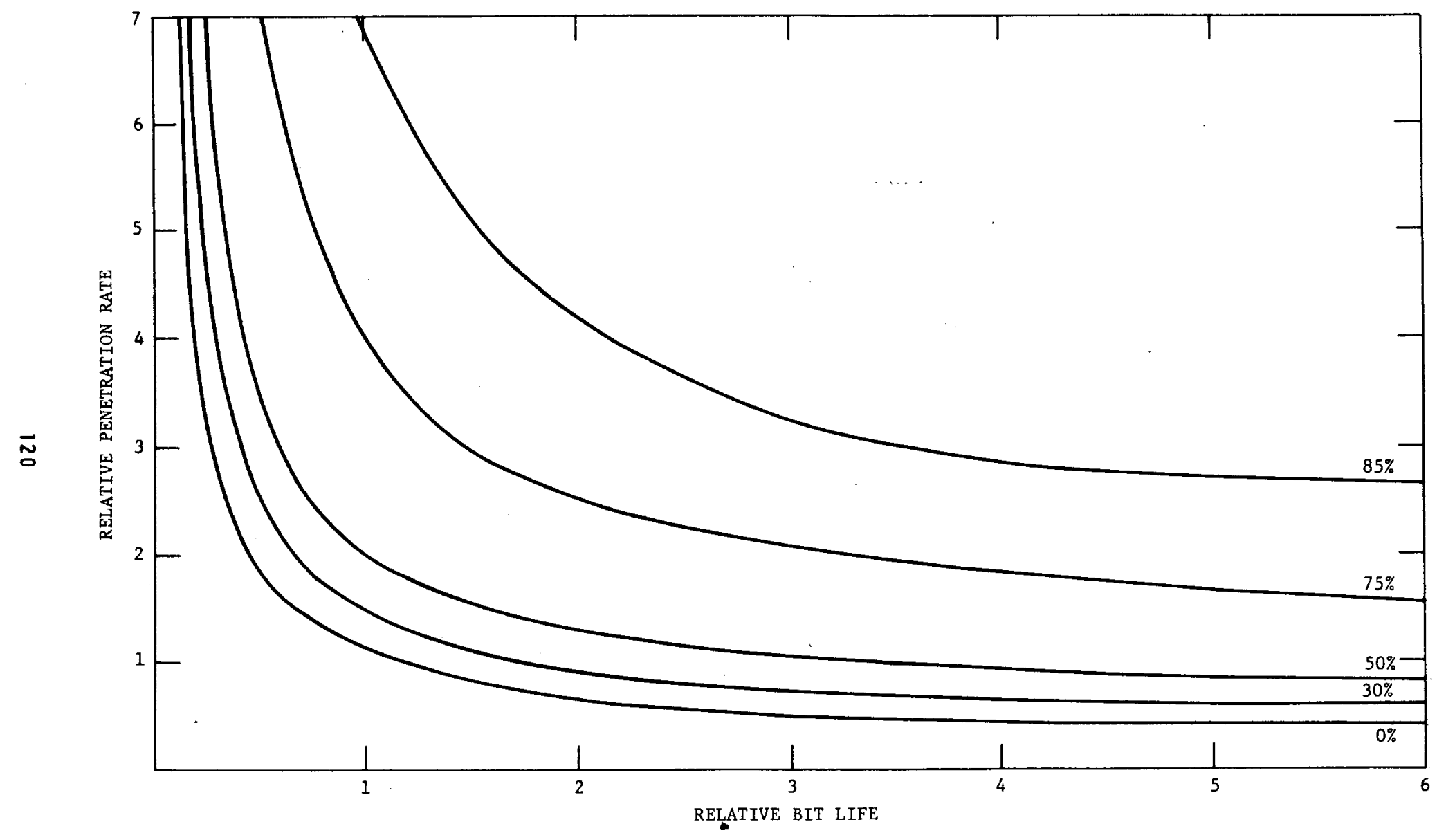

FIGURE A-8
NORMALIZED INDIFFERENCE CURVES FOR $Z=14,000$ FEET,

$C=400 \$ /$ HOUR, $B=\$ 10,000$ AND $v=0.0011$ HOUR/FOOT 


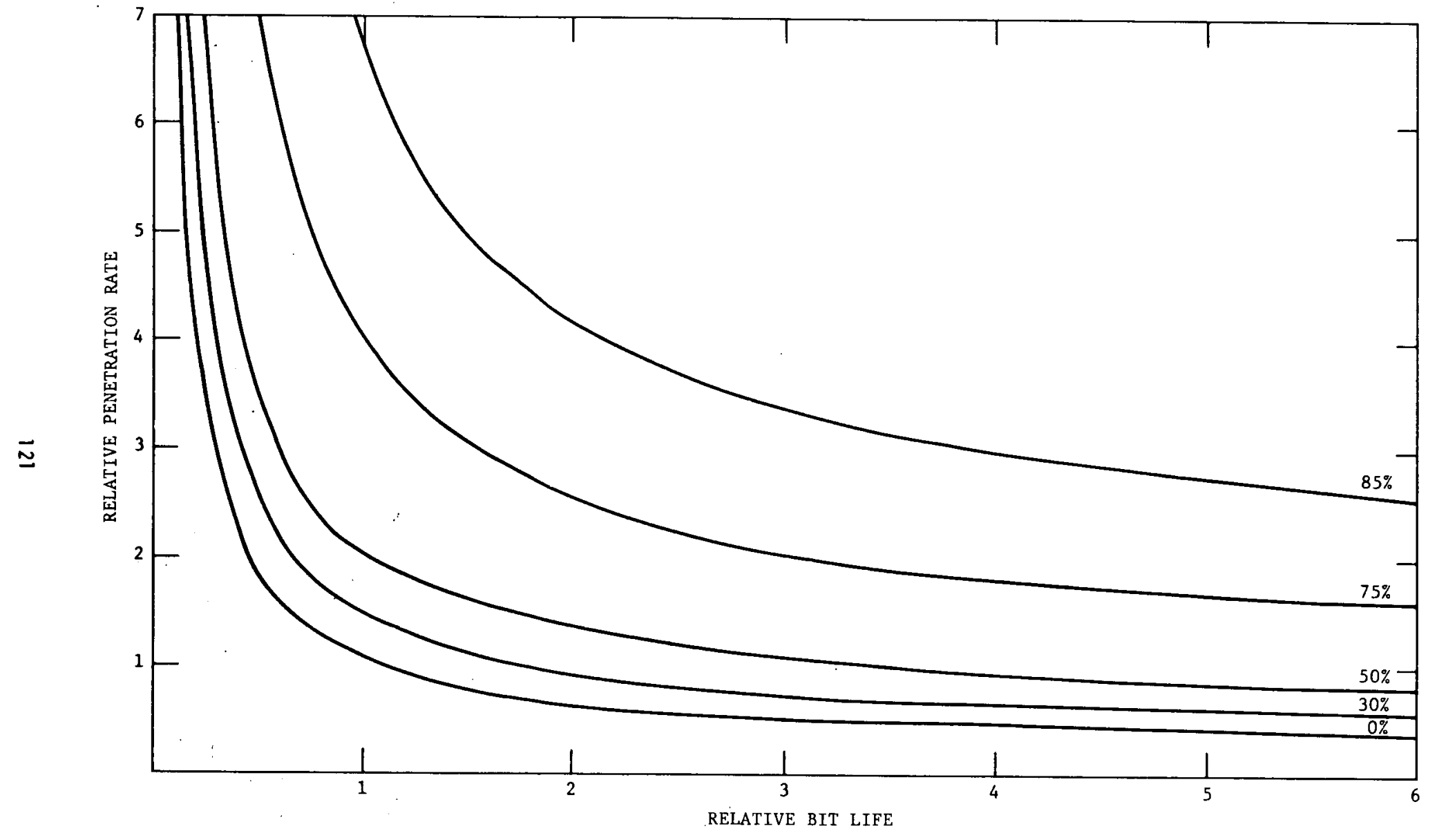

FIGURE A.9.

INDERENCE CURVES FOR $Z=18,000$ FEET

$\mathrm{C}=400 \$ / \mathrm{HOUR}, \mathrm{B}=\$ 2,000$ AND $v=0.0011$ HOUR/FOOT 

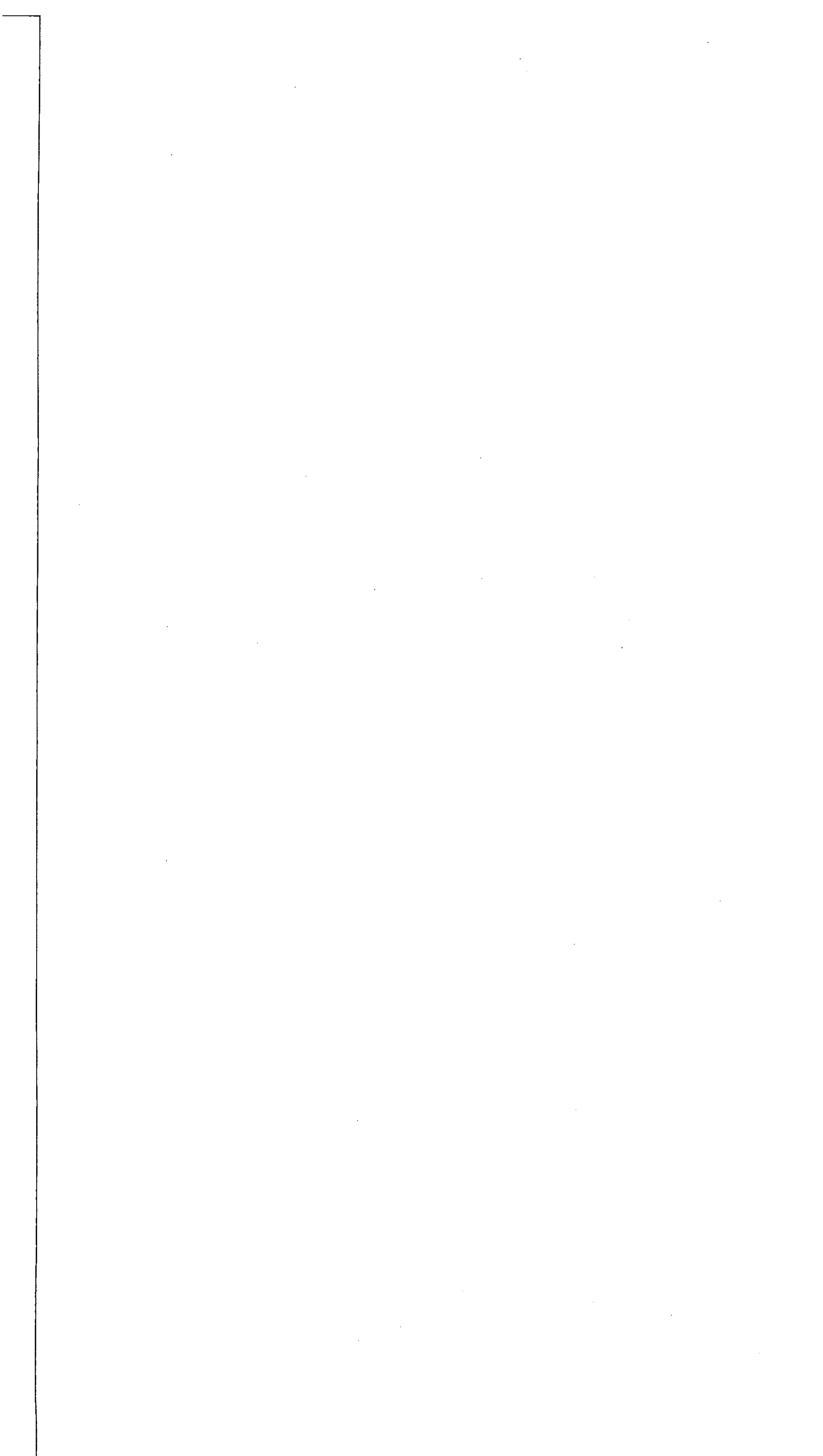
APPENDIX B

ENVIRONMENTAL IMPACT OF NEW TECHNOLOGY 
As was discussed in some detail in Section 5.0 , research needs for geothermal drilling emphasize materials research as applied generally to equipment. One exception, and the one which may be of environmental concern, is the needed developments in muds and mud additives. The inability of simple clay muds to perform adequately in the geothermal environment has led manufacturers and other researchers to investigate a number of alternative drilling fluids. The alternatives include water-based bentonite muds with the addition of chromium compounds. Disposal of the spent mud creates a potential environmental hazard from the release of heavy metal (in this case chromium) ions. Similar problems prevent the use of an otherwise attractive mud additive, asbestos.

Oil muds have been developed for substitution of water-based muds under certain drilling conditions. They, too, exhibit unattractive features which makes their disposal difficult. Foam (or detergent drilling) involves production of large quantities of suds-like material which in some cases has a considerable lifetime. Furthermore, the drill cuttings carry the residue of this material. Disposal of this material is a considerable problem.

Air drilling is a common method of geothermal drilling but exhibits some inherent environmental impacts. It adds to the already noisy environment of the drilling area as well as to the air pollution since several air compressors of considerable size may be required 
(generally powered by diesel engines). Cleaning of the engine and compressor heat exchanger has been cited as a source of pollution at The Geysers where the sudsy runoff found its way to the valleys below. The solution to this problem was to move the compressors, at considerable expense, to a more appropriate location for cleaning.

Another feature of air drilling is the use of anti-corrosion compounds which are forced through the drill string and become mixed with the cuttings. Disposal of these contaminated cuttings could create additional problems.

The environmental impact which might result from novel drilling methods has yet to be assessed. It is true, however, that many of these methods do not involve drilling muds and for that reason may avoid a number of difficulties associated with these materials. 


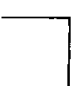


APPENDIX C

TRAVEL CONTACTS MADE DURING COURSE OF THE STUDY 
Date

Apri 118

April 19

April 20

April 21

April 22

April 23

April 24

April 26
April 25
City

Houston, TX

Houston, TX

Houston, TX

Albuquerque, NM Los Alamos, NM

Los Alamos, NM

Salt Lake City, UT

Milford, UT

Santa Rosa, CA

Irvine, $\mathrm{CA}$
Organizations Visited

Maurer Engineering, Inc.

Mudtech (Div. of Maurer Engineering) EnerTech Engineering and Research Co. Baroid Petroleum Services

Reed Tool Company

Baker Packers

Dr. M. Chenevert (Consultant)

Maurer Engineering, Inc.

Dresser Petroleum and Minerals Group

Sandia Laboratories

Los Alamos Scientific Laboratories

Los Alamos Scientific Laboratories (including Fenton Hill Drilling Site)

TerraTek, Inc.

Christensen Diamond Technology Center

Visit to Rooseve1t Hot Springs

Union Oil Company

Visit to The Geysers

Dynadrill

Smith Tool Company

A Separate Trip:

July 7

Albuquerque, NM

Sandia Laboratories 